\title{
THREE ESSAYS ON THE IDIOSYNCRASIES OF A PERENNIAL CROP: THE CASE OF THE US ALMOND MARKET
}

\author{
A Dissertation \\ presented to \\ the Faculty of the Graduate School \\ at the University of Missouri-Columbia \\ In Partial Fulfillment \\ of the Requirements for the Degree \\ Doctor of Philosophy \\ by \\ Robert D. Maltsbarger \\ Prof. Patrick Westhoff, Dissertation Supervisor \\ DECEMBER 2017
}


(C) Copyright by Robert D. Maltsbarger 2017 All Rights Reserved 
The undersigned, appointed by the dean of the Graduate School, have examined the dissertation entitled

\section{THREE ESSAYS ON THE IDIOSYNCRASIES OF A PERENNIAL CROP: THE CASE OF THE US ALMOND MARKET}

presented by Robert D. Maltsbarger,

a candidate for the degree of doctor of philosophy,

and hereby certify that, in their opinion, it is worthy of acceptance.

Professor Patrick Westhoff

Associate Professor Wyatt Thompson

Professor Laura McCann

Professor Emeritus Abner W. Womack

Associate Professor Francisco X. Aguilar 


\section{ACKNOWLEDGMENTS}

I would like to express my sincere gratitude to my advisor Prof. Patrick Westhoff for the continuous support during this Ph.D. study and research process. His patience, especially in answering my questions was of tremendous help throughout. This document would never have been completed without his feedback and suggestions.

I would like to thank Prof. Abner Womack for encouraging me to continue down the academic road, and take the next step to earn this degree. If it was not for his numerous seeds sown during my master thesis I would not have seriously considered undertaking this challenge.

I also want to thank my other committee members for their input and time resources by providing constructive criticism to guide my ideas and words assisting me to finally completing this project. The additional challenges on specific portions of me research helped me think about each problem in a more diverse manner.

I am grateful for the many, many hours of compelling coursework over the years in our Agricultural Economics department at MIZZOU from my undergraduate studies until the last $\mathrm{Ph}$.D. class. Our professors provided interesting and relevant content that made agricultural economics a fun academic pursuit. If not for an introductory class in agricultural economics by Professor Jan Dauve my freshman year I would have probably never switched to Ag Econ. Also, with a special place in my heart was the late Dr. Bruce Bullock, who both stimulated discussions in applied economics, drove to us avoid the gobbledy-gook, and even gave me a job one summer at his boat shop and a part-time assistantship grading papers for his writing intensive class during my Master's coursework. 
I finally want to extend a special thanks to my wife Erika for her support, encouragement and time sacrifices. The challenge of undertaking a Ph.D. while working full time, having a busy family life with our children Cordelia and Connor made scheduling an ever present and arduous task. 


\section{TABLE OF CONTENTS}

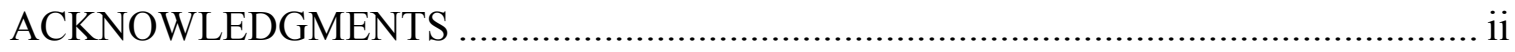

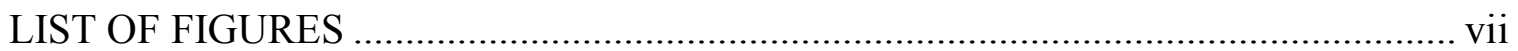

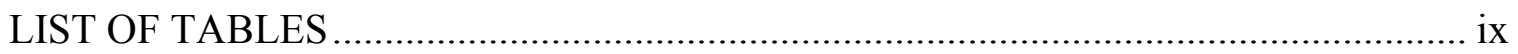

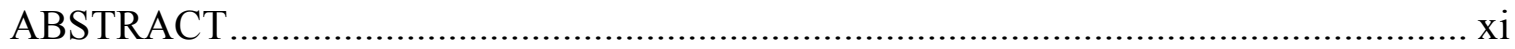

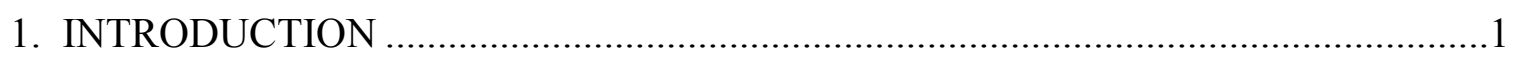

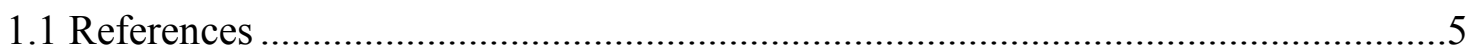

2. EXCESS DEMAND ELASTICITY OF US ALMONDS _...............................................

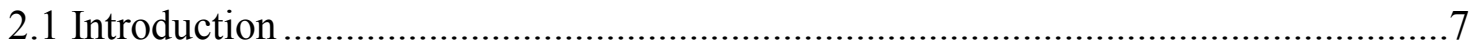

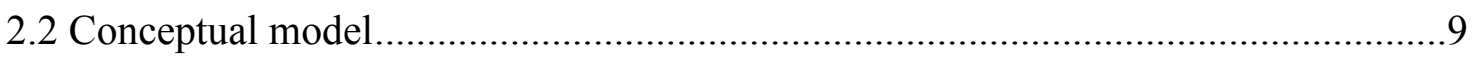

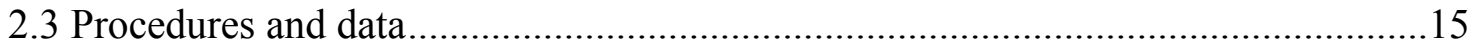

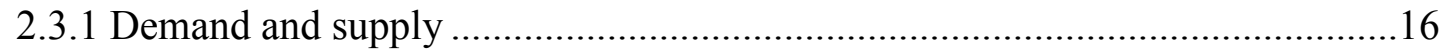

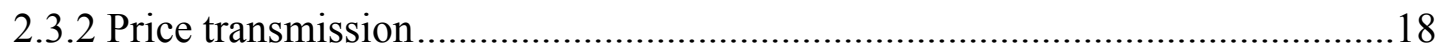

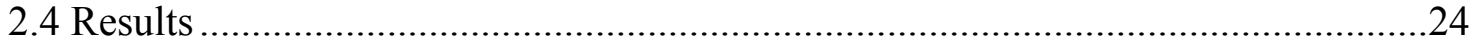

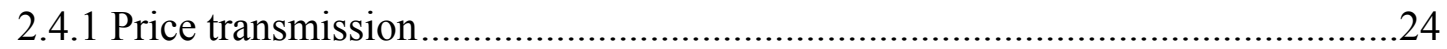

2.4.2 Demand and supply …………….........................................................26

2.4.3 Own price demand elasticities comparison ........................................................31

2.4.4 Excess demand elasticities over time and on average .........................................33

2.4.5 Comparison with previous studies...................................................................

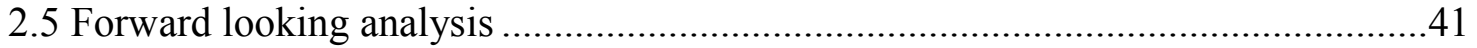

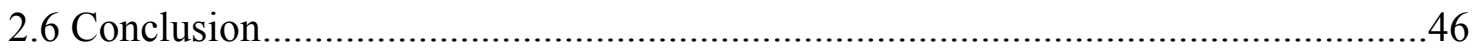

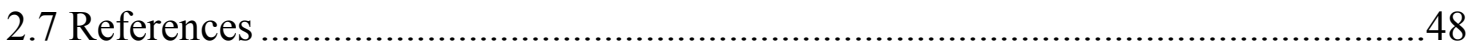

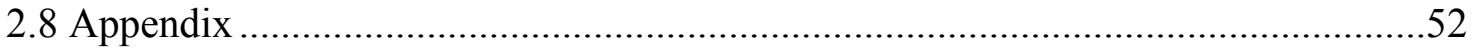

3. DOES A THREATENED ECOSYSTEM SERVICE INFLUENCE PERENNIAL FARMER INVESTMENT DECISIONS? WATER AVAILABILITY AND ALMOND

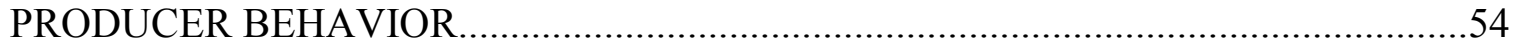

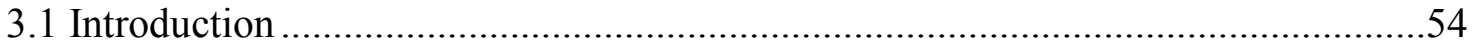

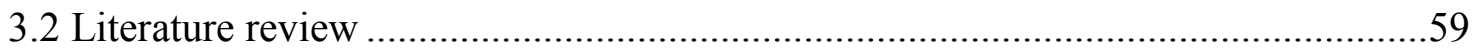

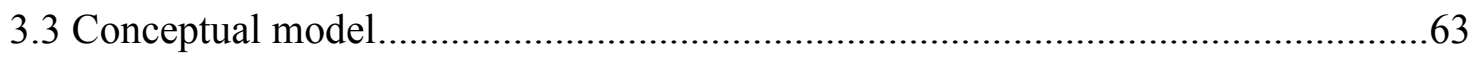


3.3.1 Price and returns expectations model ........................................................68

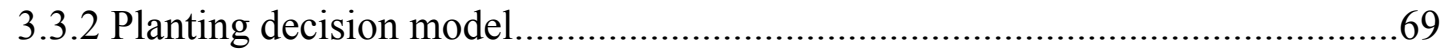

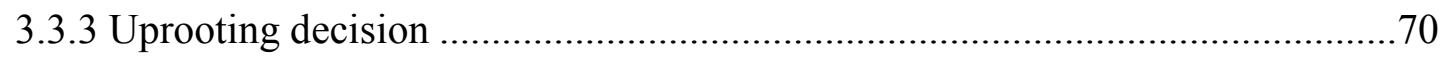

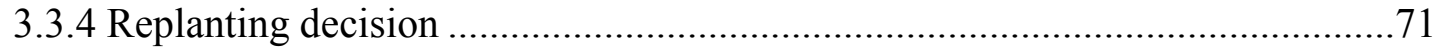

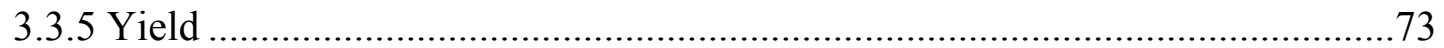

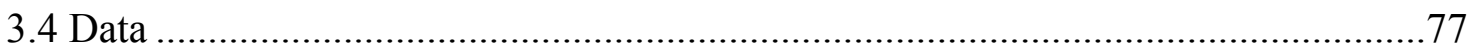

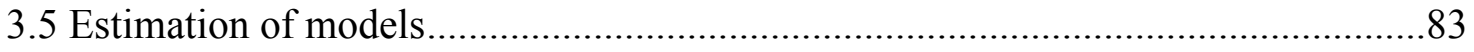

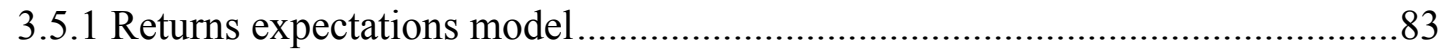

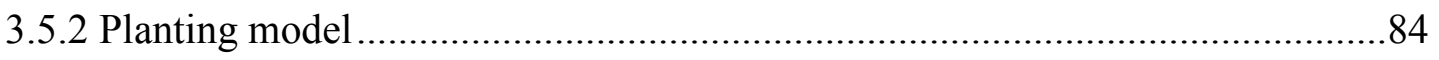

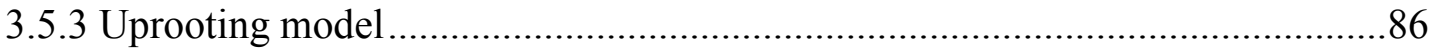

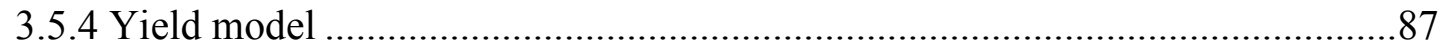

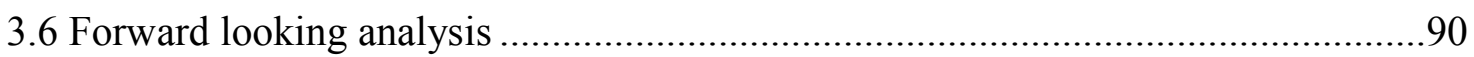

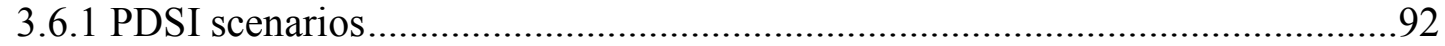

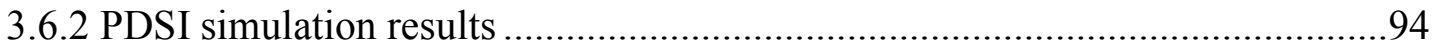

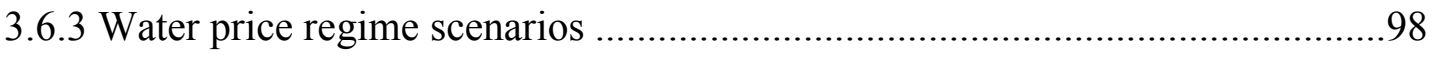

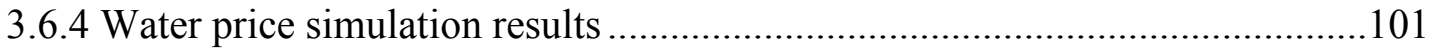

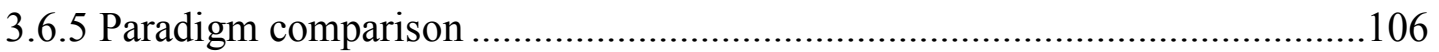

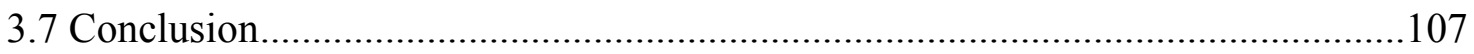

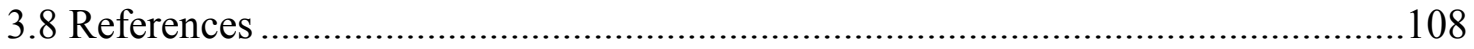

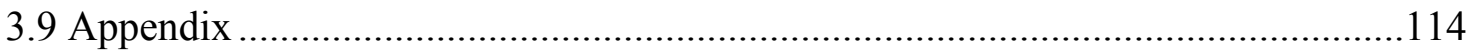

4. ECONOMIC VALUATION OF THREATENED ECOSYSTEM SERVICES: US ALMOND FARMERS FACING COLONY COLLAPSE DISORDER AND EXTREME

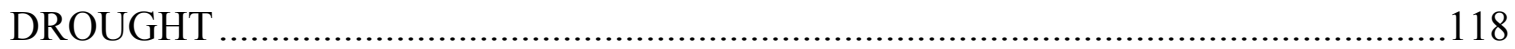

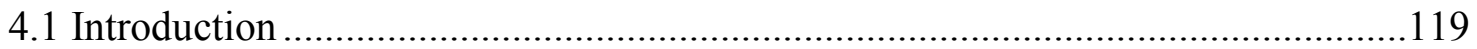

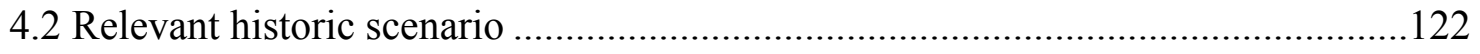

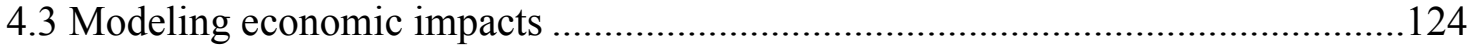

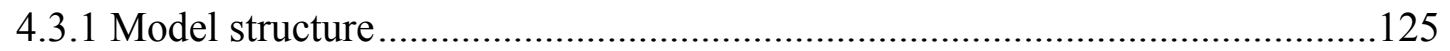

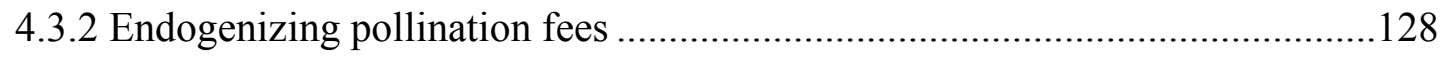

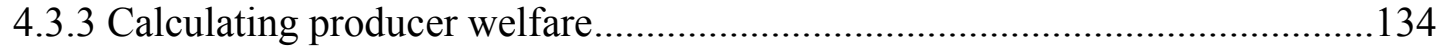

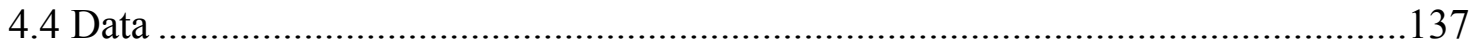

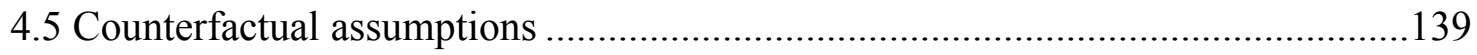




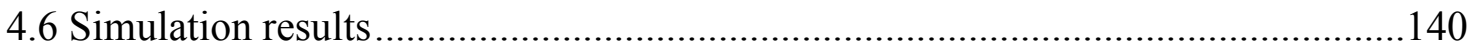

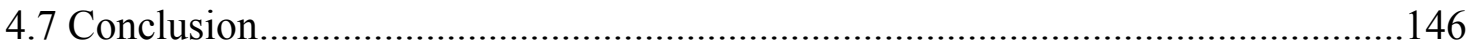

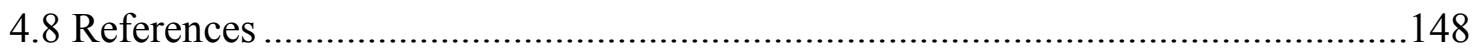

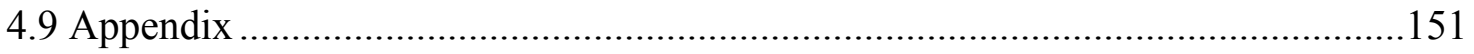

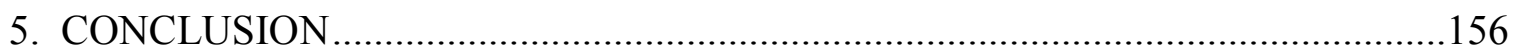

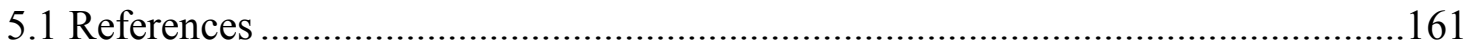

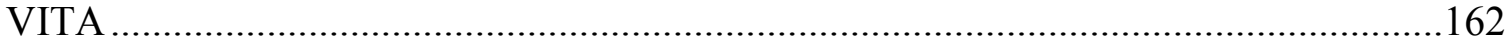




\section{LIST OF FIGURES}

Figure 1.1: US almond exports capture greater than $80 \%$ global exports since $1980 \mathrm{~s} . \ldots . . .4$

Figure 2.1: China's production change 2017-2030 from a sustained 1\% upward

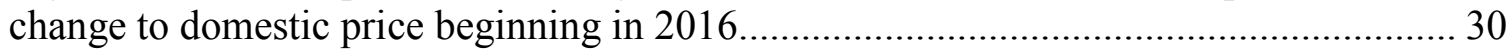

Figure 2.2: Time path of US almond excess demand elasticity $1980-2013 \ldots \ldots \ldots \ldots \ldots \ldots . . . . . . . . .36$

Figure 2.3: Changes from baseline with a 1\% annual upward price shock ................... 43

Figure 2.4: Year on year world production and US export demand changes in the $1 \%$ annual upward price shock scenario

Figure 3.1: US drought monitor showing severity of the extreme drought in

California near its most widespread point between December 2011 and April 2017..... 56

Figure 3.2: US almond exports capture greater than $80 \%$ global exports since 1980 s .... 57

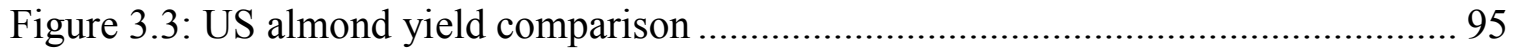

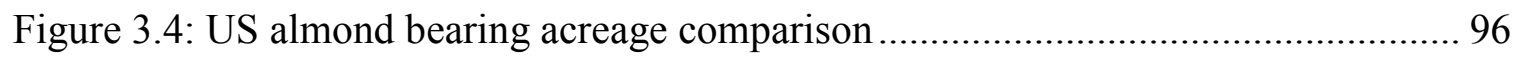

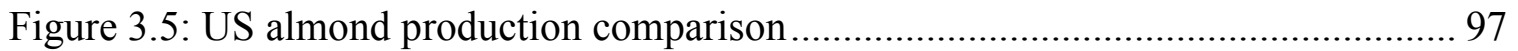

Figure 3.6: US almond grower price comparison ............................................... 98

Figure 3.7: US almond planting acreage comparison ........................................... 102

Figure 3.8: US almond planting production comparison...................................... 103

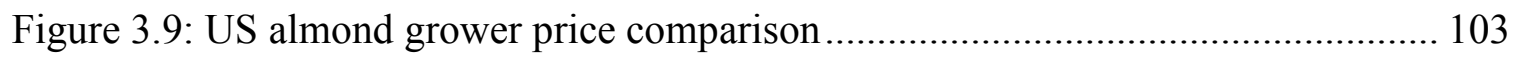

Figure 3.10: US almond grower price drought paradigm comparison ....................... 106

Figure A.3.1: Palmer's drought severity index for division 5 on a US almond crop

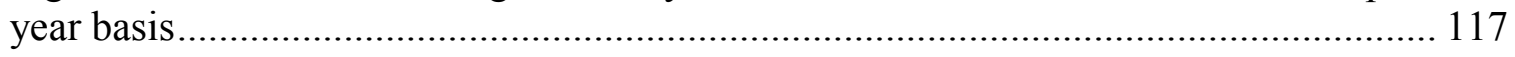

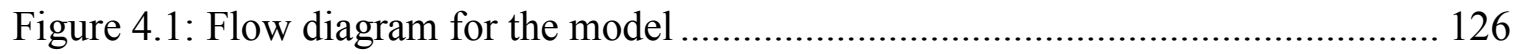

Figure 4.2: Structural linkages across countries ............................................. 128

Figure 4.3: Calculating quasirent/producer surplus using average variable costs ......... 135

Figure 4.4: US producer surplus comparison to baseline with CCD and drought......... 140 
Figure 4.5: US producer surplus difference from the baseline with CCD and drought.. 141 Figure 4.6: US producer surplus comparison to baseline with CCD ........................... 142

Figure 4.7: US producer surplus comparison to baseline with drought....................... 144

Figure 4.8: US producer revenue and cost differences from the baseline with CCD and drought 145

Figure A.4.1: US almond pollination fees . 155 


\section{LIST OF TABLES}

Table 2.1: Augmented Dickey-Fuller test of stationarity of price series ........................ 22

Table 2.2: Engle-Granger cointegration tests for price series..................................... 23

Table 2.3: Almond price transmission elasticities ...................................................... 24

Table 2.4: Almond demand and supply results..................................................... 27

Table 2.5: Almonds cross study comparison of demand elasticities .............................. 32

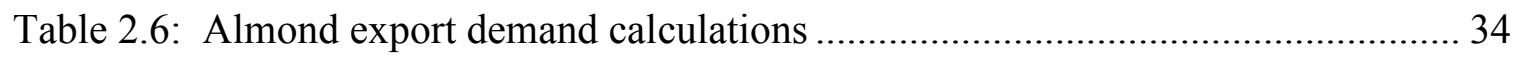

Table 2.7: Cross commodity comparison of export demand elasticities ........................ 38

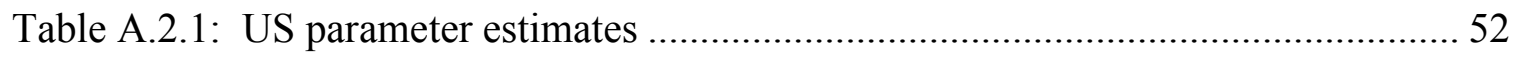

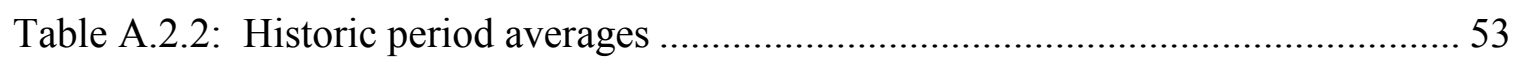

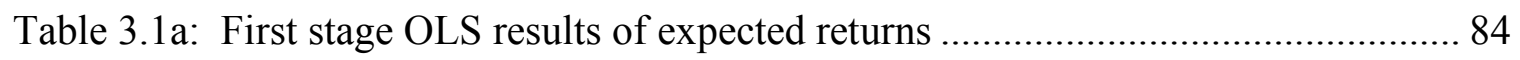

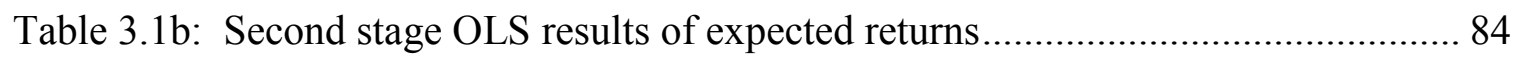

Table 3.2a: REML analysis of farmer investment decisions to plant in acres,

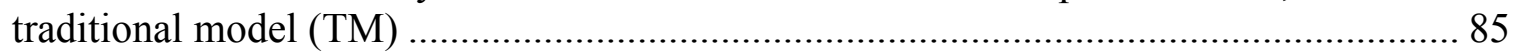

Table 3.2b: REML analysis of farmer investment decisions to plant in acres

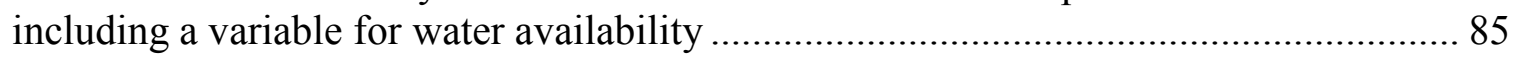

Table 3.3a: REML analysis of farmer investment decisions to uproot, traditional

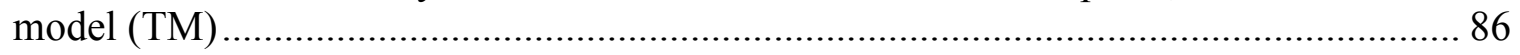

Table 3.3b: REML analysis of farmer investment decisions to uproot including a

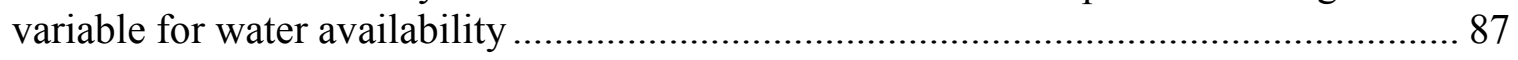

Table 3.4a: REML analysis of farmer yields, traditional model (TM) ........................ 88

Table 3.4b: REML analysis of farmer yields including Palmer's drought severity

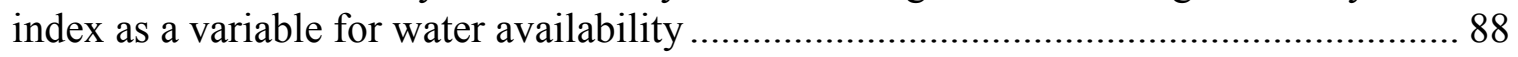

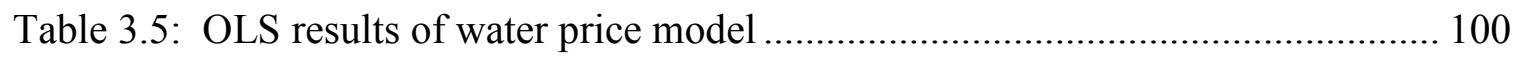

Table 3.6: US almond yield, area, production and price differences under a simulated extreme drought scenario relative to the PDSI baseline 105 
Table 3.7: US almond yield, area, production and price differences under a water pricing regime relative to a water price baseline

Table A.3.1: World almond demand and supply parameter estimates ........................ 114

Table A.3.2: World almond price linkage parameter estimates............................... 115

Table A.3.3: US parameter estimates .................................................................. 115

Table A.3.4: US almond area thousands of acres .................................................. 116

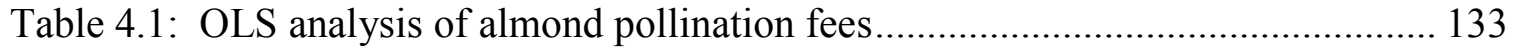

Table A.4.1: World almond demand and supply parameter estimates ...................... 151

Table A.4.2: World almond price linkage parameter estimates................................ 152

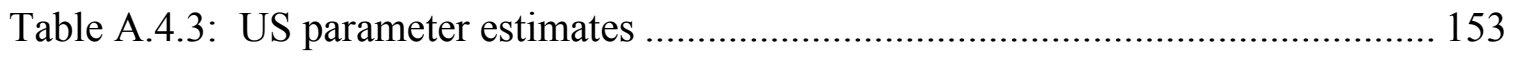

Table A.4.4: US almonds producers surplus estimates.......................................... 154

Table A.4.5: US almonds production estimates..................................................... 154

Table A.4.6: US almonds grower price estimates............................................... 154 


\title{
THREE ESSAYS ON THE IDIOSYNCRASIES OF A PERENNIAL CROP: THE CASE OF THE US ALMOND MARKET
}

\author{
Robert D. Maltsbarger \\ Prof. Patrick Westhoff, Dissertation Supervisor
}

\begin{abstract}
The United States (US) is the dominant global producer and exporter of almonds, and its exports are sensitive to both the supply and demand in other countries. In the first essay a proposed framework that captures supply idiosyncrasies of perennial crops is developed to estimate the excess demand elasticity for US almonds. Global supply, demand and price transmission elasticities are estimated and excess demand elasticities computed. The 2003-2013 mean export demand elasticity for US almonds was -0.244 in the short-run and -0.681 in the long run.
\end{abstract}

Ecosystem Services (ESS) play a key role in providing necessary natural resource inputs into almond production in California. When ESS are threatened, it affects producer investment decisions and the longer-run supply responses of perennial crop producers. In the second essay, a framework incorporating an ecological and economic (eco-economic) approach is proposed. An explicit ecological variable representing water availability is incorporated into perennial producer supply response models. The new eco-economic framework improves fit compared to traditional model specifications.

Almond production in California is not only dependent on quality water for irrigation but also commercial pollination services. Since 2005 , commercial pollinator service fees for US almond producers have skyrocketed attributed to colony collapse disorder (CCD), which increased bee colony mortality. In the third essay a model 
incorporating the influence of both CCD and water availability on Californian almond producer behavior is used to estimate producer welfare impacts of these two threatened ecosystem services. Simulation results indicate that the extreme drought reduced production leading to higher prices and a positive impact on producer surplus, whereas CCD increased farmers' costs and negatively impacted producer surplus. The net influence of these mixed impacts from drought and CCD from 2005/06 through 2015/16 was $\$ 656$ million increase in US almond farmers' producer surplus. 


\section{INTRODUCTION}

Almonds as a food commodity have a rich history. It is estimated that the almond trade began nearly 4,000 years ago (Morecraft 2013). There is even an early reference to almonds in Genesis from the Christian Bible where it was stated to, "put some of the best products of the land in your bags and take them down to the man as a gift, a little balm and a little honey, some spices and myrrh, some pistachio nuts and almonds" (Bible Hub 2017). Early almond production began in the Mediterranean region and more specifically in Israel and Turkey, before spreading westward into Greece, Italy, Spain and North Africa around $350 \mathrm{BC}$ (Morecraft 2013). In the 1700s almonds were brought to California in the United States (US) by Franciscan monks from Spain with orchards and

production developing commercially in the mid-1800s, and by the turn of the $20^{\text {th }}$ century the California almond industry was firmly established (Morecraft 2013; About Almonds 2017).

According to the Agricultural Census, the US almond market was comprised of approximately 6,800 California almond farms in 2012 (USDA-NASS 2015) with 91\% of those farms considered to be family farms with many owned and operated by $3^{\text {rd }}$ and $4^{\text {th }}$ generation farmers (Almond Board of California 2016). Harvested almonds are processed by "handlers" with approximately 100 almond handlers in the US, and the top 4 processors handling about $1 / 3$ of the each year's almond production (Almond Board of California 2016).

US almond production resides solely in the Central Valley region of California. This region spans from the foothills of the Sierra Nevada Mountains down towards the coastal region, and ranges about 40 to 60 miles wide and about 450 miles long from 
North to South, and is known for its Mediterranean style climate having a distinct wet and dry season. The almond life cycle during these distinct seasons is as follows (About Almonds 2017):

Downtime: November through February, almond trees go through a period of dormancy when the cold weather lets them sit back, relax and store up almond nutrients for next year's crop.

Bloom: Between late February and early March, almond tree buds burst into beautiful light pink and white blooms in preparation for pollination. Nonpareils are among the first to bloom, while other varieties, such as Carmel and Mission, bloom later.

Pollination: Many almond trees are not self-pollinating, so bees provide the missing piece of the puzzle. Populations of bees are brought to the orchard to carry pollen and initiate crop development.

Growing up: From March to June, almonds continue to mature, with the shell hardening and kernel forming. Also at this time, green almonds are harvested for various culinary uses.

Cracking open: In July and early August, almond hulls begin to split open exposing the almond shell and allowing it to dry. Shortly before harvest, the hulls open completely.

Harvest: From mid-August through October, mechanical tree "shakers" harvest the almonds by vigorously shaking them to the ground. The almonds then dry naturally for 8-10 days in the orchard before they are swept into rows and picked up by machine.

Shelling \& sizing: After harvest, almonds go to a huller/sheller where the kernels pass through a roller to remove the hull, shell and any remaining debris. Next stop: the handler for sizing, where the almond kernels drop into separate bins according to size.

Storage: After sizing, almonds are kept in controlled storage conditions to maintain quality until they're either shipped or further processed into any variety of different almond forms for diverse culinary uses.

Following processing almonds may be consumed in many forms including:

1)whole as snacks or embedded in confectioneries or energy bars, 2) slices or flakes for salads and cereals, 3) diced or chopped for toppings in baked goods and stuffings, 4) meal or flour for sauce thickening, flavor enhancers or coatings for fried foods, 5) almond milk for morning cereal or coffee, 6) paste and butter as an alternative to other spreads or filling for confectioneries and cereal bars, 7) oil for salad dressings and 
cosmetics/moisturizers, and 8) green almonds for salads or as a snack (About Almonds 2017).

In recent history almonds have experienced a strong rise in per capita consumption. For example, between 2001/02 to 2015/16 per capita consumption of almonds rose $84 \%$ globally, $104 \%$ in the US and $476 \%$ in China (USDA-FAS 2016). During this timeframe there have been numerous clinical and epidemiological studies that have shown positive health benefits of consuming almonds, where these benefits include measures such as improving cholesterol, decreasing coronary disease and assisting in weight loss (e.g. Fraser, Bennett, Jaceldo \& Sabate 2002; Sabate et al 2003; Milbury, Chen, Dolnikowski \& Blumberg 2003; Wien et al 2006; Josse et al 2007; Jenkins et al 2008; etc.).

The expansion of consumption globally and production of almonds in the US has led the almond market to become an important financial contributor to the Californian state economy as well as the annual supply of almonds for the world. The University of California Agricultural Issues Center estimated that the value of the California almond industry in 2014 was US\$21.5 billion (Sumner et al. 2014). Also, since the mid-1980s US produced almonds have accounted for $80 \%$ or more of global exports, and that share has risen to $91 \%$ over the last ten years (Figure 1.1). 


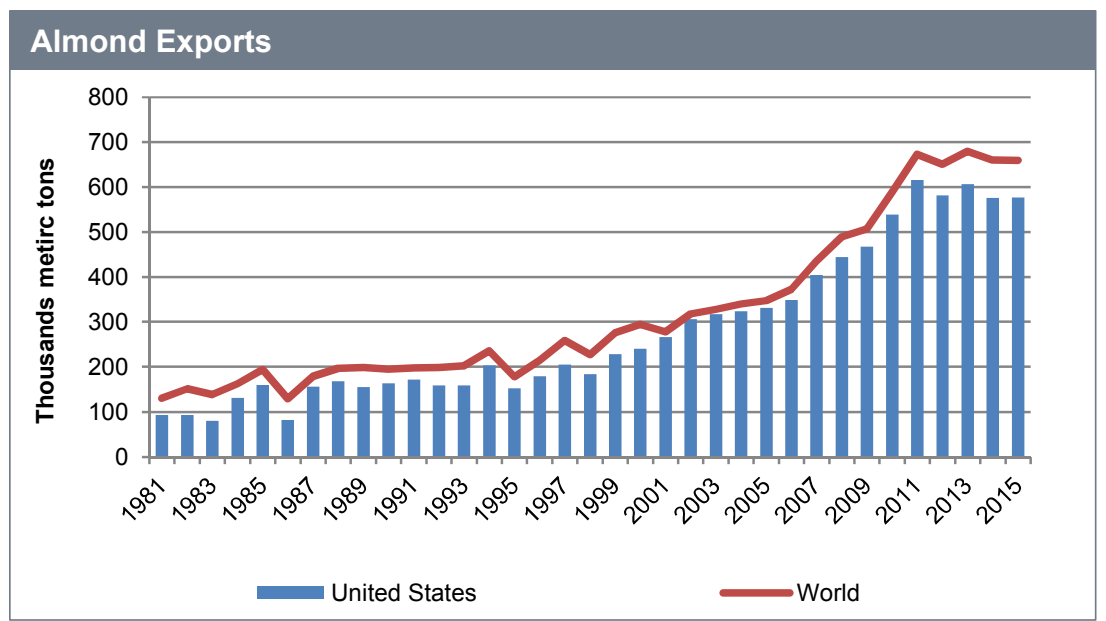

Figure 1.1: US almond exports capture greater than $80 \%$ global exports since 1980s Source: USDA-FAS 2016

Of critical importance to maintaining this mantle as the global leader of almond exports are adequate supplies of quality water for irrigation and other ecosystem services (ESS) such as pollination. ESS such as these can be threatend. For example, extended droughts can threaten water availability and the phenomenon called colony collapse disorder (CCD) has increased commercial pollinator mortality (Carman 2011). The consequent actions of producers and policy makers as they attempt to adapt to threatened ESS, influence both current and future supply and use of these ESS. Therefore, developing a deeper understanding of the decisions of almond crop producers and their relationship to the environment can contribute to public policy.

Three essays examine the US almond market and its influences. The first essay (Chapter 2) examines foreign excess demand elasticity facing the US almond market. In this essay, a new framework is proposed that extends the traditional conceptual model in a manner that explicitly incorporates idiosyncracies of a perennial crop. Foreign excess demand elasticity estimates are useful in ex ante policy evaluations and in estimating how 
short- or long-run shifts in supply and/or demand in any major country may impact commodity prices. For example, understanding how trade responds to price changes is critical in determining how prices will change when a drought limits crop supplies.

The second essay (Chapter 3) examines the influence of an ESS on the supply responses of perennial crop producers. An ecological and economic (eco-economic) approach is proposed that includes an explicit ecological variable representing water availability in perennial producer supply response models. This addition not only extends the traditional perennial supply response model literature, but also allows for forward looking analysis of the possible impacts of future drought scenarios.

The third essay (Chapter 4) examines the producer welfare impacts of both the recent extreme drought event and CCD on US almond producers. The eco-economic perennial supply response models from the second essay and the global market model from the first essay are combined with an examination of US almond commercial pollination fees in this essay to produce counterfactual simulations. Using these counter factual simulations, estimates of producer welfare changes are calculated. The calculations illustrate how the extreme drought and CCD have impacted US almond producers, considering the influences of the global market on the US almond market.

\subsection{References}

About Almonds. (2017). Retrieved from Almond Board of California: www.almonds.com/consumers/about-almonds/

Almond Board of California. (2016). Almond Almanac 2016 Annual Report. Retrieved from newsroom.almonds.com/sites/default/files/pdf_file/2016\%20Annual\%20Report.p $\mathrm{df}$

Bible Hub. (2017). Retrieved 2017, from biblehub.com: biblehub.com/genesis/43-11.htm 
Carman, H. (2011). The Estimated Impact of Bee Colony Collapse Disorder on Almond Pollination Fees. ARE Update University of California Giannini Foundation of Agricultural Economics, 14(5), 9-11.

Fraser, G. E., Bennett, H. W., Jaceldo, K. B., \& Sabate, J. (2002). Effect on Body Weight of a Free 76 Kilojoule (320 Calorie) Daily Supplement of Almonds for Six Months. Journal of the American College of Nutrition , 21 (3), 275-283.

Jenkins, D. J., Kendall, C. W., Marchie, A., Josse, A. R., Nguyen, T. H., Faulkner, D. A., et al. (2008). Almonds Reduce Biomarkers of Lipid Peroxidation in Older Hyperlipidemic Subjects. The Journal of Nutrition , 138, 908-913.

Josse, A. R., Kendall, C. W., Augustin, L. S., Ellis, P. R., \& Jenkins, D. J. (2007). Almonds and postprandial glycemia-a dose-response study. Metabolism , 56 (3), 400-404.

Milbury, P. E., Chen, C.-Y., Dolnikowski, G. G., \& Blumberg, J. B. (2006).

Determination of Flavonoids and Phenolics and Their Distribution in Almonds. Journal of Agricultral and Food Chemistry, 54, 5027-5033.

Morecraft, Jr., B. (2013). USDA.gov. Retrieved 2017, from www.usda.gov/oce/forum/past_speeches2013_Speeches/Morecraft.pdf

Sabate, J., Haddad, E., Tanzman, J. S., Jambazian, P., \& Rajaram, S. (2003). Serum lipid response to the graduated enrichment of a Step I diet with almonds: a randomized feeding trial. American Journal of Clinical Nutrition , 77 (6), 1379-1384.

Sumner, D. A., Matthews, W. A., Medellin-Azuara, J., \& Bradley, A. (2014). The Economic Impacts of the California Almond Industry. University of California Agricultural Issues Center.

U.S. Department of Agriculture. (2016). Foreign Agricultural Service (FAS). Retrieved 2016, from PS\&D: https://apps.fas.usda.gov/psdonline/

U.S. Department of Agriculture. (2015). National Agricultural Statistics Service (NASS). Retrieved 2016, from Quick_Stats: https:/www.nass.usda.gov/Quick_Stats/

Wien, M., Sabate, J., Ikle, D., Cole, S., \& Kandeel, F. (2003). Almonds vs complex carbohydrates in a weight reduction program. International Journal of Obesity, 27, 1365-1372. 


\section{EXCESS DEMAND ELASTICITY OF US ALMONDS}

This paper investigates the excess demand elasticity facing the major United States (US) tree nut crop of almonds. The US is the dominant global producer and exporter of almonds and its exports are sensitive to both the supply and demand in other countries. Using almonds as a case study, a proposed framework is developed to estimate excess demand elasticity that captures supply idiosyncrasies of perennial crops. Global supply, demand and price transmission elasticities were estimated and US excess demand elasticities were computed. Results showed that the excess demand elasticity estimates fell within the wide range of those for annual crops in other studies, but ended near the inelastic end of the range. For US almonds the 2003-2013 mean export demand elasticity was -0.244 in the short run and -0.681 in the long run.

\subsection{Introduction}

Export demand elasticities were originally developed to evaluate how policy changes would affect specific commodity markets (Johnson 1977; Tweeten 1977; Bredahl, Meyers and Collins 1979). For example, a land set-aside policy will do more to raise commodity prices if excess demand is inelastic than if it is elastic. Policy interventions such as set-asides have historically been an integral part of agricultural commodity markets, and examining market impacts especially prior to policy change make this estimation procedure a powerful tool. More recent work on excess demand elasticities both extended the price transmission equation and reported a contemporary picture of excess demand response for major US crops (Reimer, Zheng and Gehlhar 2012). The usefulness of this rich literature is not only for policy evaluation, but also to estimate how other short- or long-run shifts in supply and/or demand in any major 
country may impact prices. For example, understanding how trade responds to price changes is critical in determining how prices will change when a drought limits crop supplies.

The literature has been developed and used to estimate the excess demand elasticity of annual crops, and does not consider unique features of markets for perennial crops. According to investment literature, perennial producer responses critically differ from annual producer responses (French and Matthews 1971; Akiyama and Trivedi 1987; Devadoss and Luckstead 2010). Studies that examine the specificities of producer response for perennial crops have shown that they are tied directly to the biological nature of the crops themselves. French and Matthews (1971) provided a concise list of these differences from annual crops: "1) the long gestation period between initial input and first output, 2) an extended period of output flowing from the initial production or investment decision, and 3) eventually a gradual deterioration (usually) of the productive capacity of the plants" (p. 479).

The differences led to research that showed that perennial crop producer supply response is best represented by an approach that recognizes the nature and timing of investment decisions. These temporally separated decisions led to a framework composed of a series of structural equations that jointly determine supply responses. For example, using separate equations to determine new plantings, replacements, uprooting and removals is one way to reflect the differently timed investment decisions (e.g. French, King and Minami 1985; Akiyama and Trivedi 1987; Kalaitzandonakes and Shonkwiler 1992; Alston et al. 1995; Laajimi et al. 2008; Devadoss and Luckstead 2010). Even when data availability forced supply to be modeled as a single reduced form equation, some of 
the temporal influences were able to be captured by a lag structure that reflects the timing of key investment decisions (e.g. Bateman 1965; Behrman 1968; French and Matthews 1971; Wickens and Greenfield 1973).

To effectively estimate excess demand elasticities for perennial crops, a framework is developed that extends the traditional model to reflect perennial producer investment response. Drawing on this framework, the excess demand elasticity for almonds is estimated as a case study.

\subsection{Conceptual model}

Research largely developed in the 1960s and 1970s provided the basis for estimating the elasticity of foreign excess demand facing an export supplier (Tweeten 1967; Tweeten 1977; Johnson 1977; Bredahl, Meyers and Collins 1979). These estimates were then used to enable ex ante evaluation of farm and trade policy options.

Incorporating foreign demand and supply responsiveness is essential for estimating foreign excess demand elasticity for an exporting country that does not restrict trade. By definition, estimating foreign excess demand is only relevant if we can assume that the country of interest faces neither perfectly elastic nor perfectly inelastic foreign excess demand. When this is the case, it becomes useful to estimate any relevant elasticities in order to capture effects of price and quantity changes as it impacts foreign excess demand.

The US as a major supplier of principal, annual crops has been used as the go-to case example for estimating the elasticity of foreign excess demand, or excess demand elasticity. Numerous iterations in the research have provided for opportunities of comparison across time periods, importing geographies of interest, estimation techniques 
and commodities of interest (Reimer, Zheng and Gehlhar 2012). As the robust literature has developed and estimation techniques evolved, it has provided for better estimates.

For this study the beginning conceptual model and notation of excess demand borrows heavily from Tweeten (1967; 1977), Johnson (1977), Bredahl, Meyers and Collins (1979) and Reimer, Zheng and Gehlhar (2012). This elasticity of foreign excess demand can be expressed by the division of countries and regions based on their historical net importer or net exporter position. Let $i$ represent net importers where $i=1, \ldots, \mathrm{m}$ and $j$ represent other net exporters where $j=1, \ldots, \mathrm{x}$.

Demand in a given country is represented by $Q_{d i}$ or $Q_{d j}$ and supply represented as $Q_{s i}$ or $Q_{s j}$ with the level of exports from the country of analysis, denoted as the residual exporter, heading into the global market as $Q_{e f}$. The demand facing the residual exporter is

(1) $Q_{e f}=\sum_{i=1}^{m}\left(Q_{d i}-Q_{s i}\right)-\sum_{j=1}^{x}\left(Q_{s j}-Q_{d j}\right)$.

When simplified to their net trade positions $i$ and $j$ are combined where $i=1, . ., n$ represents all foreign countries. Similar to Bredahl, Meyers and Collins (1979) the demand facing the exporter of choice, or residual exporter, once defined may effectively be reduced into a summation of rest of world demands minus the summation of rest of world supplies

$$
Q_{e f}=\sum_{i=1}^{n}\left(Q_{d i}\right)-\sum_{i=1}^{n}\left(Q_{s i}\right) .
$$

The quantity demanded in each country and region is a function of the internal price represented as $p_{i}$, which is a function of the residual exporter price, or world price, and represented as $p_{w}$. The derivative with respect to the world price is

$$
\frac{d Q_{e f}}{d p_{w}}=\sum_{i=1}^{n}\left(\frac{d Q_{d i}}{d p_{i}} \frac{d p_{i}}{d p_{w}}\right)-\sum_{i=1}^{n}\left(\frac{d Q_{s i}}{d p_{i}} \frac{d p_{i}}{d p_{w}}\right) .
$$


The elasticity of demand for exports facing the residual supplier is

$$
\frac{d Q_{e f}}{d p_{w}} \frac{P_{w}}{Q_{e f}}=\sum_{i=1}^{n}\left(\frac{d Q_{d i}}{d p_{i}} \frac{d p_{i}}{d p_{w}} \frac{p_{i}}{Q_{d i}} \frac{p_{w}}{p_{i}} \frac{Q_{d i}}{Q_{e f}}\right)-\sum_{i=1}^{n}\left(\frac{d Q_{s i}}{d p_{i}} \frac{d p_{i}}{d p_{w}} \frac{p_{i}}{Q_{s i}} \frac{p_{w}}{p_{i}} \frac{Q_{s i}}{Q_{e f}}\right)
$$

Letting $\frac{d Q_{e f}}{d p_{w}} \frac{P_{w}}{Q_{e f}}=E_{e f}, \frac{d p_{i}}{d p_{w}} \frac{p_{w}}{p_{i}}=E_{p i}, \frac{d Q_{d i}}{d p_{i}} \frac{p_{i}}{Q_{d i}}=E_{d i}$, and $\frac{d Q_{s i}}{d p_{i}} \frac{p_{i}}{Q_{s i}}=E_{s i}$ then equation (4) can be expressed as

$$
E_{e f}=\sum_{i=1}^{n}\left(E_{p i} E_{d i} \frac{Q_{d i}}{Q_{e f}}\right)-\sum_{i=1}^{n}\left(E_{p i} E_{s i} \frac{Q_{s i}}{Q_{e f}}\right)
$$

This conceptual model was recreated closely following a combination of Bredahl, Meyers and Collins (1979) and Reimer, Zheng and Gehlhar (2012), who used it with annual crops in the estimation of exported demand elasticity facing a residual exporter. A weakness of the traditional conceptual model is that it does not explicitly capture the unique dynamics associated with perennial crops. Perennial crops have been shown to have distinct differences when it comes to producer behavior in comparison to annual crops as shown by French and Matthews (1971). To capture these differences, perennial producer supply response literature has incorporated more than one lagged price influence based on the timing of the separate producer investment decisions. For examples of studies of perennial crops supply response see Alston et al. (p. 21, 1995).

If producers are assumed to form expectations of prices or returns in period $t$ using either naïve or adaptive expectations, the price in t-1 plays a part in both annual and perennial crop supply models. For both annual and perennial crops when there is a lagged dependent variable included in the empirical supply response specification, there will be both a short- and long-run price influence on supply. However, the nature of that long-run response may be very different for a perennial crop where there are long lags between some investment decision and actual production. For example, a change in prices this 
year may have little effect on supplies in the short run, but may have a much larger impact on those supplies and thus excess demand, several years later, when trees planted now finally begin to bear fruit. The implication for modeling excess demand for perennial crops is that longer price lags may need to be considered, instead of just the prices in $t$ and $\mathrm{t}-1$.

The traditional conceptual model to determine the excess demand elasticity of an annual crop does not explicitly include multiple temporal considerations for the supply elasticity and associated price elasticity. While the use of lagged price and/or a lagged dependent variable allows a model to distinguish both a short- and long-run price response, it does not reflect the more complicated supply dynamics of a perennial crop. To more accurately measure the dynamics of excess demand response for a perennial crop the traditional conceptual model framework is extended. To do this, multiple lags are included to account for not only one but multiple t-k prices that may influence current supplies. This begins by extending the second half of the right hand side of equation (4), where this supply side influence of equation (4) begins as (6) $\sum_{i=1}^{n}\left(\frac{d Q_{s i}}{d p_{i}} \frac{d p_{i}}{d p_{w}} \frac{p_{i}}{Q_{s i}} \frac{p_{w}}{p_{i}} \frac{Q_{s i}}{Q_{e f}}\right)$.

The temporal influence depending on the specific commodity of concern is summed over t-k effects on current production, $Q_{s i}^{t}$. Also, each price effect is associated with its own price elasticity in the same time period adding an associated t-k price elasticity to each applicable t-k price. Letting $k=0,1, \ldots, \mathrm{v}$ the multiple temporal price influences on the supply elasticity is the summation of $t-k$ price influences and may be expressed as 


$$
\sum_{i=1}^{n}\left\{\sum_{k=0}^{v}\left(\frac{d Q_{s i}^{t}}{d p_{i}^{t-k}} \frac{d p_{i}^{t-k}}{d p_{w}^{t-k}} \frac{p_{i}^{t-k}}{Q_{s i}^{t}} \frac{p_{w}^{t-k}}{p_{i}^{t-k}} \frac{Q_{s i}^{t}}{Q_{e f}^{t}}\right)\right\}
$$

As mentioned this extension of the conceptual model is associated with the addition of more than one supply side price influence to represent the idiosyncratic nature of perennial supply response. For simplicity the demand portion remains fundamentally unchanged. Superscripts for time $t$ were added to demand to represent current time period effects. Any additional temporal price influence on demand is ignored, but may be added if applicable. With the added temporal specificities on the supply side the new elasticity of foreign excess demand is

$$
\frac{d Q_{e f}^{t}}{d p_{w}^{t-k}} \frac{p_{w}^{t-k}}{Q_{e f}^{t}}=\sum_{i=1}^{n}\left(\frac{d Q_{d i}^{t}}{d p_{i}^{t}} \frac{d p_{i}^{t}}{d p_{w}^{t}} \frac{p_{i}^{t}}{Q_{d i}^{t}} \frac{p_{w}^{t}}{p_{i}^{t}} \frac{Q_{d i}^{t}}{Q_{e f}^{t}}\right)-\sum_{i=1}^{n}\left\{\sum_{k=0}^{v}\left(\frac{d Q_{s i}^{t}}{d p_{i}^{t-k}} \frac{d p_{i}^{t-k}}{d p_{w}^{t-k}} \frac{p_{i}^{t-k}}{Q_{s i}^{t}} \frac{p_{w}^{t-k}}{p_{i}^{t-k}} \frac{Q_{s i}^{t}}{Q_{e f}^{t}}\right)\right\}
$$

Letting $\frac{d Q_{e f}^{t}}{d p_{w}^{t-k}} \frac{p_{w}^{t-k}}{Q_{e f}^{t}}=E_{e f}^{t}, \frac{d p_{i}^{t}}{d p_{w}^{t}} \frac{p_{w}^{t}}{p_{i}^{t}}=E_{p i}^{t}, \frac{d Q_{d i}^{t}}{d p_{i}^{t}} \frac{p_{i}^{t}}{Q_{d i}^{t}}=E_{d i}^{t}, \frac{d p_{i}^{t-k}}{d p_{w}^{t-k}} \frac{p_{w}^{t-k}}{p_{i}^{t-k}}=E_{p i}^{t-k}, \frac{d Q_{s i}^{t}}{d p_{i}^{t-k}} \frac{p_{i}^{t-k}}{Q_{s i}^{t}}=$ $E_{s i}^{t-k}$, then equation (8) can now be expressed as

$$
E_{e f}^{t}=\sum_{i=1}^{n}\left(E_{p i}^{t} E_{d i}^{t} \frac{Q_{d i}^{t}}{Q_{e f}^{t}}\right)-\sum_{i=1}^{n}\left\{\sum_{k=0}^{v}\left(E_{p i}^{t-k} E_{s i}^{t-k} \frac{Q_{s i}^{t}}{Q_{e f}^{t}}\right)\right\} .
$$

In equation (9a) supply price influences for perennial crops may begin as early as time $\mathrm{t}$ where $\mathrm{k}$ is equal to 0 . For example, the harvest decision for natural rubber may be influenced by current prices, where farmers have the option to tap (harvest) more or less trees depending on profitability of harvestable product versus harvesting costs (Hartley, Nerlove and Peters 1987). Whereas, for other perennial crops such as almonds the harvesting decision is generally assumed to occur if a harvestable crop is available (Alston et al. 1995). In these instances the first supply price modeled to influence current production is the lagged price in $\mathrm{t}-1$, where $\mathrm{k}$ is equal to 1 . 
To more explicitly clarify equation (9a) for empirical application to examine US almond excess demand elasticity including multiple lags, it may be modified to express these different temporal supply price influences. As it is assumed that $t-1$ is the first supply price that influences almond production in time $t$, or current year production, it is consequently assumed that any price shift in time t only has a demand side influence in the extreme short run, or intra-year, on excess demand elasticity. With no current year supply price influence intra-year excess demand elasticity is

(9b) $E_{e f}^{t}=\sum_{i=1}^{n}\left(E_{p i}^{t} E_{d i}^{t} \frac{Q_{d i}^{t}}{Q_{e f}^{t}}\right)$.

The next step is the inclusion of the first supply price on current production. In the empirical applications of annual crops the reported excess demand elasticities that included the t-1 supply price influence were referred to as short-run excess demand elasticity (Devadoss and Meyers 1990; Reimer, Zheng and Gehlhar 2012). In a similar manner the estimated results in this examination including the $t-1$ supply price influence will be referred to as the short-run excess demand elasticity. When $\mathrm{k}=1$ let the short-run excess demand elasticity be (9c) $\left.E_{e f}^{t}=\sum_{i=1}^{n}\left(E_{p i}^{t} E_{d i}^{t} \frac{Q_{d i}^{t}}{Q_{e f}^{t}}\right)-\sum_{i=1}^{n}\left\{E_{p i}^{t-1} E_{s i}^{t-1} \frac{Q_{s i}^{t}}{Q_{e f}^{t}}\right)\right\}$.

In the examinations of annual crops the long-run excess demand elasticity was estimated using this short-run excess demand elasticity with the inclusion of any lagged effects when lagged dependent variables were used. For the case of a perennial crop where an older lagged price is used to represent the initial investment or planting decision, there is still another supply price to be included in the equation in addition to any lagged dependent affects. This addition uses t-k where $\mathrm{k}$ is greater than 1 . 
The longer lagged supply price influence is commodity and country specific as it is largely determined by geographical differences including variety, ecology and husbandry that impact harvestable production timing. The gestation lag for almonds from planting to bearing productive life can be as little as three to four years with almond trees generally reaching full mature productivity between five and seven years after planting (Alston et al. 1995). With this in mind the longer lag price influence for almonds may be represented by $\mathrm{t}-\mathrm{k}$ where the earliest longer lagged price may be $\mathrm{k}$ equal to 3 or up to 7 , or possibly some moving average thereof (French and Matthews 1971).

When all supply price influences are considered, including the effects of longer lagged prices where $\mathrm{k}$ is greater than 1 , the excess demand elasticity is best represented by equation (9a) and may be described as the long-run excess when the supply prices and all lagged dependent influences are included. Using equation (9b) provides the intra-year excess demand elasticity. Equation (9c) provides the short-run excess demand elasticity, whereas additional intermediate excess demand elasticities may be calculated up to and including the long-run excess demand elasticity where all t-k supply price influences where $\mathrm{k}$ is from 0 to $\mathrm{v}$, and all associated lagged dependent influences are applied.

\subsection{Procedures and data}

To parameterize the empirical model a system of equations is proposed. The supply and demand of foreign countries and price transmission specifications are developed following closely the methods and empirical models used by Reimer, Zheng and Gehlhar (2012) with applicable adjustments or additions as necessary from French and Matthews (1971), Akiyama and Trivedi (1987) and FAPRI (2004). Historical relationships are estimated with the intent of producing elasticities that represent how the 
change in an assumed exogenous world price affects foreign prices, demand, supply and trade.

\subsubsection{Demand and supply}

It is assumed that foreign prices are determined using price transmission equations. Foreign prices for a representative producer are denoted as $S p_{s i}^{t}$ for the nearerterm lagged price and $L p_{s i}^{t}$ for the longer-term lagged price, and foreign prices for a representative consumer are denoted as $p_{d i}^{t}$ in year $t$. Prices for estimation of both supply and demand equations incorporate real, or deflated, local currency units. The commodity of choice is considered a homogenous good operating in a market under competitive conditions.

Supply for each given country is represented by the quantity of production and denoted as $Q_{s i}^{t}$ and demand is represented by the quantity of disappearance and denoted as $Q_{d i}^{t}$ of the commodity both in time $t$. At a given price a net importers' domestic quantity demanded $Q_{d i}^{t}$ is greater than the domestic quantity supplied $Q_{s i}^{t}$ and vice versa for a net exporter.

Let foreign demand be

(10) $\ln Q_{d i}^{t}=\beta_{0 i}+\beta_{1 i} \ln p_{d i}^{t}+\beta_{2 i} \ln Y_{i}^{t}+\beta_{3 i} \ln N_{i}^{t}+\sum_{f=4}^{v} \beta_{f i} \ln U_{f i}^{t}+\varepsilon_{i}^{t}$, where the $\beta$ s are the demand parameters to be estimated. $p_{d i}^{t}$ represent the almond price, $Y_{i}^{t}$ represents income and $\mathrm{N}$ represents population. $U_{f i}^{t}$ includes any other demand shifters, such as the prices of substitute goods, and $\varepsilon_{i}^{t}$ is the error term. $\beta_{1 i}$ represents the elasticity of domestic demand. The expected sign of $\beta_{1 i}$ is negative. For simplicity any potential lags in demand have not been included to estimate disappearance. 
For select perennial commodities ending stocks may be very important. In this analysis, a stock holding equation was not included because the data source used for foreign countries did not include stock holding data.

Let foreign supply be

(11) $\ln Q_{s i}^{t}=\delta_{0 i}+\delta_{1 i} \ln S p_{s i}^{t-1}+\delta_{2 i} \ln \sum_{k=2}^{r} L p_{s i}^{t-k}+\delta_{3 i} \ln Q_{s i}^{t-1}+\sum_{f=4}^{z} \delta_{f i} \ln Z_{f i}^{t-1}+$ $u_{i}^{t}$

where the $\delta$ s are the supply parameters to be estimated. Both $\delta_{1 i}$ and $\delta_{2 i}$ represent the elasticities of supply response to a price change in a particular period. In the reduced form single equation approach, the longer term lagged price in $\mathrm{t}-\mathrm{k}$ is representative of a commodity specific gestation lag prior to productive harvest associated with the initial planting, or expansion, decision. This longer lagged price term may be best represented by either a single previous year price such as k equaling 3,4 or 5 for almonds, or a moving average of prices depending on data availability and the nature of the production process.

The lagged dependent variable $Q_{s i}^{t-1}$ is the previous year's production. This variable allows for a partial adjustment in the system. $Z_{f i}^{t-1}$ is any other lagged supply shifter such as any applicable cross price(s) or opportunity $\operatorname{cost}(\mathrm{s})$ of the land such as prices, or returns, of a competing commodity, and $u_{i}^{t}$ is the error term. The long-run supply elasticities are $\left(\delta_{1 i}+\delta_{2 i}\right) /\left(1-\delta_{3 i}\right)$. All supply parameters except $Z_{f i}^{t-1}$ are expected to be positive.

Supply and demand equations were not estimated simultaneously similar to the approach of Reimer, Zheng and Gehlhar (2012). Each individual foreign country that was estimated was chosen because it was involved in international trade, where domestic 
production and domestic demand do not equal. Domestic disappearance was not provided explicitly by the data source. Disappearance for foreign countries was calculated as the identity of production plus imports minus exports in each given year. Neither stock holding nor stock holding changes were provided by the data source for foreign countries. This left the identity for disappearance as a residual calculation. It is important to note that calculating disappearance in this manner pushes any potential stockholding responsiveness into the consumers' overall price responsiveness of demand, which overstates consumer price response (Wright 2011; Diffenbaugh et al. 2012).

The historical source for supply and utilization and price data for most countries was the Food and Agriculture Organization (FAO) of the United Nations from their online database FAOSTAT. The exception was for the US where the United States Department of Agriculture's (USDA) Production, Supply and Distribution online database was used, as the USDA was expected to be more reliable for its domestic data. The rest of world (ROW) figures were computed as the difference between the FAO world totals and the sum of select individual countries. The country selection left the average ROW figures to make up less than $25 \%$ of the world total in any category. All applicable macroeconomic data came from the USDA's International Macroeconomic Data Set (USDA-ERS 2015). There are likely errors caused by inconsistent data sources, and given the method used to calculate the ROW, these errors would fall into this residual category.

\subsubsection{Price transmission}

There are many approaches used for price analysis. One focus of price analysis is horizontal, or spatial, price transmission across countries or regions. The purpose here 
was to estimate the spatial price transmission in a tractable way. To accomplish this, a price transmission procedure was used in estimating how much a local price changes as the world price (in this case, the US grower price) changes.

When dealing with time series, cointegration models are widely used for the analysis of price transmission. In this paper to test for the long-run relationships between the US price and foreign country prices I used the Engle-Granger (1987) cointegration procedure. Once cointegration was established the price transmission relationships were used as estimates for $E_{\text {pit }}$ from equation (9a). To account for imperfect adjustment or constrained adjustments to a world price, a partial-adjustment model was developed by Abbott (1979) and used by others since (Mittal and Reimer 2008; Reimer, Zheng and Gehlhar 2012). Following this partial-adjustment price transmission model, let price transmission be (12) $\ln p_{i}^{t}=\beta_{0 i}+\beta_{1 i} \ln p_{U S}^{t}+\beta_{2 i} \ln p_{i}^{t-1}+\beta_{3 i}$ Trend $^{t}+\varepsilon_{i}^{t}$, where the real, or deflated, internal price for a given foreign country $i$ at time $t$ is denoted as $p_{i}^{t}$ and the real US price is denoted by $p_{U S}^{t}$. The real lagged foreign price is $p_{i}^{t-1}$ and Trend represents a time trend $1,2,3 \ldots$ where the time trend when applied captures other factors that may cause foreign prices to rise or fall over time, and $\varepsilon_{i}^{t}$ is the error term. The $\beta$ 's are to be estimated, and the long-run price elasticities are represented by $\beta_{1 i} /(1-$ $\left.\beta_{2 i}\right)$.

It is important to note that Reimer, Zheng and Gehlhar (2012), pointed out that "an econometric concern with estimating" (12) "is the potential for endogeneity for the lagged value of the dependent variable $p_{i}^{t-1}$ " (p. 505). The concern was that when a lagged dependent variable is not independent of the error terms, ordinary least squares 
methods may provide biased estimates in small samples. Equation (12) is a partial adjustment model, and as stated in Greene (2008) a partial adjustment model has, "significant practical advantages...its disturbance is nonautocorrelated" (p. 679). Also, parameters of a partial adjustment model can be estimated efficiently and consistently by ordinary least squares methods and related techniques (Greene 2008).

The method of estimation here followed that used by Reimer, Zheng and Gehlhar (2012), restricted maximum likelihood (REML), for all price transmission, supply and demand equations. As maximum likelihood is known to have bias, especially with small sample sizes, REML was useful for this study in that it adjusts the degrees of freedom by the number of parameters leaving its estimators to be considered unbiased (Kleinbaum et al. 2008). Also, REML is reportedly known to retain good properties even under firstorder autoregressive (AR[1]) errors (p. 649, Greene 2008).

Since a partial adjustment model was included as the specification of the price transmission equation, the Godfrey LaGrange Multiplier test (Godfrey 1978; p. 644, Greene 2008) was performed on all the price series to estimate any autocorrelation for up to three potential lags under a $5 \%$ significance level. For all 10 of the cases, the null hypothesis that 1, 2, or 3 autoregressive coefficients were simultaneously equal to zero could not be rejected. So, generally there was no evidence of first, second, or third-order autocorrelation in these price series.

Prices came from a variety of historical data sources. The US price was from the USDA-NASS, and represented the US grower price converted from a US\$/pound basis to US\$/metric ton. Foreign prices sources included FAOSTAT, the European Commission's online database (Eurostat), the USDA's Foreign Agricultural Service Global Agricultural 
Trade System Online (GATS) and Global Trade Information Services online database (GTIS). From FAOSTAT producer prices in US\$/metric ton were used for both Australia and Turkey. From Eurostat the Spain producer price, which is the leading producer in the EU-28, was used as the internal price for the European Union with the price converted from Euros/100 kilograms into US\$/metric ton. GATS export trade unit values from the US to the trading partner were used for Canada, China, Hong Kong and Japan with the total export aggregated unit values used to capture a Rest of World price proxy. An average import trade unit value was also used from GTIS for Iran's price proxy.

The US is the primary almond exporter averaging over $90 \%$ of world exports across the last ten years with only a few smaller net exporters but many net importers. The countries used to capture foreign supply and demand are included in Table 2.1 below. As mentioned the difference of the sum of all foreign countries and the US from World totals provides for a Rest of World aggregate, which is the summation of all smaller producers and consumers.

To test price series for a cointegrating vector, the first step is to determine if a unit root exists. A unit root provides evidence that a series is nonstationary. If a series is nonstationary its mean, variance and autocorrelation structure change over time. For this reason Augmented Dickey-Fuller (ADF) tests were conducted on each price series. 


\begin{tabular}{lcc}
\hline & \multicolumn{2}{c}{ Single Mean Tau Value with zero lag } \\
\hline Australia & nominal & first difference \\
Canada & -1.94 & -3.77 \\
China & 0.11 & -3.05 \\
European Union & -2.23 & -7.40 \\
Hong Kong & -0.93 & -5.40 \\
Iran & -0.71 & -4.27 \\
Japan & -0.90 & -3.72 \\
Turkey & -0.65 & -3.22 \\
US & -0.54 & -4.67 \\
Rest of World & -1.24 & -6.87 \\
\hline
\end{tabular}

Notes: Null hypothes is is nonstationary.

At the $5 \%$ significance level the critical value is -3.0 with $n=25$ and -2.93 with $n=50$.

Critical values were obtained from MacKinnon (1991).

The results presented in Table 2.1 in the first column confirm there is the presence of a unit root within each nominal price series. This means the series showed evidence of nonstationarity. To compensate for this the price series were transformed. Thus the tests were re-run on the series after they were differenced. The results in the second column show that all prices series after the transformation were stationary indicating that the price series are I(1).

As there is evidence of the price series being I(1) the next step is to test for the presence of statistically significant long-run relationships between the US and foreign price series. I used the Engle-Granger (1987) two-step procedure. This procedure was run on the price series in a pair-wise fashion. This procedure is a residual based test for cointegration. First, the relationship between pairs was estimated using equation (12). Once the price transmission equation is estimated the residuals are collected and then 
ADF unit root tests were run on the residuals. Stationarity of the unit root implies that the analyzed series are cointegrated.

Table 2.2: Engle-Granger cointegration tests for price series

\begin{tabular}{ll} 
Pair of series & ADF \\
\hline Australia-US & $-5.87 * * *$ \\
Canada-US & $-8.11^{* * *}$ \\
China-US & $-6.04 * * *$ \\
European Union-US & $-4.55^{* * *}$ \\
Hong Kong-US & $-5.19 * * *$ \\
Iran-US & $-3.67 * *$ \\
Japan-US & $-5.87 * * *$ \\
Turkey-US & $-4.41 * * *$ \\
Rest of World-US & $-4.92 * * *$ \\
\hline Notes: Astericks denote levels of significance $(* *$ for $5 \%$ and $* * *$ for $1 \%)$. \\
Critical values were obtained from MacKinnon (1991).
\end{tabular}

The ADF test results in Table 2.2 show evidence that cointegration is present. I conclude that all of the tested foreign almond prices are cointegrated with the US almond price. Since the pair-wise series are cointegrated, the results of the regressions that analyze the relationship between them are consistent (see equation 12). Thus using this specification the $\beta_{1 i}$ is the short-run price transmission elasticity and the long-run price transmission elasticities are represented by $\beta_{1 i} /\left(1-\beta_{2 i}\right)$. 


\subsection{Results}

\subsubsection{Price transmission}

Table 2.3 below reports the estimation results of equation (12) for each of the seven individual countries and the Rest of World aggregate. As a log-log specification was used, the first column represents the short-run price transmission elasticity to the US price. Whenever the trend variable was not found to be statistically significant at least at the $10 \%$ significance level it was dropped from the specification. All of the short-run price transmission elasticities fall in the $(0,1)$ interval. This was expected under an imperfect price transmission assumption. The short-run elasticities range from 0.267 for Turkey and 0.302 for Iran up to 0.593 for the EU. Most of the coefficients were significant at the 0.01 level and all but one were significant at the 0.05 level.

Table 2.3: Almond price transmission elasticities

\begin{tabular}{|c|c|c|c|c|}
\hline & $\ln$ U.S. Price & In Lagged Own Price & Trend & Intercept \\
\hline Australia & $0.349 * * *(0.120)$ & $0.613 * * *(0.136)$ & - & $0.22 \quad(0.615)$ \\
\hline Canada & $0.403 * * *(0.054)$ & $0.574 * * *(0.091)$ & - & $(0.342)$ \\
\hline China & $0.446 * * \quad(0.220)$ & $0.267 * \quad(0.173)$ & - & $1.204 \quad(1.062)$ \\
\hline European Union & $0.593 * * *(0.101)$ & $0.404 * * *(0.099)$ & $0.005 * *(0.003)$ & $-0.904 * *(0376)$ \\
\hline Hong Kong & $0.399 * * *(0.117)$ & $0.526 * * *(0.131)$ & $0.01 * *(0.005)$ & $0.004 \quad(0.506)$ \\
\hline Iran & $0.302 \quad(0.233)$ & $0.533 * * \quad(0.219)$ & $-0.053 *(0.025)$ & (1.609) \\
\hline Japan & $0.583 * * *(0.107)$ & $0.484 * * *(0.116)$ & & -0.193 \\
\hline Turkey & $0.267 * * \quad(0.126)$ & $0.778 * * *(0.036)$ & - & $-0.294 * *(0.511)$ \\
\hline Rest of World & $0.352 * * *(0.071)$ & $0.531 * * *(0.118)$ & - & $0.518 \quad(0.471)$ \\
\hline
\end{tabular}

For Iran the price transmission elasticity was not found to be significant even at the $10 \%$ level. Even though the almond market is assumed to be homogenous for the purposes of this study, a portion of almonds produced in Iran are called Mamra almonds 
(Slette 2016). Mamra almonds are native to Iran and Afghanistan with some production in India, but make up only a small portion of global almond production.

According to a recent USDA Gain Report for India (Slette 2016) Iranian varieties of almonds such as Mamra often command a higher price premium attributed to their popularity in the western and northwestern regions of India. With more limited production both in total quantity and spatially these regional specific Iranian almonds may be somewhat differentiated from the bulk of the market. Despite any concerns for a limitation of substitutability between the Mamra variety and other almond varieties, the cointegration procedure provided evidence that the Iranian price was cointegrated with the US price. Also, considering the short run elasticity value was at 0.302 meaning that a $1 \%$ increase in the US price is associated with a $0.302 \%$ increase in Iran's price, and given the 0.533 coefficient on the lagged dependent variable, the implication is that the long run price transmission elasticity is $0.302 /(1-0.533)$, or 0.649 . This long run price transmission elasticity is nearer to 1 as would be expected in a cointegrated market. Having a long run elasticity below 1 was not a surprise given that the USDA report showed that Iranian Mamra almonds were sold at a price premium to Californian almonds in each of the reported years since 2011/12 (Slette 2016).

The simple average of the short run price transmission elasticities were well below 1 at 0.411 . Many were lower than a priori expectations, but this was in part attributed to using a partial adjustment specification. When looking at the calculated long-run price transmission elasticities using the formula $\beta_{1 i} /\left(1-\beta_{2 i}\right)$ as reported in Table 2.6 the long run elasticities averaged much closer to 1.0 at 0.893 . 


\subsubsection{Demand and supply}

Both equations for demand (10) and supply (11) were estimated individually using REML as mentioned above. Results for both are reported in Table 2.4. The standard error (SE) for each parameter is listed in the table in parenthesis below its corresponding coefficient. Most estimated coefficients had the a priori expected signs. Similar to the price transmission regressions not all parameters ended with a coefficient that was statistically different from zero at least at a $10 \%$ critical value level. 
Table 2.4: Almond demand and supply results

\begin{tabular}{|c|c|c|c|c|c|c|c|c|c|}
\hline & Australia & Canada & China & $\begin{array}{c}\text { European } \\
\text { Union }\end{array}$ & Hong Kong & Iran & Japan & Turkey & $\begin{array}{l}\text { Rest of } \\
\text { World }\end{array}$ \\
\hline $\begin{array}{l}\text { Demand Equation } \\
\text { ln almond price }\end{array}$ & $\begin{array}{c}-0.192 * * * \\
(0.037)\end{array}$ & $\begin{array}{c}-0.267 * * * \\
(0.045)\end{array}$ & $\begin{array}{c}-0.009^{* * *} \\
(0.005)\end{array}$ & $\begin{array}{c}-0.142^{* *} \\
(0.059)\end{array}$ & $\begin{array}{c}-0.150 * * * \\
(0.047)\end{array}$ & $\begin{array}{l}-0.148 \\
(0.589)\end{array}$ & $\begin{array}{l}-0.119 \\
(0.164)\end{array}$ & $\begin{array}{c}-0.099 * * * \\
(0.035)\end{array}$ & $\begin{array}{l}-0.088 \\
(0.138)\end{array}$ \\
\hline ln GDP/capita & $\begin{array}{c}3.481 * * * \\
(0.247)\end{array}$ & $\begin{array}{l}0.975^{*} \\
(0.68)\end{array}$ & $\begin{array}{r}0.417 * * \\
(0.038)\end{array}$ & $\begin{array}{l}0.51 * * * \\
(0.103)\end{array}$ & $\begin{array}{c}6.874 * * * \\
(1.23)\end{array}$ & $\begin{array}{c}2.55 \\
(2.916)\end{array}$ & $\begin{array}{c}0.989 \\
(0.757)\end{array}$ & $\begin{array}{c}1.009 * * * \\
(0.233)\end{array}$ & $\begin{array}{c}2.854 * * * \\
(0.252)\end{array}$ \\
\hline $\ln$ trend & - & $\begin{array}{c}0.816^{* * *} \\
(0.237)\end{array}$ & - & - & - & $\begin{array}{l}-1.085 \\
(3.172)\end{array}$ & - & - & - \\
\hline Intercept & $\begin{array}{c}-26.479 * * * \\
(2.787)\end{array}$ & $\begin{array}{l}-2.240 \\
(6.644)\end{array}$ & $\begin{array}{c}6.603 * * * \\
(0.388)\end{array}$ & $\begin{array}{l}7.87^{* * *} \\
(1.034)\end{array}$ & $\begin{array}{c}-57.539 * * * \\
(11.623)\end{array}$ & $\begin{array}{l}-6.522 \\
(13.69)\end{array}$ & $\begin{array}{l}-0.049 \\
(7.657)\end{array}$ & $\begin{array}{c}1.657 \\
(2.202)\end{array}$ & $\begin{array}{c}-10.421^{* * * *} \\
(1.905)\end{array}$ \\
\hline $\begin{array}{l}\text { Supply Equation } \\
\ln \text { almond price t-1 }\end{array}$ & $\begin{array}{c}0.213^{* *} \\
(0.1)\end{array}$ & - & $\begin{array}{l}0.070 * \\
(0.049)\end{array}$ & $\begin{array}{c}0.144 \\
(0.149)\end{array}$ & - & $\begin{array}{c}0.307 \\
(0.743)\end{array}$ & - & $\begin{array}{c}0.052 \\
(0.105)\end{array}$ & $\begin{array}{l}0.259^{*} \\
(0.181)\end{array}$ \\
\hline In almond price $\mathrm{t}-\mathrm{k}^{++}$ & $\begin{array}{c}0.038 \\
(0.114)\end{array}$ & - & $\begin{array}{l}0.115^{* *} \\
(0.047)\end{array}$ & $\begin{array}{r}0.155++ \\
(0.122)\end{array}$ & - & $\begin{array}{c}0.132 \\
(0.612)\end{array}$ & - & $\begin{array}{r}0.029++ \\
(0.109)\end{array}$ & $\begin{array}{c}0.151 \\
(0.180)\end{array}$ \\
\hline In lagged production & $\begin{array}{l}0.46^{* *} \\
(0.26)\end{array}$ & - & $\begin{array}{c}0.476^{* * *} \\
(0.163)\end{array}$ & $\begin{array}{c}0.076 \\
(0.254)\end{array}$ & - & $\begin{array}{c}0.16 \\
(0.58)\end{array}$ & - & $\begin{array}{l}0.42 * * \\
(0.228)\end{array}$ & $\begin{array}{l}-0.044 \\
(0.235)\end{array}$ \\
\hline ln trend ${ }^{+}$ & $\begin{array}{c}0.0845^{* *+} \\
(0.037)\end{array}$ & - & $\begin{array}{c}0.029 * * *+ \\
(0.008)\end{array}$ & $\begin{array}{c}-0.012 * * *+ \\
(0.004)\end{array}$ & - & $\begin{array}{c}1.555 \\
(3.276)\end{array}$ & - & $\begin{array}{c}0.041^{* * *+}+ \\
(0.016)\end{array}$ & $\begin{array}{c}1.635^{* * *} \\
(0.384)\end{array}$ \\
\hline Intercept & $\begin{array}{c}2.301^{* *} \\
(1.263)\end{array}$ & - & $\begin{array}{l}3.57 * * * \\
(1.344)\end{array}$ & $\begin{array}{c}10.91 * * * \\
(3.445)\end{array}$ & - & $\begin{array}{c}2.112 \\
(11.749)\end{array}$ & - & $\begin{array}{c}4.524 * * \\
(1.883)\end{array}$ & $\begin{array}{c}6.014 * * * \\
(2.143)\end{array}$ \\
\hline
\end{tabular}

Notes: Standard error is in parentheses. R-square is not available for equations estimated with restricted maximum likelihood estimator. The asterisks $* * *, * *, *$ denote statistical

significance at the $1 \%, 5 \%$ and $10 \%$ levels respectively. + denotes trend instead of ln trend; ++ denotes exceptions to the rule that $\mathrm{k}=4$. For the European Union $\mathrm{k}=5$ and for Turkey $\mathrm{k}=3$. 
It is important to note that the final specification of select empirical country models included either a time trend or log trend. The inclusion of the trend variable was used according to its historical fit. The evaluation of fit was based primarily on model comparisons between its inclusion and exclusion using both the log likelihood and AIC results comparisons. In each case where the trend was included in the final specification it had improved the model fit, and in each case excluding the supply and demand equations for Iran, the trend variable was itself also statistically significant.

The first row of results represents the demand parameter estimates. In Australia, as an example, the estimated elasticity was -0.192 . This means that a $1 \%$ increase in the domestic almond price translates into a $0.192 \%$ decrease in domestic consumption. Spanning the estimated demand price elasticities they range from the smallest at -0.009 for China up to the largest at -0.267 in Canada. All listed countries including the Rest of World aggregate have a relatively price inelastic demand. In the bottom half of Table 2.4 the estimated parameters of the supply equation are provided. The partial response to a change in price is provided for both $\mathrm{t}-1$ and $\mathrm{t}-\mathrm{k}$ where $\mathrm{k}$ was equal to 3,4 or 5 .

The Chinese estimated partial supply effect of a change in price in t-1 was 0.070 and in $\mathrm{t}-4$ was 0.115 . The 0.070 supply price elasticity for $\mathrm{t}-1$ would mean that a $1 \%$ increase in domestic price in t- 1 translates into a $0.070 \%$ increase in domestic production in time t. A $1 \%$ increase in domestic price in t- 4 would mean a $0.115 \%$ increase in Chinese production in time $t$, before considering the effects of other equation parameters. The estimated short-run supply price elasticities for $\mathrm{t}-1$ ranged from 0.052 in Turkey up to 0.307 in Iran, and the partial response price elasticities for t-k ranged from 0.029 in Turkey up to 0.155 in the European Union. 
No supply elasticities are shown for Canada, Hong Kong or Japan, as these three countries do not have any reported production. It is possible that these countries may have a minimal amount of production, grown under glass, but if this is the case the amount of production is not high enough to be deemed as commercial production in the utilized data source.

It is important to note that the impacts of the supply specification including both a lagged dependent variable and more than one lagged supply price vary across time. The effects on production in time $t$ would actually be the result of a sum of temporal price effects as specified in equation (9a) in addition to including any influences that the lagged dependent variable plays on prices from both $\mathrm{t}-1$ and $\mathrm{t}-\mathrm{k}$ price changes as specified in the explanation for equation (11). To illustrate this I performed a domestic price shock across time to test production changes for China in a forward looking manner. Figure 2.1 below shows the influence on China's production from a sustained $1 \%$ price change to the domestic China price. 


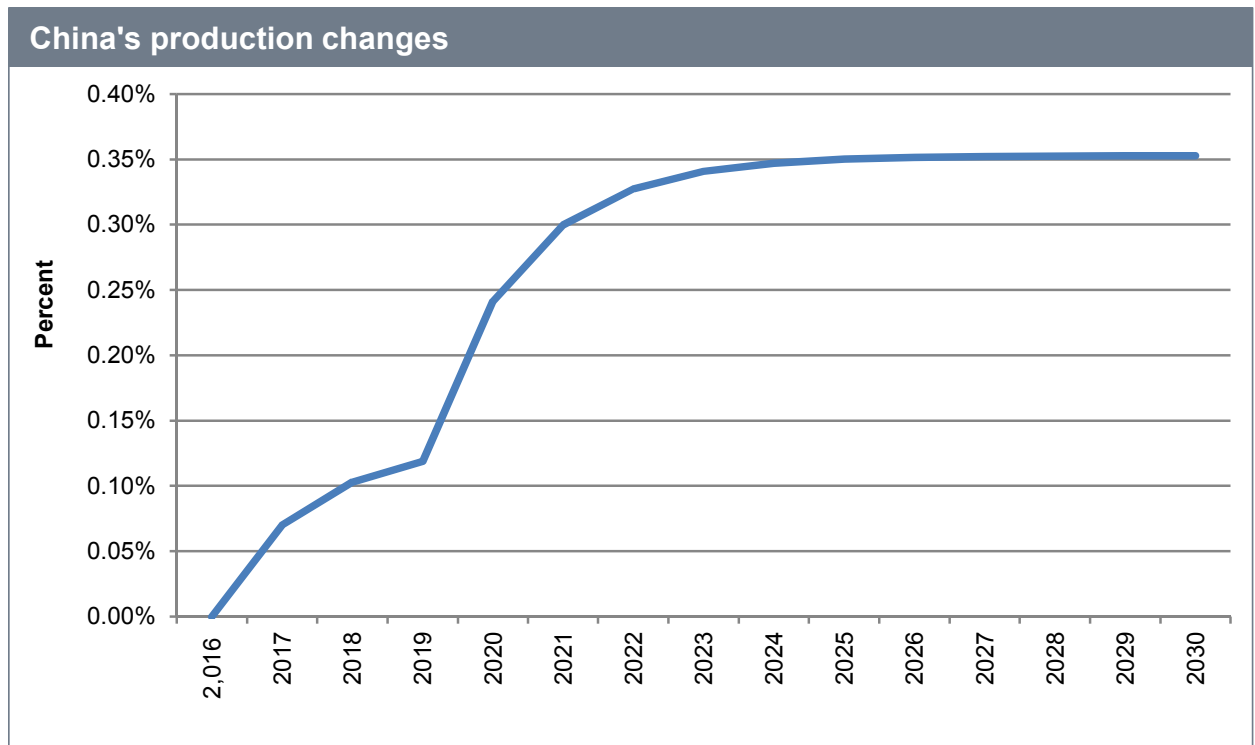

Figure 2.1: China's production change 2017-2030 from a sustained 1\% upward change to domestic price beginning in 2016

In Figure 2.1 the production change in 2017 from a lagged upward price shock is observed to have a positive influence on production. The $1 \%$ change in domestic price in 2016 had a $0.070 \%$ influence upward on China's production in 2017 as expected.

Following this shift, the magnitude of production change from the sustained price shock increased between the years of 2017 and 2019 as it also included the sum of each additional t-1 price shock plus the applicable effects from the lagged dependent variable in each year after the initial t-1 price change. Once reaching 2020, the t-4 supply price response is also added providing a larger shift. Following this effect the inclusion of each $\mathrm{t}-1$ influence as well as each lagged influence of $\mathrm{t}-1$ price change must be added to the $\mathrm{t}-4$ supply price influence in concert with each of its lagged price effects moving forward. Once the combination of $\mathrm{t}-1, \mathrm{t}-4$ and lagged effects are all actively impacting production, the changes converge on the long-run supply elasticity of 0.354 as detailed for China in Table 2.6. 


\subsubsection{Own price demand elasticities comparison}

The estimated own price demand elasticities in this study were generally more inelastic than previous estimates as observed in Table 2.5 below. There are numerous causes for elasticity differences between studies including time period of analysis, data sources, estimation methods, definitional differences of demand (i.e. food disappearance, industrial disappearance, combined disappearance, etc.) among others. One of the most obvious differences was the time period of analysis. The Bushnell and King (1986) study used data between 1960 and 1980, while the Alston et al. (1995) study included observations as early as 1961 and as late as 1989 depending on the country. The present study included observations as early as 1980 to as late as 2015 also depending on the country estimated. As the difference of the timeframes of estimation across studies spanned decades it is possible that consumer tastes and preferences have changed allowing elasticities to become either more or less elastic in different periods.

Another important difference from this study to Bushnell and King (1986) was that they estimated demand as only being demand for almonds as a manufacturing input and excluded disappearance attributed to sale as snacks. In part they attributed this to their country selection where they explained that European countries during that time used almonds more as an ingredient than a snack product. It was also pointed out that as a manufacturing input there may be reasonable substitutes such as filberts that would not necessarily be the case when consumed as a snack food (Bushnell and King 1986). In the context where suitable substitutes exist it would increase the potential for more elastic demand. 
In the Alston et al. (1995) study the elasticities were a computation of total own price demand elasticity for each country and then these authors used that number and calculated an elasticity of residual demand for California almonds. In this context the demand price elasticities given in Table 2.5 are similar to the country level own price demand elasticities estimated in the present study, whereas the calculated elasticities of demand for California almonds were subsequently more relevant as a comparison to the export demand elasticities in Table 2.7. Beyond the difference in the dependent variable, the largest notable difference to the present study was the time period of analysis.

\section{Table 2.5: Almonds cross study comparison of demand elasticities}

\begin{tabular}{lccc}
\hline & This Study & Alston et al. (1995) & Bushnell and King (1986) \\
\hline Australia & -0.19 & -0.68 & - \\
Austria & - & -0.77 & - \\
Belgium & - & -0.38 & -0.39 \\
Canada & -0.27 & -0.93 & - \\
China & -0.01 & - & - \\
Denmark & - & -0.24 & - \\
European Union & -0.14 & - & -0.83 \\
France & - & -0.41 & -1.24 \\
Germany & - & -0.19 & -0.47 \\
W. Germany & - & - & - \\
Great Britian & - & -0.52 & - \\
Hong Kong & -0.15 & - & \\
Iran & -0.15 & - & -0.58 \\
Italy (imports) & - & -0.18 & - \\
Japan & -0.12 & -0.43 & - \\
Netherlands & - & -0.62 & -1.04 \\
Norway & - & -0.36 & - \\
N.W. Europe & - & - & - \\
Sweden & - & -0.57 & - \\
Switzerland & - & -0.39 & - \\
Turkey & -0.10 & - & \\
Rest of World & -0.09 & -0.85 & - \\
\hline
\end{tabular}




\subsubsection{Excess demand elasticities over time and on average}

The price transmission, supply and demand price elasticities provide the parameters needed to calculate the excess demand elasticity for US almonds using equation (9a). The domestic production and disappearance data in countries outside the US is divided by US exports as a part of the excess demand elasticity calculation. The top portion of Table 2.6 captures the necessary elements including price transmission elasticities, demand price elasticities and supply price elasticities with consideration given to lagged dependent variables as defined below.

The final rows of Table 2.6 provide average intra-year, short-run, intermediate and long-run excess demand elasticities for different time periods. The mean excess demand elasticities are the average of the annual elasticities for each of the years in the selected time period. The calculation of excess demand elasticities incorporated constant price elasticities coupled with changing export ratios $\left(\frac{Q_{\text {dit }}}{Q_{e f t}}\right.$ and $\left.\frac{Q_{s i t}}{Q_{e f t}}\right)$ from Equation (9a) across years. This resulted in changing values for the excess demand elasticity each year based on the constant elasticities multiplied by the changing domestic supply and demand to US export ratios. The means represent a simple average across selected periods to provide illustrative examples of changes across time. 
Table 2.6: Almond export demand calculations

\begin{tabular}{|c|c|c|c|c|c|c|c|}
\hline & & $\begin{array}{l}\text { Short-run } \\
\text { Price } \\
\text { Transmission } \\
\text { Elasticity }\end{array}$ & $\begin{array}{l}\text { Long-run } \\
\text { Price } \\
\text { Transmission } \\
\text { Elasticity }\end{array}$ & $\begin{array}{c}\text { Demand price } \\
\text { Elasticity }\end{array}$ & $\begin{array}{c}\text { Supply Price } \\
\text { Elasticity } \\
\text { t-1 }\end{array}$ & $\begin{array}{c}\text { Supply Price } \\
\text { Elasticity } \\
\text { t-k* }\end{array}$ & $\begin{array}{c}\text { Long-run } \\
\text { Supply } \\
\text { Elasticity }\end{array}$ \\
\hline Canada & & 0.403 & 0.948 & -0.268 & - & - & - \\
\hline China & & 0.446 & 0.609 & -0.009 & 0.070 & 0.115 & 0.599 \\
\hline European Union & & 0.593 & 0.995 & -0.143 & 0.145 & 0.156 & 0.852 \\
\hline Japan & & 0.583 & 1.130 & -0.120 & - & - & - \\
\hline Turkey & & 0.267 & 1.205 & -0.099 & 0.052 & 0.029 & 1.106 \\
\hline Rest of World & & 0.352 & 0.751 & -0.088 & 0.259 & 0.151 & 0.663 \\
\hline & Intra-year & Short run & \multicolumn{4}{|c|}{ Intermediate } & Long run \\
\hline US excess demand elasticity & $\mathrm{t}$ & $\mathrm{t}-1$ & $\mathrm{t}-2$ & $\mathrm{t}-3$ & $\mathrm{t}-4$ & $\mathrm{t}-5$ & $\mathrm{t}-6$ \\
\hline
\end{tabular}


The intra-year US excess demand elasticities does not include any effects of supply elasticities as supply price elasticities were modeled only using lagged prices to affect production in time $t$. These lagged prices began in $\mathrm{t}-1$ and included a separate $\mathrm{t}-\mathrm{k}$ price with the longest $\mathrm{t}-\mathrm{k}$ influence in the EU where $\mathrm{k}$ was 5 . As mentioned previous annual studies such as Devadoss and Meyers (1990) and Reimer, Zheng and Gehlhar (2012) results included the t-1 supply influence in their "short-run" reporting. Given this definition and for illustrative comparison purposes the short-run excess demand elasticity using equation (9b) using the $\mathrm{t}-1$ supply price effect is used in Table 2.7 for comparison to other studies.

Note that parameter estimates were based on underlying data source time period availability. For example when a price series was only available from 1991 through 2013, the estimated elasticity from the regression was assumed as constant and held fixed in the excess demand calculations even prior to 1991. In this manner elasticities such as price transmission and other elasticities corresponding to the regression period are implicitly assumed to be representative of the larger historic period. This is done in order to make comparisons over time such as in Figure 2.2 below. This method has been used in other studies such as Devadoss and Meyers (1990) and more recently in Reimer, Zheng and Gehlhar (2012) in order to illustrate how even when assuming constant elasticities the share of US exports across net importers and net exporters shifts excess demand elasticity making it dynamic from year-to-year. 


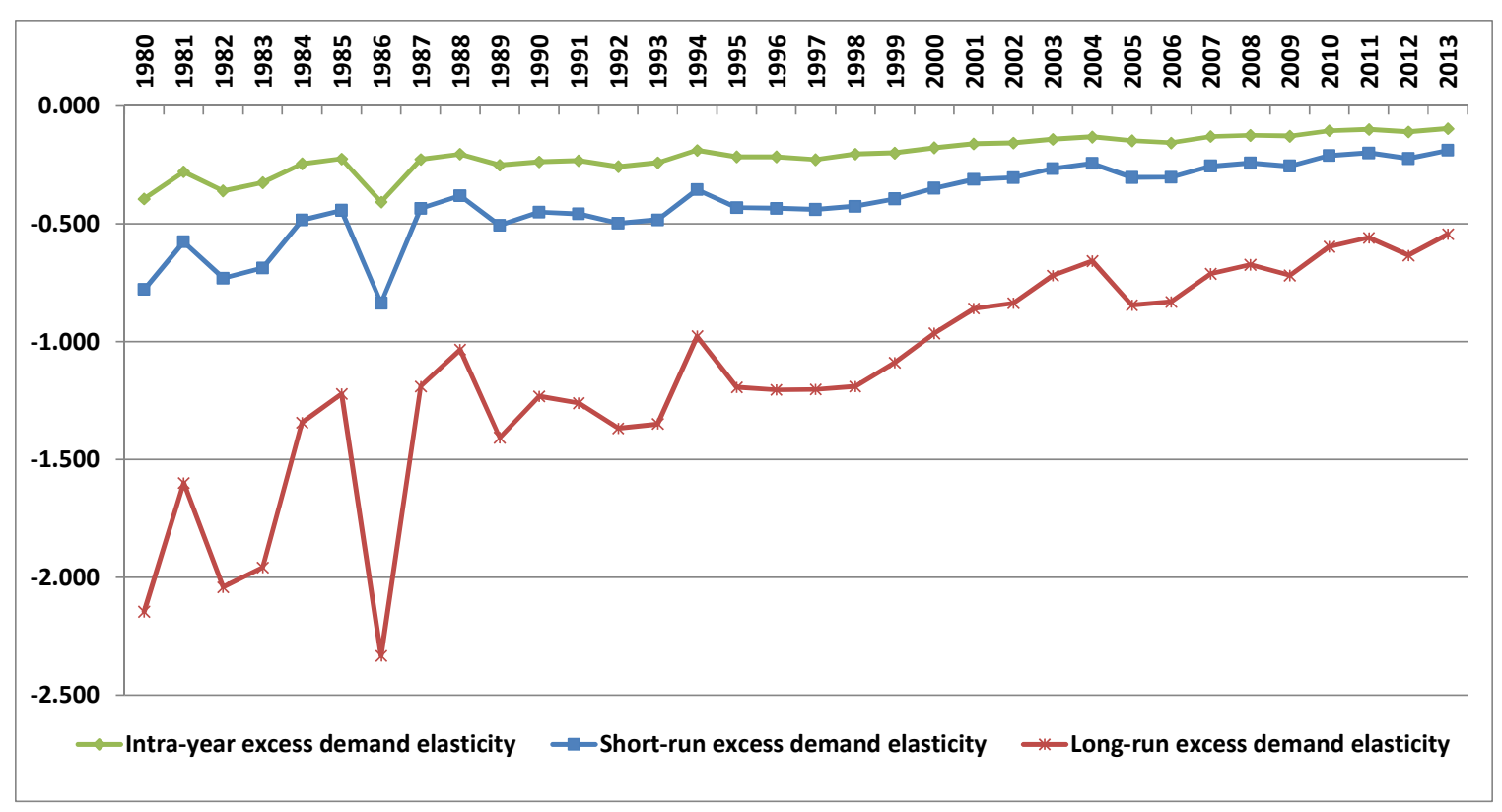

Figure 2.2: Time path of US almond excess demand elasticity 1980-2013

For 1980-2013 the mean intra-year excess demand elasticity for US almonds is -

0.206 . This means that a $1 \%$ increase in the US grower price translates into a $0.206 \%$ fall in foreign excess demand, holding all else equal. The mean short-run excess demand elasticity for US almonds is -0.408 and in the long-run it is -1.132 .

When comparing the longer time period to the more recent time frame of 20032013 the US excess demand elasticity for almonds became smaller, or less negative, where the inra-year mean shifted to -0.124 and the short-run mean shifted to -0.244 and the long-run to -0.681 . This indicates that US almond excess demand had become less sensitive to price than it was historically. It is important to note that the shift to a more inelastic excess demand may be attributed to the computation technique used and the changing supply and demand changes for the countries' share of US exports across the time period. In this study since constant price transmission, supply and demand elasticities were used, the largest factor impacting change from year to year was the 
dynamic of each country's production and demand ratio to US exports. As production and consequently exports from the US grew dramatically between 1980 and 2013, the influence of many other countries' share of world totals declined. For example, in 1980 US accounted for about $26 \%$ of world production, but by 2013 it accounted for $56 \%$. The key is that foreign countries' supplies have become small relative to foreign consumption leaving foreign supply response muted when calculating US excess demand elasticity.

\subsubsection{Comparison with previous studies}

There is a challenge when comparing the results from this study with previous work, as no other study has specifically examined perennial crops using the framework proposed. There were a few studies that examined almond export demand, although not all of them reported export demand elasticity ${ }^{1}$. This left the two studies as seen below in Table 2.7 that provided almond export demand elasticities for comparison (Alston et al. 1995; Onunkwo and Epperson 2001).

In an attempt to compensate for the lack of breadth of almond excess demand elasticity comparisons, other export demand elasticities for annual crops were included. Annual crop estimates came from studies that used either single equation export demand estimates or used the annual crop excess demand frameworks that were a precursor to the one proposed in this paper.

\footnotetext{
${ }^{1}$ For example, Crespi and Chacon-Cascante (2004) estimated world almond export demand, but only reported the parameter coefficient without any elasticity or data to calculate it from the mean. Attempts were made to recreate the data series from contemporary sources to estimate an associated elasticity using the provided coefficient for the real price of almonds, but the collected data series were truncated 15 years. The results from this exercise were peculiar and not useful for comparison.
} 


\section{Table 2.7: Cross commodity comparison of export demand elasticities}

\begin{tabular}{lccc}
\hline & Period & Short-run Elasticity & Long-run Elasticity \\
\hline Almonds & & & \\
this study & $2003-2013$ & $-0.24^{* * *}$ & -0.68 \\
Alston et al. (1995) & $1961-1989$ & -0.43 to $-1.12^{*}$ & - \\
Onunkwo and Epperson (2001) & $1986-1996$ & $-2.71 ;-0.85^{* *}$ & - \\
Corn & & & \\
Bredahl, Meyers and Collins (1979) & $1972 / 73-1975 / 76$ & - & -1.31 \\
Chambers and Just (1981) & $1969-1977$ & -0.47 & -0.63 \\
Reimer, Zheng and Gehlhar (2012) & $2001-2011$ & -1.11 & -1.64 \\
Soybeans & & & - \\
Bredahl, Meyers and Collins (1979) & $1972 / 73-1975 / 76$ & - & -0.47 \\
Chambers and Just (1981) & $1969-1977$ & -0.20 & -0.29 \\
Miller and Paarlberg (2001) & $1964-1999$ & - & -1.27 \\
Reimer, Zheng and Gehlhar (2012) & $2001-2011$ & -0.90 & -1.45 \\
Wheat & & & -1.67 \\
Bredahl, Meyers and Collins (1979) & $1972 / 73-1975 / 76$ & - & "near - \\
Johnson et al. (1985) & 1985 & -0.16 & - \\
Devadoss and Myers (1990) & $1982 / 83-1987 / 88$ & -0.48 & -1.45 \\
Miller and Paarlberg (2001) & $1985-1999$ & -1.65 & -1.25 \\
Reimer, Zheng and Gehlhar (2012) & $2001-2011$ & -0.45 & \\
\hline *Range of individual countries; elasticity of demand for California almonds; **US almond export demand for Asia and EU; ***short- \\
run includes t-1 supply price influence; select annual crop comparison examples were derived from Reimer et al (2012) and validated \\
in the original source.
\end{tabular}

Looking specifically at Onunkwo and Epperson (2001), they did not estimate excess demand elasticities, but instead a single equation export demand elasticity specification for US almonds was used with two regions' estimated using dummy variables for regions. Their elasticity for Asia at -2.71 was much more elastic than their estimate for the EU at -0.85 . Attributed largely to the objective of the study, the export demand specification included several additional explanatory variables such as other tree nuts, the associated tree nut promotional expenditures and dummy variables to segregate the regions. It is possible that the inclusion of other tree nuts as potential substitutes for almond exports led to more elastic estimates than in this study. It is also likely that as mentioned previously that the continued growth in the US share of global exports has 
caused US excess demand response to be more inelastic since 1996, the last year of Onunkwo and Epperson's (2001) estimation period.

When comparing the list of excess demand elasticities reported in Table 2.7, the almond estimates from this study fall within the range of annual crops from other studies, but remains near the inelastic side of reported results. The short-run excess demand response was fairly inelastic at -0.24 , but still more elastic than the smallest of the listed short-run elasticities. The lowest short-run demand elasticity estimate was for wheat at 0.16 by Johnson et al. (1985). The largest, or most elastic, short-run excess demand elasticity was -1.65 also for wheat by Miller and Paarlberg (2001). For the long-run demand elasticity the result from this study was -0.68 . As expected, long-run export demand estimates are larger than short-run elasticities. In all comparison studies included in Table 2.7 above this assumption held true. Similar to the short-run excess demand elasticity comparison this study's long-run excess demand elasticity fell on the inelastic side of the range compared to the annual crop studies. The lowest long-run export demand elasticity was found for soybean at -0.29 from the Chambers and Just (1981) study, whereas the largest elasticity, or most elastic estimate, was at -1.67 for wheat from the Bredahl, Meyers and Collins (1979) study.

As mentioned in the own price export demand elasticity comparison section above, there are numerous reasons that estimates across studies will yield different results. First, the framework used for this study is unique in that it extends the conceptual model to explicitly capture idiosyncrasies of perennial crops beyond that used previously. For example even though other studies such as Reimer, Zheng and Gehlhar (2012) and Bredahl, Meyers and Collins (1979) both used a similar conceptual model, neither 
included price influences, excluding those implicit from any lagged dependent variables, beyond $\mathrm{t}$ and $\mathrm{t}-1$.

Second, the price transmission specification, although not unique was only used by one other study listed (Reimer, Zheng and Gehlhar 2012). For example, in Bredahl, Meyers and Collins (1979) the price transmission was not econometrically estimated, but instead used an implied price transmission of either 0 or 1 depending on assumptions of trade policies by commodity and by country for the time period.

Third, the idiosyncrasies of the underlying commodity market are unique across time and across commodity. No study compared was found to use the same level of aggregation or individual country coverage. For example, typically the most important countries specific to each commodity are chosen by factors such as which are the top producers or top traders with some level of aggregation for the rest of the world. As ecological factors vary across regions, commodities grown in those regions will be more closely based on comparative advantage and subsequent profitability making country selection for each commodity idiosyncratic.

A final point as mentioned previously is the time period of estimation. For the time period in this study the US increased its share of global almond production and exports. Even if we could assume things were equal across the commodities such as country selection, estimation time frame and domestic elasticities, the US excess demand elasticities for commodities such as corn, soybeans and wheat could not be assumed to be the same and may be likely have become more elastic, as found by Reimer, Zheng and Gehlhar (2012). One reason is that, contrary to the experience with almonds, the underlying US shares of global production and exports for these commodities have declined. 


\subsection{Forward looking analysis}

To take the analysis of this framework a step further, a global structural model of the almond market was developed incorporating the parameters estimated in this study and US parameter estimates as detailed in the Appendix (see table A.2.1). Using this forward looking model, a baseline projection was developed incorporating exogenous variables from the USDA's International Macroeconomic Data Set (USDA-ERS 2015).

The purpose of this forward looking analysis was to compare and validate the computational method for estimating foreign excess demand elasticity for a perennial crop specifically US almonds from equation (9a) versus simulated price effects on US exports. Understanding that these two methods are not equivalent; the comparison to a simulated price shock was used as an analytical tool to determine if the direction and magnitude of change would be similar to that estimated from the computational method as proposed in this study.

To produce simulated results for evaluation, the structural model was shocked by increasing the US prices by $1 \%$ relative to baseline levels in each year for 7 years from 2016-2022. Changes in US exports from the baseline were used to provide an indication of model dynamics, identifying not just shorter- and longer-run responses, but the time path as well.

The computation method provided similar results to those presented at the bottom of Table 2.6 that used equation (9a) and considered the applicable price transmission, demand and supply elasticities including any lagged dependent influences on these elasticities given the modeled foreign countries' supply and demand to US export ratios in the forward looking years. The forward computation results differ from those in Table 
2.6 as the baseline projection for foreign supply and demand and US exports were used for the export ratio portions of equation (9a).

The results of the price shock generally followed a priori expectations. Looking at Figure 2.3 below it can be seen that the $1 \%$ upward change to annual price led to both increased world production and decreased US export demand with the direction of both as expected. The modeled impact in time t of the exogenous $1 \%$ increased price shock to US exports was $-0.108 \%$. As expected the forward looking price effect in time $t$ using the empiric specification for production from equation (11) would not have a supply side price influence. This means there would only be demand side effects in a time t price shock. Using equation (9a) the computation in a forward looking application for time $\mathrm{t}$ without any supply response also resulted in a $-0.108 \%$ excess demand elasticity estimate matching the simulated shock response.

Looking beyond time $t$, the simulated impacts on US exports in $t+1$ through $t+6$ to US exports were $-0.272 \%,-0.407 \%,-0.502 \%,-0.620 \%,-0.763 \%$ and $-0.877 \%$. The $y / y$ computed excess demand elasticities during the same timeframe were $-0.229 \%,-0.431 \%$, $-0.520 \%,-0.592 \%,-0.782 \%$ and $-0.851 \%$, respectively. The results differ slightly because the former incorporates changing values for exogenous 


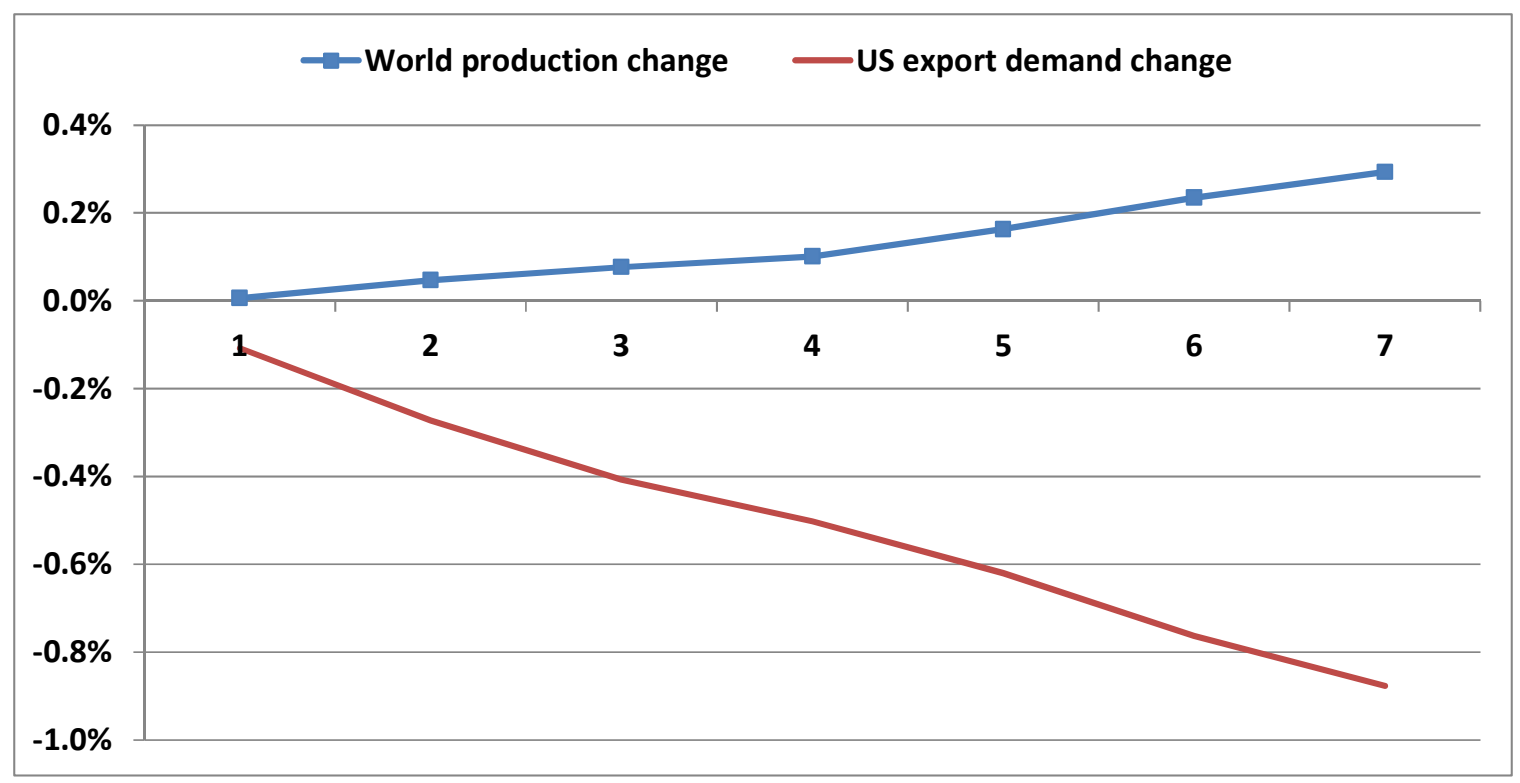

Figure 2.3: Changes from baseline with a 1\% annual upward price shock

Examining the results illustrates an important divergence in the historical trend for US excess demand elasticity. The calculated long-run elasticity was $-1.132 \%$ for 1980-2013, while it was $-0.681 \%$ for $2003-2013$. This shift was largely representative of a decreasing influence of foreign production as a ratio to US exports through the time period. In the simulated projection period the calculated mean of 2016-2030 long run excess demand elasticity was $-0.907 \%$. As can be seen in Figure 2.3, the long run impact of the exogenous price shift had an increasingly negative effect. The model incorporated constant elasticities, leaving the increasingly more elastic excess demand elasticity largely attributed to a shifting share of world production and consumption coming from foreign countries. From the first year to the fifteenth year of the baseline simulation, foreign production increased its share of world total by almost $9 \%$ while the share of foreign consumption declined $2 \%$. With this shift in the share of foreign supplies it was 
assumed to lead US excess demand elasticity to become more elastic in the forward looking simulation.

To provide an example of the impact of the shift in foreign production it is necessary to revisit the conceptual model. As the numerator in the supply ratio portion of Equation (9a) increases $\frac{Q_{\text {sit }}}{Q_{e f t}}$ holding other factors constant the consequent excess demand elasticity is increased. This modeling system incorporated constant elasticities. If supply and demand ratio effects were held constant from Equation (9a) this would result in a constant long-run excess demand elasticity once all demand and temporal supply elasticities were active. The dynamics of the structural model consequently led to a shift away from the historical trend of more inelastic US excess demand elasticity due to the change in production and consumption ratios to US exports.

Drilling down on projected changes in foreign supply and demand ratios to US exports it was observed that each shifted similarly in both the baseline and the simulated exogenous price shock scenario. On the supply side the primary driver was increasing production in Australia. On the demand side, changes in the foreign demand to US exports ratios were more muted than the supply ratio changes, but all foreign countries' ratios increased by 2022 also affecting the change in the excess demand elasticity calculation. The consequent combination of these changes to foreign supply and demand ratios to US exports led to a shift in the trend in US excess demand response to become more elastic through the projection period instead of more inelastic as was the historic trend. 
Examining the results of the exogenous price shock a bit differently, the year on year (y/y) differences of the changes to the baseline is shown below, as in Figure 2.4.

This is used to illustrate the idiosyncrasies from the perennial specification in the model.

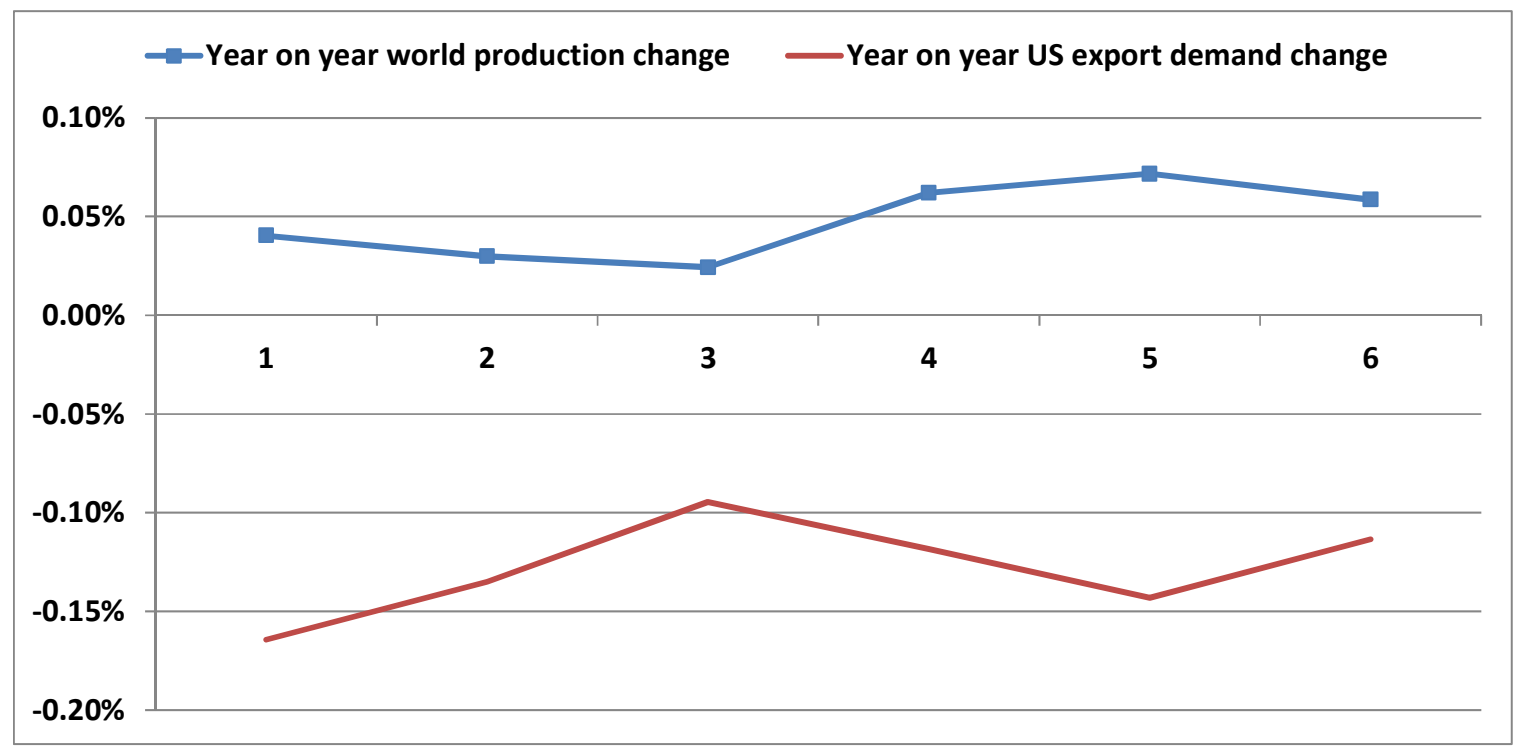

Figure 2.4: Year on year world production and US export demand changes in the $1 \%$ annual upward price shock scenario

As expected in $t+1$ (period 1 in Figure 2.4) there is a shift in both supply and export demand from the baseline. When looking at Figure 2.3 it can be observed that the magnitude of the production change continued to grow throughout the projection period from an increase to prices. When examining the $\mathrm{y} / \mathrm{y}$ changes though, production changes grew but at a decreasing rate until $\mathrm{t}+4$ (period 4 in Figure 2.4), when the longer lagged prices (t-k) influenced the model and bumped the magnitude of change again. The latest lagged supply price influence in any given country was in $t+5$ for the EU. Following this lagged price influence from the EU (period 5 in Figure 2.4) the supply side continued to grow, but again at a decreasing rate as expected. 
The usefulness of the forward looking analysis was two-fold. First, it provided another method of analysis to calculate excess demand elasticity for a perennial commodity. Second, the scenario provided an example of how the modeled perennial supply specification differs from an annual crop supply specification that contains only one lagged price influence. The proposed approach incorporating an additional lagged price allows for more complex dynamics as expected from a perennial crop. Using this approach can result in the type of pattern seen in Figure 2.4, which would not be possible when only using a single-lagged price and a lagged dependent variable.

\subsection{Conclusion}

There were two primary objectives of this study. The first objective was to develop a framework building on previous literature to capture the idiosyncrasies specific to perennial crops in estimating excess demand elasticities. The second objective was to estimate US excess demand elasticity for almonds.

The first objective was accomplished by incorporating temporal specificities into the supply side of the excess demand conceptual model. This allowed supply prices from more than one period to be included in the excess demand elasticity calculation.

Following this conceptual model extension this study estimated supply, demand and price transmission relationships using contemporary data. With the inclusion of these elasticities historical excess demand elasticities were calculated using equation (9a). For the 2003-2013 timeframe, the short-run excess demand elasticity for US almonds averaged -0.244 and -0.681 in the long run. Excess demand elasticity for almonds was found to be more inelastic in 2003-2013 compared to previous timeframes. 
It was difficult to compare these results to previous studies, because of differences in approach, data period and assumptions. Two previous studies estimated almond export demand elasticities that were more elastic than the results found here. When including annual crop studies past estimates of export demand elasticities faced by the US for corn, wheat and soybean industries found elasticities both larger and smaller than those estimated in this study for almonds but near the inelastic end of the range. As the results fell near the inelastic end of the range it suggests that there are specificities that make the almond export market more inelastic than the markets for most annual crops.

This study used constant price transmission, supply and demand elasticities, which left other countries' share or ratio of production and consumption to US exports as the primary annual shifter of export elasticities from year to year. The significant growth in US production and exports across the historic time period made US almond export elasticities more inelastic over time (Table 2.6). In this sense previous estimates of almond export elasticity based on earlier data would be expected to be more elastic other things being equal. This implies that export demand elasticities might increase over time for commodities where US exports are declining as a share of global supply and demand.

To better understand the dynamics of perennial crops and excess demand elasticity further research needs to be undertaken not only for other tree crops, but also other perennial crops to provide more explicit cross commodity comparisons. Once excess demand elasticities are estimated for other perennial crops they could be used, similar to what motivated the initial researchers in this area, for ex ante policy and market analysis of those crops. Also, and possibly more important the approach may be used to evaluate both shorter- or longer-run shifts in supply or demand in any major country that might affect prices. This methodological extension even has the potential to extend 
beyond just additional perennial crops. For example, it is possible that this framework may be generalized to examine select livestock commodities characterized by herd dynamics where multiple price lags are critical to production decisions.

This research both extends the excess demand elasticity framework to capture idiosyncrasies of perennial crops and it examines the economically important commodity to the US of almonds. The proposed framework is useful in that it allows the examination of how trade responds to a price change, which can be necessary in determining how prices change when a natural event such as a drought limits crops supplies, or when trade policy expands or limits trade especially in a major producer or consumer. The estimates also provide a useful reference for other researchers that may undertake the daunting task of parameterizing large simulations models that include multi-national implications and idiosyncrasies of perennial crops or similar commodities.

\subsection{References}

Abbott, P. C. (1979). Modeling International Grain Trade with Government Controlled Markets. American Journal of Agricultural Economics, 61, 22-31.

Akaike, H. (1974). A New Look at the Statistical Model Identification. IEEE transactions on automatic control, 19(6), 716-723.

Akiyama, T., \& Trivedi, P. K. (1987). Vintage Production Approach to Perennial Crop Supply. Journal of Econometrics, 36, 133-161.

Alston, J. M., Carman, H. F., Christian, J. E., Dorfman, J., Murua, J.-R., \& Sexton, R. J. (1995, February). Optimal Reserve and Export Policies for the California Almond Industry: Theory, Econometrics and Simulations. Giannini Foundation Monograph, 42, 1-130.

Bateman, M. J. (1965). Aggregate Regional Supply Functions for Ghanian Cocoa 194662. Journal of Farm Economics, 50, 384-401.

Bredahl, M. E., Meyers, W. H., \& Collins, K. J. (1979). The Elasticity of Foreign Demand for U.S. Agricultural Products: The Importance of the Price 
Transmission Elasticity. American Journal of Agricultural Economics, 61(1), 5863.

Breusch, T. S. (1978). Testing for Autocorrelation in Dynamic Linear Models. Australian Economic Papers, 17(31), 334-355.

Bushnell, P. G., \& King, G. A. (1986). The Domestic and Export Markets for California Almonds. University of California, Agricultural and Resource Economics. Giannini Foundation.

Chambers, R. G., \& Just, R. E. (1981). Effects of Exchange Rate Changes on US Agriculture: A Dynamic Analysis. American Journal of Agricultural Economics, 63(1), 32-46.

Crespi, J. M., \& Chacon-Casante, A. (2004). Do US Marketing Orders Have Much Market Power? An Examination of the California Almond Board. Agribusiness, 1, $1-15$.

Devadoss, S., \& Luckstead, J. (2010). An Analysis of Apple Supply Response. International Journal of Production Economics, 124, 265-271.

Devadoss, S., \& Meyers, W. H. (1990). Variability in Wheat Export Demand Elasticity: Policy Implications. Agricultural Economics, 4, 381-394.

Diffenbaugh, N. S., Hertel, T. W., Sherer, M., \& Verma, M. (2012, July). Response of Corn Markets to Climate Volatility Under Alternative Energy Futures. Nature Climate Change, 2, 514-518.

Enders, W., \& Siklos, P. L. (2001). Cointegration and Threshold Adjustment. Economic Statistics, 19(2), 166-176.

Engle, R. F., \& Granger, C. W. (1987). Cointegration and Error Correction; Representation, Estimation and Testing. Econometrica, 55(1), 251-276.

FAPRI. (2004). Documentation of the FAPRI Modeling System. University of Missouri. Columbia, Missouri: FAPRI-UMC.

French, B. C., \& Matthews, J. L. (1971). A Supply Response Model for Perennial Crops. American Journal of Agricultural Economics, 53, 478-490.

French, B. C., King, G. A., \& Minami, D. D. (1985). Plantings and Removals Relationships for Perennial Crops: An Application of Cling Peaches. American Journal of Agricultural Economics, 67, 215-223.

Godfrey, L. G. (1978). Testing Against General Autoregressive and Moving Average Error Models when the Regressors Include Lagged Dependent Variables. Econometrica: Journal of the Econometric Society, 1293-1301. 
Greene, W. H. (2008). Econometric Analysis (Sixth ed.). Upper Saddle River, New Jersey: Pearson.

Hartley, M. J., Nerlove, M. \& Peters, K. (1987). An Analysis of Rubber Supply in Sri Lanka. American Journal of Agricultural Economics, 69, 755-761.

Johnson, P. R. (1977). The Elasticity of Foreign Demand for U.S. Agricultural Products. American Journal of Agricultural Economics, 59(4), 735-736.

Johnson, S. R., Womack, A. W., Meyers, W. H., Young, R. E., \& Brandt, J. (1985). Options for the 1985 Farm Bill: An Analysis and Evaluation. Food and Agricultural Policy Research Insititue. Columbia: University of Missouri.

Kalaitzandonoakes, N., \& Shonkwiler, J. S. (1992). A State-space Approach to Perennial Crop Supply Analysis. American Journal of Agricultural Economics, 74, 343352.

Kleinbaum, D. G., Kupper, L. L., Nizam, A., \& Muller, K. E. (2008). Applied Regression Analysis and Other Multivariable Methods (Fourth ed.). Belmont, CA, USA: Brooks/Cole, Cengage Learning.

Laajimi, A., Guesmi, A., Mahfoudhi, A., \& Dehibi, B. (2008). Analyzing Supply Response of Fruit Tree Products in Tunisia: The case of peaches. Agricultural Economics Review, 9(1), 24-33.

MacKinnon, J. G. (1991). Critical Values for Cointegration Tests, Chapter 13. In R. F. Engle, \& C. J. Granger (Eds.), Long-run Economic Relationships: Readings in Cointegration. W.J. Oxford University Press.

Miller, D. J., \& Paarlberg, P. L. (2001). An Alternative Approach to Determining the Elasticity of Excess Demand Facing the United States. American Agricultural Economics Association.

Mittal, S., \& Reimer, J. J. (2008). Would Indian Farmers Benefit from Liberalization of World Cotton and Sugar Markets? Agricultural Economics, 38, 301-312.

Onunkwo, I. M., \& Epperson, J. E. (2001, March). Export Demand for U.S. Almonds: Impacts of U.S. Export Promotion Programs. Journal of Food Distribution Research, 140-151.

Reimer, J. J., Zheng, X., \& Gehlhar, M. J. (2012, November). Export Demand Elasticity Estimation for Major U.S. Crops. Journal of Agricultural and Applied Economics, 44(4), 501-515.

Slette, J. (2016). India Tree Nuts Annual 2016. USDA Gain Report. United States Department of Agriculture Foreign Agriculture Service. 
Tweeten, L. (1967). The Demand for United States Farm Output. Food Research Institute Studies, 7(3), 343-369.

Tweeten, L. (1977). The Elasticity of Foreign Demand for U.S. Agricultural Products: Comment. American Journal of Agricultural Economics, 59(4), 737-738.

U.S. Department of Agriculture. (2015). Economic Research Service (ERS). Retrieved February 22, 2016, from International Macroeconomic Data Set: http://www.ers.usda.gov/data-products/international-macroeconomic-data-set/

U.S. Department of Agriculture. (2015). National Agricultural Statistics Service (NASS). Retrieved 2016, from Quick_Stats: https://www.nass.usda.gov/Quick_Stats/

U.S. Department of Agriculture. (2016). Foreign Agricultural Service (FAS). Retrieved 2016, from PS\&D: https://apps.fas.usda.gov/psdonline/

Wickens, M. R., \& Greenfield, J. N. (1973). The economics of agricultural supply: an application to the world coffee market. Review of Economics and Statistics, 55, 433-440.

Wright, B. D. (2011). The Economics of Grain Price Volatility. Applied Economic Perspectives and Policy, 33(1), 32-58. 


\subsection{Appendix}

\section{Table A.2.1: US parameter estimates}

\begin{tabular}{|c|c|c|c|}
\hline Equation & Variable name & Coefficient estimate & Elasticity at mean \\
\hline \multirow[t]{5}{*}{ Planting } & Intercept & $24431^{* *}$ & \\
\hline & Lagged plantings in t-1 & $0.567 * *$ & 0.580 \\
\hline & Deflated expected net returns & $816^{* *}$ & 0.249 \\
\hline & Deflated lagged walnut grower price & $-2093009^{*}$ & -0.709 \\
\hline & Palmer's drought severity index & $1936^{* *}$ & -0.047 \\
\hline \multirow[t]{4}{*}{ Removals } & Intercept & $23201^{*}$ & \\
\hline & Deflated expected net returns & $-250^{* *}$ & -0.208 \\
\hline & Lagged bearing area in $\mathrm{t}-20$ & -0.008 & -0.186 \\
\hline & Palmer's drought severity index & $-913 * *$ & 0.070 \\
\hline \multirow[t]{5}{*}{ Yield } & Intercept & $1267 * *$ & \\
\hline & Trend & $61 * *$ & 0.726 \\
\hline & Yield t-1 & $-0.55^{*}$ & -0.540 \\
\hline & Yield $\mathrm{t}-1$ minus Yield $\mathrm{t}-2$ & 0.18 & 0.005 \\
\hline & Palmer's drought severity index & $-50^{*}$ & 0.015 \\
\hline \multirow[t]{5}{*}{ Consumption per capita } & Intercept & 0.16 & \\
\hline & Deflated US almonds grower price & $-6.7^{* *}$ & -0.291 \\
\hline & Deflated US walnuts grower price & 2.4 & 0.048 \\
\hline & real GDP per capita & $0.0000077^{* *}$ & 0.682 \\
\hline & Shift trend beginning 2004 & $0.051^{* *}$ & 0.215 \\
\hline \multirow[t]{5}{*}{ Ending stocks } & Intercept & $29799^{*}$ & \\
\hline & Deflated US almonds grower price & -672908 & -0.155 \\
\hline & US almond production & $0.27^{* *}$ & 1.277 \\
\hline & US almond production $\mathrm{t}+1$ & $-0.18 * *$ & -0.881 \\
\hline & US almond ending stocks t-1 & $0.43 * *$ & 0.417 \\
\hline \multirow[t]{2}{*}{ 1st stage expected net returns } & Intercept & 1.2 & \\
\hline & Deflated US almond net returns $\mathrm{t}-1$ & $0.92 * *$ & 0.868 \\
\hline \multirow[t]{3}{*}{ 2nd stage expected net returns } & Intercept & 2.4 & \\
\hline & Deflated US almond net returns t-1 & $0.76^{* *}$ & 0.724 \\
\hline & Difference of 1st stage and actual net returns $t-1$ & $-0.66^{* *}$ & -0.028 \\
\hline
\end{tabular}

*: Statistically significant at 0.05 level

**: Statistically significant at 0.01 level 
Table A.2.2: Historic period averages

\begin{tabular}{|c|c|c|c|c|c|c|}
\hline Country & Area & $\begin{array}{l}\text { Yield } \\
\end{array}$ & Production & Imports & Exports & Domestic Dis appearance \\
\hline & (hectares) & (metric tons per hectare) & & & (metric tons) & \\
\hline Australia & 9,703 & 1.52 & 16,796 & 1,635 & 3,988 & 14,443 \\
\hline Canada & - & - & - & 11,185 & 37 & 11,149 \\
\hline China & 10,339 & 1.12 & 12,100 & 1,310 & 173 & 13,237 \\
\hline European Union & 758,999 & 0.30 & 230,921 & 178,023 & 62,754 & 346,190 \\
\hline Hong Kong & - & - & - & 9,095 & 4,703 & 4,391 \\
\hline Iran & 69,218 & 0.79 & 47,027 & 27 & 1,590 & 45,464 \\
\hline Japan & - & - & - & 21,352 & 7 & 21,346 \\
\hline Turkey & 19,167 & 1.30 & 24,977 & 1,336 & 1,281 & 25,031 \\
\hline United States & 214,776 & 1.76 & 410,210 & 2,784 & 277,451 & 133,852 \\
\hline Rest of World & 445,787 & 0.38 & 175,127 & 63,731 & 9,406 & 231,601 \\
\hline
\end{tabular}




\section{DOES A THREATENED ECOSYSTEM SERVICE INFLUENCE PERENNIAL FARMER INVESTMENT DECISIONS? WATER AVAILABILITY AND ALMOND PRODUCER BEHAVIOR}

Ecosystem Service(s) (ESS) play a key role in providing necessary natural resource inputs into crop production. When ESS are threatened they influence producer investment decisions. These influences are critically important in understanding longerrun responses of perennial producers and the relationship in observed changes over time. In this paper an ecological and economic (eco-economic) approach is proposed, which includes an explicit ecological variable representing water availability into the perennial producer supply response models. In each structural model of perennial producer supply response the new eco-economic framework improved fit compared to the traditional model specifications. Forward looking scenario analysis showed that the model including a variable to represent the ESS directly in area equations is more responsive to changes from a simulated drought than when ESS is excluded from modeled producer behavior.

\subsection{Introduction}

Perennial tree crop production, including commodities such as oil palm, coconut, cocoa, coffee and tree fruits and nuts, represents an integral source of export revenue for many countries. These revenues provide for employment along the value chain and generate direct and indirect tax revenues for governments. For example, the University of California Agricultural Issues Center estimated that the value of California almond industry in 2014 was US\$21.5 billion (Sumner et al. 2014), which is greater than or equal to the GDP of more than 24 countries combined in 2014 (IHS 2017).

Adequate supplies of water and other ESS are essential to tree crop production. Droughts can threaten water availability, and the actions of producers and policy makers 
can affect both current and future supplies of this ESS. A better understanding of the decisions of perennial crop producers and their relationship to the environment can contribute to public policy.

Multiple approaches have been developed over time to model perennial producer behavior. Some models have included variables such as spring rainfall or indicators for adverse weather conditions such as frosts or freezes to capture the influence of weather on perennial supply response (Dorfman, Dorfman and Heien 1988; Alston et al. 1995; Devadoss and Luckstead 2010). However, previous approaches only capture a very narrowly defined portion of the effect of ESS on perennial crop supply. Short-term weather, such as intra-seasonal rainfall or frosts, may affect production in a given year, but a broader range of ESS may affect longer-term investment decisions.

The California drought event that began to develop in the winter of 2011/12 was a major threat to water availability as an ESS and crop production across the state. California experienced "extreme warm and dry conditions that led to acute water shortages, groundwater overdraft and critically low streamflow (Diffenbaugh, Swain and Touma 2015, p. 3931).” This drought was “accentuated by a record dry 2013 (Harter and Dahlke 2014, p. 54)" and was deemed as both an "Extreme Drought" or an "Exceptional Drought" for large portions of the state by the US Drought Monitor (Figure 3.1). During this drought event California was said to have, "experienced the most severe drought conditions in its last century"...and was, "driven by reduced though not unprecedented 
precipitation and record high temperatures (p. 9017, Griffin and Anchukaitis 2014).”

\section{U.S. Drought Monitor CONUS}

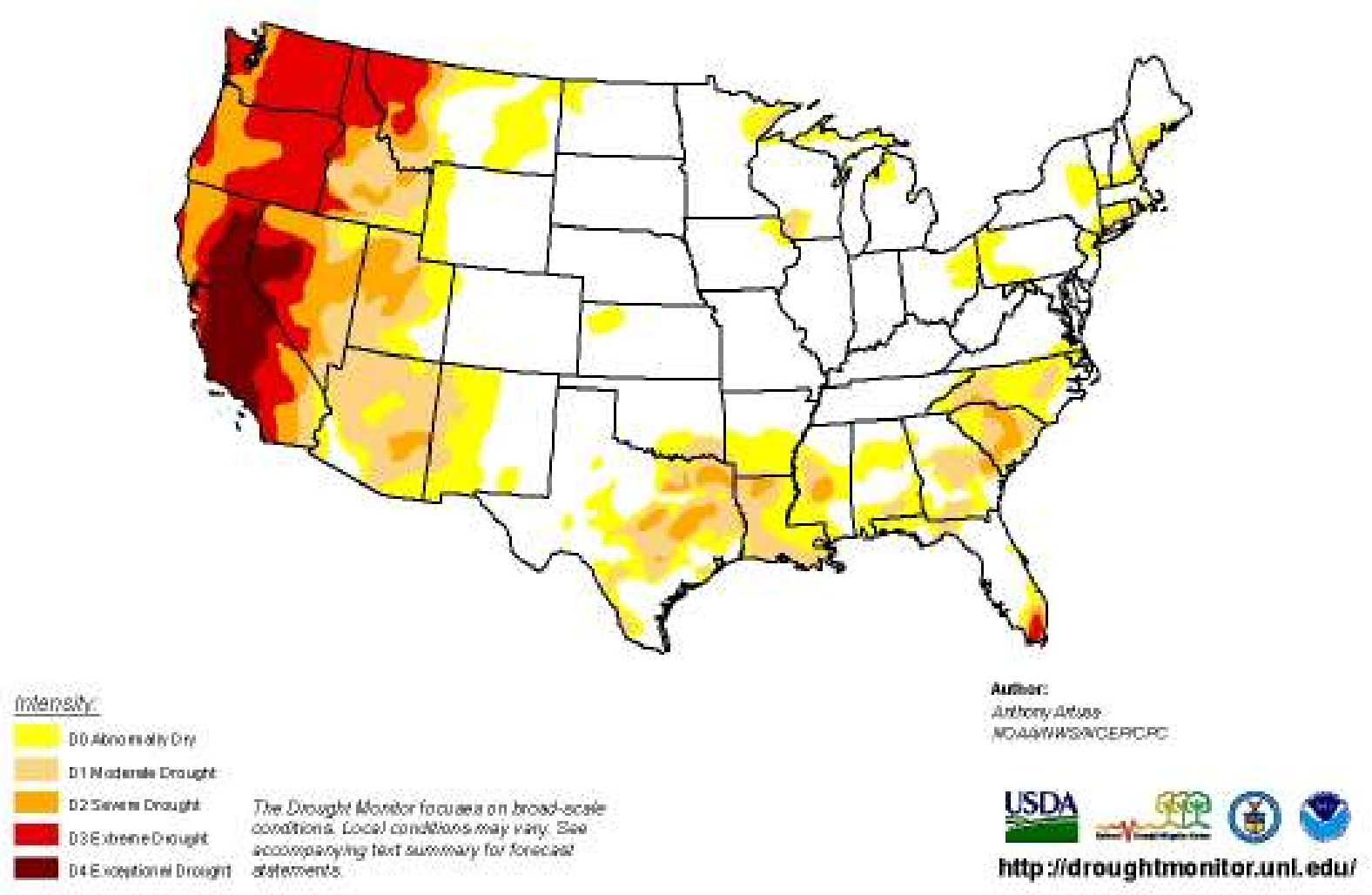

August 25, 2015

(Roloasod Thursday, Aug 27, 2015)

Valid 8 a.m. EDT

Figure 3.1: US drought monitor showing severity of the extreme drought in California near its most widespread point between December 2011 and April 2017.

Source: The National Drought Mitigation Center

While the drought in California officially ended when Governor Jerry Brown issued an executive order that lifted the drought emergency in April 2017, the concern for future droughts was not eliminated. For example, as the governor stated, "this drought emergency is over, but the next drought could be around the corner (Boxall 2017).” It has been predicted that with the changing climate there is an increasing risk of future 
droughts and drought severity in the Western United States and California (e.g. Cook, Ault and Smerdon 2015; Diffenbaugh, Swain and Touma 2015).

With the increasing risk for future drought events in California, the influence of the persistent degradation of surface and groundwater supply and quality would have dramatic implications on future production of almonds and could significantly shift the world supply with producer decisions in turn having an effect on water use. California has been the largest domestic and global provider of almonds. Since the mid-1980s, US produced almonds have accounted for $80 \%$ or more of global exports, and over the last ten years have averaged $91 \%$ of global exports (Figure 3.2).

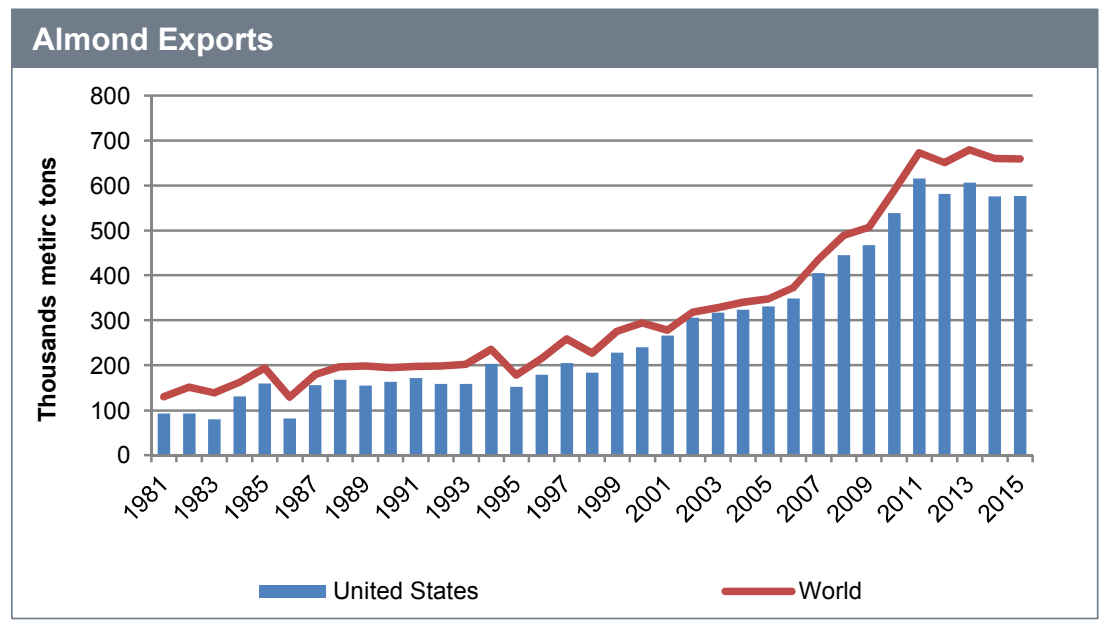

Figure 3.2: US almond exports capture greater than $80 \%$ global exports since 1980s Source: USDA-FAS

The extreme drought situation experienced through 2016 had forced producers to make critical decisions about sourcing water for irrigation purposes (Heim 2014). Producer options included drilling deeper and/or new groundwater wells (Harter and Dahlke 2014), increased pumping from publicly managed water districts where available, reduced water use for other crops, and even removing older, less productive trees to reduce water needs (Rodriguez 2014). In each of these scenarios, producers were faced 
with cost impacts or potential revenue reductions. This placed the leading global producer and exporter of almonds in a precarious position as it worked to adapt to the reduction of ESS, leaving the US market for almonds at a critical point in history. This extreme drought environment experienced by the California almond industry provided a case to test whether a threatened ESS service has an influence on perennial supply response.

Hence, this study focuses on the supply side of the market for California almonds. The first objective was to estimate the impacts that an ESS has on the observed economic decisions of almond producers. To accomplish this I estimated structural models for new plantings, removals and yields that incorporate both ecological and economic (ecoeconomic) influences. These equations therefore add to the literature in that they test an extension of the traditional perennial supply response models to explicitly include an ecological variable that represents a specific ESS. The second objective was to test and validate in a forward looking sense if this new specification would respond as expected to a reoccurence of the extreme drought event.

The next section reviews previous studies modeling perennial commodities as well as literature related to water as an ESS. The third section discusses the conceptual model and its empirical specification. The fourth section describes the data used for the study. The fifth section presents the empirical results and challenges from estimation followed by results and output from a forward looking scenario analysis. The final section provides concluding remarks. 


\subsection{Literature review}

Traditional producer investment literature since the 1950s has evolved and developed methods to empirically model and test supply response in production agriculture. These studies examined producer responses, first focusing on annual crops and then extending into perennial crops. Studies that examine producer response for perennial crops consider the distinct biological characteristics of the crops themselves. French and Matthews (1971) provide a concise list of these differences from annual crops, "1) the long gestation period between initial input and first output, 2) an extended period of output flowing from the initial production or investment decision, and 3) eventually a gradual deterioration (usually) of the productive capacity of the plants" (p. 479).

With these specific characteristics of perennial crops in mind, research has built upon approaches developed in the 1960s and early 1970s incorporating some form of the Nerlovian adjustment modeling approach (Nerlove 1956, 1958b). This approach was used to capture the differences between a desired production or acreage level and that which was actually achieved. For perennial crops this can be attributed especially to the long gestation period (Nerlove 1979).

Throughout the literature on perennial crop response authors have taken one of two generalized approaches largely dependent on available data. Many early studies use a reduced form equation that models total area and/or yield (e.g. Bateman 1965; Behrman 1968; French and Matthews 1971; Wickens and Greenfield 1973).The second approach creates separate structural equations for particular producer decisions such as new plantings, replacements, uprooting and removals (e.g. French, King and Minami 1985; 
Akiyama and Trivedi 1987; Kalaitzandonoakes and Shonkwiler 1992; Laajimi et al. 2008; Devadoss and Luckstead 2010).

The rich literature provides various model specifications to capture producer response to economic variables such as prices and input costs. As mentioned occasionally a weather variable was included, such as a frost or freeze indicator variable affecting removals or a spring rainfall variable in a yield equation. The glaring gap is that none of the studies explicitly model individual ecological factors related to ESS and how they might affect longer-term investment decisions, especially as farmers attempt to adapt to changing climatic conditions. Some model specifications include only output prices, and even those that consider input costs did not explicitly consider how a threatened ESS may affect those costs and returns. Whether a reduced form or structural models approach was used, the explicit relationships of producers of perennial crops to a threatened ESS had yet to be examined.

Water availability has an influence on both the private and social costs of this critical ESS. For example, in most parts of the world when water resources are scarce, the prices paid by users are considered to be well beneath the marginal value of water (Schoengold and Zilberman 2007). This is relevant as farmers are typically known to pay pumping and conveyance costs but not any scarcity value (Brewer, Glennon, Ker, and Libecap 2008). In this sense these farm users of surface water face the private costs, or price, of irrigation. This price of irrigation includes fixed costs such as operation and maintenance costs and sometimes variable costs based on the quantity, or volume, of water pumped from the pumping district. On farm labor and electricity used for pumping is also included in average irrigation costs, but generally initial capital costs of the water project are not included (Schoengold and Zilberman 2007). When this is the case the 
irrigation cost would not capture the cost of delivery much less the full value, or social costs, of water especially during years when surface water is limited (Schoengold and Zilberman 2007).

This difference between the private costs faced by farmers and social costs only becomes an imminent concern to producers when water as an ESS becomes threatened and quality irrigation water availability is constrained by natural or political means. This will become even more dire for Californian almond prdoucers as climate change is expected to increase drought severity with significantly drier conditions as compared with the $20^{\text {th }}$ century (Cook, Ault and Smerdon 2015).

Many Californian almond farmers also incorporate groundwater resources for irrigation water supplies. For any groundwater users where the recharge rate of the aquifer is slower than the discharge rate, the result is an open access problem where users ignore both the effects on other users and on future resource availability (Schoengold and Zilberman 2007). Therefore ground water has been described as being a common pool, or common property resource (Provencher and Burt 1993; Brewer, Glennon, Ker, and Libecap 2008). This can lead to an open access resource response where a limited groundwater resource is exploited, attributed to both a pumping cost externalitiy and a stock externality to the detriment of future use and users (Provencher and Burt 1993). Even if the cost of groundwater for irrigation includes the extraction costs such as a capital cost of drilling the pump and variable costs of pumping (electricity and labor), it does not capture the opportunity cost associated with the loss of future benefits. As a result, the private price of groundwater is typically less than the social value of water as an input (Schoengold and Zilberman 2007). Furthermore, deeper and depleted aquifers may provide reduced water quality which may ultimately lead to the elimination, or 
irreversibility, of groundwater as a resource for irrigation purposes (Gleick 1998). One example of a concern of irreversibility for coastal water basins such as several located in California is for seawater intrusion from nearby sources, which can be the result when pumping exceeds the recharge rate (Tsur and Zemel 2004).

It is important to note that the challenges facing both surface water and groundwater resources in large part are because of the weaknesses of current water allocation systems. Across time, water has been allocated using various systems. For the bulk of the Western US including California, surface water largely follows a prior appropriation system based on the principle of first in time, first in right (Grafton et al. 2011). Water rights are staged as senior and junior with the first person to divert water for beneficial use appropriating senior rights. So, "those with the earliest claims have the highest priority, and those with subsequent claims have lower priority or junior claims ( $\mathrm{p}$. 94, Brewer, Glennon, Ker, and Libecap 2008).” In times of scarcity junior water right holders are limited or rationed first with senior rights holders limited or rationed only under exceptional conditions. When water access is rationed or limited but groundwater use is not, the incentive to exploit groundwater resources increases leading to the open access concerns mentioned above. The additional use of a groundwater raises the likelihood of discharge rates exceeding the recharge rate.

During the recent extreme drought event in California restrictions were placed on both junior and select senior water rights holders across almond producing counties limiting access to surface water. These restrictions as well as depleting aquifers had led to both increased and deeper drilling of groundwater wells for farm irrigation purposes. During that time, the California state government in 2014 passed the Sustainable Groundwater Management Act, which is set to more clearly define as well as regulate 
groundwater use by 2020 and especially, "to bring water basins in a state of overdraft into balance" (SGM 2015). Both restrictions to surface water and blossoming regulations on groundwater increase uncertainty on how access and the cost of quality water for irrigation purposes may change.

In modeling producer response, understanding that current water pricing through irrigation costs is not equal to the marginal value of product of water as an input is irrelevant if farmers only ever face these private costs of water. With the combination of the increasing risk of and severity of droughts that constrained surface water availability, increased new and deeper groundwater wells and new groundwater legislation in California, there is a likelihood of a fundamental shift in the expectations of future costs and returns. The relevant question then is do perennial farmers incorporate some expectation of water cost beyond what may be captured by average irrigation cost of production included in the traditional perennial supply response model? My hypothesis is that Californian almond farmers consider the cost and availability of water beyond average irrigation costs in their investment decisions, and that the addition of an exogenous ecological variable to represent water availability as a critical ESS captures almond farmers' observed supply responses better than the traditional models (TM).

\subsection{Conceptual model}

For the proposed eco-economic framework it is assumed that perennial crop producers make investment decisions to maximize expected profits and face constant returns to scale in a competitive market. Output produced by mature trees is assumed homogenous to other farmers' output of the same commodity. Similar to French and Matthews (1971), these producers are assumed to have in mind a "normal" rate of long 
run profitability per unit of output, although the industry level of expected long run economic profit will likely remain near zero under competitive conditions. Producers, therefore, given their profit expectations, will attempt to adjust their level of investment in order to maximize long run expected profits.

For almonds, as the perennial commodity of concern in this study, the supply model must consider the biological gestation period prior to production, expectations about productive life and its output during that life cycle, and assumptions about how input prices impact producer investment decision. The gestation lag for almonds from planting to bearing productive life is approximately three to four years (Alston et al. 1995; USDA-NASS 2015). Almond trees generally reach full mature productivity between five and seven years after planting, with productivity declining once they reach 20 to 25 years (Alston et al. 1995). Given the gestation lag and assuming that adjustment costs associated with investment decisions are convex, "it follows that the scale of these activities is determined jointly by expected future profitability and past investment decisions (p. 138, Akiyama and Trivedi 1987).” This implies that the basic investment decision facing almond farmers is whether to add or remove area (French and Matthews 1971).

For this analysis a variable to represent an ESS is included as an explicit exogenous factor affecting the investment decision. Including an exogenous variable for the ESS makes it possible to test if there is evidence of an eco-economic link by extending the supply response models beyond variables included in the traditional perennial investment models.

All current and past investment decisions affect the current area under almond cultivation. This accumulation of investment decisions over time represents the current 
total bearing area, or the area that has any harvestable production in the current period, time $t$. The impact of investment decisions may then be represented by the first difference or change in this bearing area $\Delta \beta$ expressed as

(1) $\Delta \beta=\beta_{t}-\beta_{t-1}$,

where lagged bearing area $\beta_{t-1}$ is subtracted from current bearing area $\beta_{t}$. This change consequently is representative of the concert of past planting decisions and current removal, or uprooting decisions where the planting decision may be segregated further into new planting and replanting, dependent upon available data. The combination therefore may form an identity to represent each investment decision impacting the present change of total bearing, or productive, area in time $t$ (French and Matthews 1971; Alston et al. 1995). Let the identity be (2) $\beta_{t}-\beta_{t-1}=P L_{t-k}+R P_{t-k}-U R_{t}$, where $P L_{t-k}$ represents newly planted area and $R P_{t-k}$ represents replanted area in $t-k$ years in the past that becomes bearing area in the current time where $\mathrm{k}$ is based on commodity specific gestation lag, and $U R_{t}$ is any uprooted area in the current year. Breaking out the area investment decisions into separate categories captures the idiosyncrasies of each investment. There are three primary area decisions including whether to plant new trees to extend plantation area, to uproot less productive and damaged trees or to replace uprooted trees. Together, these decisions impact the current tree stock as well as expected future output. Separately, the decisions encapsulate different aspects of how area can change the total bearing area in the current time period. These area decisions alone though, do not completely capture the supply response. The final investment decision is directly related to harvest and has been called the short-term harvest decision (Akiyama and Trivedi 1987). For almonds, unlike natural rubber it is 
assumed in this examination that the decision to harvest is inevitable if there is harvestable bearing area (Hartley, Nerlove and Peters 1987; Alston et al. 1995).

The three area investment decisions are based on the idea that changes in expected profits, the difference between output prices per unit and average costs, incentivize adjustments through additions or reductions in the area of the commodity. Also important are opportunity costs for the land, such as the expected profits of producing another crop. A number of alternative approaches have been developed in the literature to provide a proxy for expected profit, but it is generally recognized that expected profits are positively related to expected output prices and negatively related to expected input prices (Colman, 1983).

A profit proxy using a backward looking expected price or returns approach is common historically across both annual and perennial supply response literature. In most supply models, "it is implicitly or explicitly assumed that the model's representation of producer expectations is correct" (p. 4, Arnade and Cooper 2013). Various schemes have been used to proxy price or profit expectations. Once a scheme is selected the parameters of the expectations model are then estimated. Examples of some common and seminal price expectations models include naïve expectations (Houck and Gallagher 1976 ; Shumway and Chang 1980), adaptive expectations models (Nerlove 1958), futures prices (Gardner 1976; Chavas, Pope and Kao 1983) and rational expectations models (Muth 1961; Lucas 1975).

A weakness with any of these price expectations schemes is that none perfectly represents every producer. These schemes are useful primarily in that they provide a level of abstraction allowing for a tractable estimation of producer behavior. This process of abstraction described as "absolutely essential" provides a method of "concentrating on 
crucial variables to the exclusion of less important variables" (p. 59, Randall 1987). The benefit of doing so allows the modeler to distill down to the components essential to address the objective of the study, and as long as the abstraction works similar to its essential components then it is appropriate (Randall 1987). One challenge is that as dynamics of a market shift, approaches may need to be extended or modified to better capture idiosyncrasies in a changing environment.

In a number of perennial supply response studies a net returns approach has been incorporated (e.g. French and Bressler, 1962; French and Matthews, 1971; Alston, Freebairn and Quilkey, 1980; and French, King and Minami, 1985; Devadoss and Luckstead, 2010). This approach aggregates the proxy for profit by taking a price of the output per unit minus some aggregated average cost per unit, normally variable costs, and then divided by a deflator to put it into constant or real terms. A second but similar profit variable has been called Expected Net Present Value (ENPV) (e.g. Dorfman and Heien, 1989; Alston et al., 1995). This proxy for profit transforms a summation of expected profits across an assumed number of years and uses an assumed discount rate to compute a net present value ${ }^{2}$.

Other studies, especially when cost data was unavailable, have substituted the profit proxy variable with variables representing real output (e.g. Akiyama and Trivedi, 1987; Kalaitzandonakes and Shonkwiler, 1992; Elnagheeb and Florkowski, 1993; Laajimi et al. 2008).

\footnotetext{
${ }^{2}$ In both the net returns and ENPV approaches output prices and average costs of inputs are combined and transformed in some way to create the proxy for profits in the investment equations, typically using past prices as the basis for determining expected prices. The two approaches are similar in practice as long as prices and costs are not assumed to change in the future. The ENPV approach allows for the possibility of future changes in costs and may be useful when comparing dissimilar investments, such as a perennial crop that takes 5 years before first harvest as compared to an annual crop.
} 
In addition to the profit proxy and assuming an appropriate competing commodity existed, the real output prices of one or more competing commodities were only occasionally included to capture an opportunity cost for the land. These expected price and net returns variables could then be arguments in equations for all three types of area investment decisions.

\subsubsection{Price and returns expectations model}

The price expectations method used for this paper was a modified naïve expectations approach following the method developed by Arnade and Cooper (2013). This approach incorporates the use of two stage least squares. In the first stage, estimates for price in $t$ are estimated as a function of the price in the previous period. In the following stage the expected price is determined as a function of the first stage and lagged forecast errors from the first stage equation. Let equation (3a) represent the first stage returns expectations where naïve expected returns $\pi_{t}^{n e}$ are a function of the previous year's returns $\pi_{t-1}$ : (3a) $\pi_{t}^{n e}=\theta_{o}+\theta_{1} \pi_{t-1}+\varepsilon_{t}$.

This method allows for the exploitation of forecasting errors to develop better estimates of producers' price expectations. It is assumed that producers will likely act either more or less cautiously in planning for this season when the naïve method of predicting returns has led to an overly high or low forecast. Assuming this is the case for the modified expectations $\pi_{t}^{m e}$, as represented in equation ( $3 \mathrm{~b}$ ) below, the parameter $\theta_{2}$ for the lagged fitted residuals $\widehat{F_{t-1}^{n e}}$ of the expectation's forecasting errors $\left(\pi_{t-1}^{n e}-\pi_{t-1}\right)$ should have a negative sign, while the parameter $\theta_{1}$ for lagged returns has a positive sign (Arnade and Cooper 2013): 
(3b) $\pi_{t}^{m e}=\theta_{o}+\theta_{1} \pi_{t-1}+\theta_{2} \widehat{F_{t-1}^{n e}}+\varepsilon_{t}$.

An advantage of this price expectations method is that it does not presuppose perfect rationality in producers' behavior. The application more closely resembles statistical learning methods under a bounded rationality ${ }^{3}$. This approach was then applied to generate expected net returns instead of an expected price, incorporating the combination of average revenues per bearing acre and average costs from survey production budgets per acre to create the historical net returns series as detailed more fully in the data section.

\subsubsection{Planting decision model}

The first and primary area investment decision is planting, where $P L_{t}$ represents the decision to increase or extend plantation area (acres), akin to a new or initial investment. Let planting be

(4) $P L_{t}=\theta_{o}+\theta_{1} \pi_{t}+\theta_{2}$ Water $_{t}+\theta_{3} P_{A t}+\varepsilon_{t}$,

where the $\theta$ s are the parameters to be estimated. The new or additional investment includes considerations of expected profits $\pi_{t}$ from the output of the investment decision as well as any opportunity costs $P_{A t}$ such as the price or returns of a competing crop for the area under consideration. The largest difference from previous studies is that instead of only modeling expected costs and revenues included in the expected profit proxy, a separate exogenous variable is added in the specification for the ESS of water availability

\footnotetext{
${ }^{3}$ It has also been called "adaptive learning" where "agents are identical and can be represented by an 'average agent', who adapts his behavior trying to learn an optimal rule within a class of simple (e.g. linear) rules" (p. 1, Hommes 2009). Results from testing the theory of rational expectations and learning have suggested that, "a learning method can eventually yield rational expectations even if it based upon a misspecification of the model in the situation when agents are learning... rational expectations are, if anything, a long run rather than a short run phenomenon” (p. 330, Bray 1982). Therefore this price expectations framework can draw closer to a rational expectations framework while remaining tractable for estimation.
} 
represented as Water $_{t}$. Including this variable assumes that this ESS has an influence on the perennial crop investment decision not already fully captured by the other variables. The parameter for expected profits, or returns, $\theta_{1}$ is expected to have a positive sign. The parameter for water availability $\theta_{2}$, which in this case is a hydrological index (appendix Figure A.3.1), is expected to have a positive sign as the index ranges from positive to negative with the negative range representing drought as detailed further in the data section. The expected sign for the competing commodity, $\theta_{3}$ as a potential profitable alternative for the area is also expected to be negative.

\subsubsection{Uprooting decision}

The second equation is the Uprooting decision, where $U R_{t}$ represents the removal of area, or disinvestment. Let uprooting be

(5) $U R_{t}=\theta_{o}+\theta_{1} \pi_{t}+\theta_{2}$ Water $_{t}+\theta_{3} O_{t}+\varepsilon_{t}$,

where the decision to remove almond area is attributed to a combination of small amounts of damaged area from freezes or insects and to a larger extent older, less productive area. These older trees come from previous plantings and the decision to remove them is largely determined by how productive the trees remain after the vintage, or grouping of trees within the same planting year, reach the declining productivity stage.

Considering productivity declines as trees age, older vintage trees $O_{t}$ are expected to have a positive sign on the parameter $\theta_{3}$ and the older vintage is the more likely it will be uprooted. The parameter $\theta_{1}$ for the expected profit variable $\pi_{t}$ is expected to have a negative sign. In any given year uprooting of declining vintages typically occurs after harvest. On one hand if expected profit is high in a given year some uprooting may be delayed until the next year to keep as much land in production as possible. On the other 
hand if expected profit is low in a given year additional uprooting may occur to begin the transition to a more productive newer vintage.

The parameter $\theta_{2}$ for Water $_{t}$ is expected to have a negative sign. The reason for this is two-fold. First, if irrigation water availability is constrained during a drought (negative hydrological index number), this drought may lead to tree stress and even death, where the only option is removal. Second, as water availability is constrained older less productive vintages that remain water intensive may be eliminated to reduce water needs leaving necessary water for younger more productive vintages and/or newly planted unproductive vintages that would use less water in the current year. In either case the expectation of constrained water availability would increase the incentive to disinvest in the least productive vintages.

\subsubsection{Replanting decision}

The third area investment equation is the replacement decision where replanting $R P_{t}$ is performed regularly following the uprooting decision. Let replanting be

(6) $R P_{t}=\theta_{o}+\theta_{1} \pi_{t}+\theta_{2}$ Water $_{t}+\theta_{3} P_{A t}+\theta_{3} U R_{t-1}+\theta_{4} R P_{t-1}+\varepsilon_{t}$, where replanting is considered qualitatively different from new plantings as the land is already developed for the current commodity and may incorporate different costs and consequently different producer response than new planting (Akiyama and Trivedi 1987; Kalaitzandonakes and Shonkwiler 1992; Alston et al. 1995). Rigidities are still expected in the replanting process attributed to potential shortages of nursery stock, credit constraints, etc. (Akiyama and Trivedi, 1987; Kalaitzandonakes and Shonkwiler, 1992; Alston et al. 1995). The rigidities suggest that replacements are not instantaneous and that the concept of replanting may be slow to shift to the desired levels allowing for the 
inclusion of a partial adjustment specification. Akiyama and Trivedi (1987) in their empiric specification incorporated a combination of lagged uprooting $U R_{t-1}$ or lagged replanting $R P_{t-1}$ and similar right hand variables to the new planting decision.

The signs on the parameters $\theta$ s for replanting are expected to be the same as those in the new planting investment decision. The parameters for water $\theta_{2}$, lagged uprooting $\theta_{3}$ and for lagged replanting $\theta_{4}$ are expected to have a positive signs. Plentiful water provides a favorable growing medium for new plantings, whether it is new or replanted area. Also, uprooting increases area available for replanting, although the rigidities of replanting allow for a portion of area to have a lag before replanting is complete.

Most perennial supply response literature did not include a separate structural equation for replanting as most data sources do not segregate planted area into newly planted and replanted, but instead only report a total planted number. For example, Akiyama and Trivedi (1987) did not estimate replanting for each country in their study as the data was not available. This was a similar challenge in this study as area for US almonds does not report new planting separately from replacements. This limited the empirical analysis to examining total plantings even though new investment is considered qualitatively different from replacements ${ }^{4}$. With the exception of the explicit inclusion of dynamics associated with lagged replanted area and lagged uprooting the essential right hand side variables for replanting are the same as the conceptual model for new planting. To capture these lagged influences the lag of total plantings was included into the planting specification.

\footnotetext{
${ }^{4}$ Kalaitzandonakes and Shonkwiler (1992) created a latent variable, unobserved components, state space model that estimated replanted area from reported total plantings. Despite the interesting nature of this modeling technique, the estimation of a historic replacement area series was outside the scope of this study.
} 
By using one equation for both newly planted area and replanted area I was able to incorporate a reduced form of the more complete two-equation approach where change in bearing area from equation (2) is the sum of planted and replanted area in t-k minus uprooted area in $\mathrm{t}$.

\subsubsection{Yield}

The final supply response equation called the harvest decision is represented by factors impacting tree productivity, or yield $Y L D_{t}$. Let yield be

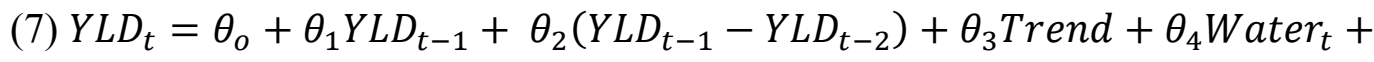
$\theta_{5} y b_{t}+\theta_{6} o b_{t}+\theta_{7} \pi_{t}+\varepsilon_{t}$ where yield in pounds per acre is representative of the identity of quantity of production divided by harvested, or bearing area. Total production is the result of the combination of the three previous area investment decisions as detailed above and the inclusion of technological advancements improving productivity, or yield over time (e.g. cultural practices, better yielding varieties, etc.) (Alston et al. 1995). In the yield equation the technology variable is represented by a time indicator, Trend, to capture productivity improvements over time. The parameter for time $\theta_{3}$ is expected to be positive as the incorporation of better cultural practices or new better yielding varieties would improve general tree productivity.

There are four additional factors that may impact yields beyond technology improvements. The first is especially important for tree crops. It is the cyclical nature of alternate bearing patterns. Generally, tree crops will follow a biannual productivity pattern where a higher productivity year will be followed by a lower productivity year and then followed by a higher productivity year and so forth (Alston et al. 1995). 
There are two variables that represent this alternative bearing cycle. These include the lagged yield $Y L D_{t-1}$ and separately lagged yield minus yield in $t-2\left(Y L D_{t-1}-\right.$ $\left.Y L D_{t-2}\right)$ (Dorfman, Dorfman and Heien 1988; Alston et al. 1995). The parameter $\theta_{1}$ for lagged yield is expected to have a negative sign as years following a higher productivity year would be expected to have lower productivity and vice versa. The sign for the parameter $\theta_{2}$ for the older lag difference is more ambiguous as it may be either postive or negative. In the case where this variable measures alternate bearing effects not captured by the one year lagged yield varible then it would similarly be negative, but if this term is capturing some effects of technology improvements separate from alternate bearing effects then it should be positive (Alston et al. 1995).

The second additional factor for tree crop yields is that they may vary across vintages. For younger trees vintages $y b_{t}$ yields are low but increase until maturity. Mature tree yields remain higher until reaching a specific age when they are considered older vintages $o b_{t}$ and yields decline. The parameter $\theta_{5}$ for the proportion of younger bearing almond vintages between 3 and 7 years old is expected to have a negative sign, and the parameter $\theta_{6}$ for proportion of vintages older than 20 years is also expected to have a negative sign.

The third major factor affecting yield response is traditionally weather. Weather may be represented by numerous variables including those for frosts/freezes, precipitation (whether accumulated or for select critical months) and temperature (using means, degree days, and many other approaches). Previous studies' specifications for yields have explicitly included these types of shorter-term weather variables, so the extension of adding a variable representing the longer-term influence of an ESS for water 
availability Water $_{t}$ that by definition includes also includes shorter-term weather events was a natural extension.

Literature has shown that water deficits have a generally negative influence on almond trees. Water deficit effects have taken various forms across the literature, but have been mostly tested through field trials that limited irrigation water (e.g. Goldhammer and Smith 1995; Goldhammer, Fereres and Salinas 2003; Goldhammer, Viveros and Salinas 2006; Yadollahi et al. 2011; Espadafor et al. 2015). Water was applied at varying rates across various developmental periods with intra-seasonal and/or inter-seasonal effects measured. In most cases, with the exception of narrowly implemented regulated deficit irrigation; yields, fruit set, kernel size and/or vegetative budding were all negatively impacted. In the cases where it was examined, tree productivity eventually returned to 'normal' after a varying, but sufficient time that full irrigation was provided (Goldhammer and Smith 1995; Goldhammer, Viveros and Salinas 2006; Yadollahi et al. 2011).

Despite the research on yield impacts of water deficits on almonds, the parameter for water $\theta_{4}$ is expected to have a negative sign. This may seem counter intuitive as rainfall is typically beneficial to yields. For California almonds it has been found that rainfall, especially February rainfall, has a statistically significant negative effect on almond yields in California (Dorfman, Dorfman and Heien 1988; Dorfman and Heien 1989; Alston et al. 1995). Increased rainfall during this critical flowering month reduced the effectiveness of pollinators thereby having a negative impact on yields. As Water $_{t}$ in this examination represents a hydrological index including impacts of temperature on water content available in the soil, and since California's wet season is generally from November through March this water variable captures both higher and lower 
precipitation changes across the wet seasons. The impact of the variable on yields is therefore expected to have a similar negative sign as previous studies that incorporated February precipitation on aggregate California almond yields.

A separate final factor that has been included in yield literature is the profit proxy. Expected profits $\pi_{t}$ or its underlying price and/or cost components have been occasionally included in perennial supply response literature but not consistently. It is expected that a profit maximizing producer would be incentivized to effectively manage inputs that would influence yields, where the sign for the parameter $\theta_{8}$ for expected profits is expected to be positive. Despite the likelihood that profit should have a nonzero impact on yields in many perennial supply response studies, expected profit or any underlying price or costs components in the estimated empirical yield equations were dropped or not even included in the conceptual models (French and Matthews 1971; Bushnell and King 1986; Dorfman, Dorfman and Heien 1988; Alston et al. 1995; Laajimi et al. 2008). Dropping this variable(s) may be attributed to a combination of reasons including statistical insignificance or unexpected signs, but in most of the perennial crop studies reviewed it was just simply not discussed. At least for the beginning conceptual yield model in this examination expected profit is included.

The inclusion of explicit exogenous variables representing an ESS into perennial area investment decisions extends the literature by examining the relationships that an ESS has on perennial producer supply response beyond the strict influences of the selected profit proxy and other traditional modeled variables. This becomes increasingly important for Californian almond producers as the risk for drought and its severity is expected to grow with the changing climate. By both establishing that the relationship exists and estimating the relationships, it adds a dynamic to the literature that establishes 
a precedent for additional research that can be used for other commodities and simulation scenarios where ESS are influenced by climate changes and subsequent policy changes.

\subsection{Data}

The empirical analysis was based on data for the time period ranging from 1968 to 2015. Data on total acreage, plantings by vintage and grower prices are reported by the USDA's National Agricultural Statistic Service (NASS). These data are incomplete and internally inconsistent. For example, the sum of national reported bearing and nonbearing area does not equal the sum of the detailed bearing and non-bearing area reported by county or variety. NASS uses a voluntary survey of approximately 6,000 almond growers. It is stated that, "it is difficult for USDA, NASS to detect growers that are planting almonds for the first time" and that the survey, "is unlikely to ever attain $100 \%$ completeness (2015)", although these inconsistencies were considered in this examination to be relatively minor. For example, when estimated current year removals are subtracted from lagged bearing area and plantings in $\mathrm{t}-3$ are added the difference across 1980 through 2015 was an average of $0.087 \%$ of total reported bearing area.

Planting data is only provided at the detailed level by year, or vintage. This detailed data is the standing area reported as planted that year by producers. Changes in the vintage area number reported in the annual updates represent the adjustment to the tree stock of each year reported back twenty-nine years with the older vintages beyond the twenty-ninth year aggregated. These reported standing tree stocks vary over time. The change may be positive or negative depending on reporting results from the surveys. For example the plantings or acres standing reported for 2010 in the 2011 report may be adjusted higher or lower in the subsequent annual updates in 2012, 2013, etc. As different 
growers report acres of trees standing by vintage, historic revisions upward have been made to vintages up to fourteen years prior. This was based on a review of reports issued since the 1996 California Almond Acreage Report. For purposes of this analysis detailed plantings were calculated as the largest reported tree stock by vintage for any report available since the 1996 report, which included detailed tree stock by vintage back to 1968. Another important fact to address is that in the detailed report planted and standing area by year for time $\mathrm{t}$ and lagged plantings in $\mathrm{t}-1$ and $\mathrm{t}-2$ were considered non-bearing. Then by definition in the detailed reports bearing area includes area that was planted in t3 and prior. It was also reported in the cost of production surveys that trees generally begin to yield in the third year, despite have relatively small yields (UCDAVIS 2015). This is relevant as bearing area in previous studies have used a number of different lagged planted vintages as the beginning point for bearing area. As USDA-NASS data considers area planted three years ago to be bearing area, the model developed here also assumes that area planted three years ago is bearing area today. So, for purposes of this examination $\mathrm{k}$ is equal to 3 whenever the notation for $\mathrm{t}-\mathrm{k}$ is used to describe planted area in the US.

After examining the planted area, the identity (2) incorporated by Alston et al. (1995) and French and Matthews (1971) was rearranged to attempt to determine removals, or total uprooting to create equation (8):

(8) $U R_{t}=P L_{t-k}+R P_{t-k}+\beta_{t-1}-\beta_{t}$.

Using the identity (8) led to multiple years where calculated removals were negative, as the change in bearing area was greater than the reported level of planted area. Removals by nature cannot be negative, so another method was employed to estimate removals. Following the estimation method similar to that described in a phone 
conversation with the NASS regional office, the vintage acreage change from one annual report to the next was used as an indicator of removals and summed across all vintages by report year (USDA-NASS 2015). In a number of years, the reported vintage standing was greater than in the previous year, which is not feasible, so these positive changes were excluded for the relevant vintage changes in that given year. The data permitted this new removal series to be calculated effectively for 1999 to 2014 . For a summary of area data series see appendix Table A.3.4.

With the knowledge that these data are estimated from survey responses and are imperfect measures, neither total plantings nor removals were revised further to force the identity (8) to balance. Instead both total plantings and the estimated removals were accepted as best available data for purposes of estimation without additional manipulation. The implied statistical discrepancy between the reported bearing areas was quite small, as mentioned above, and its average historic value was used in forward looking simulations.

Net returns were calculated as the difference between average revenue per bearing acre and average costs per acre. The price given as farm-gate, or grower price equivalent, by USDA-NASS was on a shelled, kernel weight per pound basis. This price was multiplied by the average yield per bearing acre to generate revenues per acre used for the expected net returns estimation. Historical yields were calculated from the USDANASS estimates of production in a given year divided by total bearing area the same year.

For the costs side, almond cost and return studies were collected from the Agricultural and Resource Economics Department at UC Davis with numerous studies from 1980 to 2012 (UCDAVIS 2015). These studies were used to calculate a time series 
of average total cash costs per acre. Only twelve years during the thirty-two year sample period did not have a cost and returns study available. For the missing years the underlying cultural cash costs, harvest costs and cash overhead costs were calculated. Previous year costs for each category were multiplied by the proportional change in the USDA-NASS index for price paid for commodities, services, interest, taxes and wage rates. These calculated series were summed to provide a proxy for the missing year's total cash costs per acre.

An important observation of the available cost budget data is that irrigation costs across budgets are defined by the source as only including electrical costs for pumping water and labor costs (UCDAVIS 2015). Therefore, by definition the budgets excluded any water costs beyond electricity and labor as actual costs of water per acre-foot are left unreported. Almond production is reported for 28 of the 58 counties in California with the bulk of this production from the Central Valley, which spans about 450 miles North to South. With a diverse system of surface water and groundwater sources used for irrigation water supplies, it is likely that water sourcing costs under current water rights regulations are also very diverse, limiting the benefit of including it as an average line item in the cost of production surveys. Despite the weaknesses of this underlying cost, the observed costs via survey data were accepted as the best proxy for variable costs in the industry for use when estimating net returns for the incorporated expectations method.

As potential opportunity costs for almond area, urbanization, wine grapes and walnuts were considered. Even though urbanization may be a relevant opportunity cost to include for almond area, at least attributed to the reported historical evidence and its statistical insignificance in current regression analysis it was dropped as a viable option 
in this study ${ }^{5}$. When considering competing crops, Carman (1981) reported that investors and developers switched to walnuts and grapes in California during the 1970s as profitable alternatives from citrus and almonds. More recently Lapsely (2010) reviewed the wine grape market for San Joaquin Valley, California and examined returns for almonds, walnuts, pistachios and wine grapes, finding that all except wine grapes were profitable options for land in the region. With wine grapes reported as having negative returns by Lapsely (2010) and with poor estimation results in attempts to use wine grape prices, walnuts were chosen as a profitable opportunity competitor to almonds in the region. The grower price for walnuts as reported from USDA-NASS is used as the proxy for competing crop returns.

The water availability variable was derived from the Palmer Drought Severity Index (PDSI) provided by the National Oceanic and Atmospheric Administration (NOAA) Satellite and Information Service. The drought severity index was preferred over other proxies for water availability such as rainfall because it incorporates the impact of prolonged dry or wet weather. Prolonged dry weather is more likely to influence the need for irrigation as well as limit surface water supplies and consequently demand for groundwater supplies. The chosen index was for Division 5 in California. This index encompasses the Central Valley region, including the majority of both the San Joaquin and Sacramento Valleys where most of the almond production in California resides. Monthly reported data was converted to a July to June crop year annual average for 1981 to 2013 . The divisional values provided were, “derived from area-weighted

\footnotetext{
${ }^{5}$ As aggregate irrigated land values sold for residential conversions were not readily available by the state of California, California Department of Conservation reports for farmland conversions including net irrigated land changes were used as proxy for urbanization (2016). Tests for this proxy as an opportunity costs of land in the planting specification was statistically insignificant. Also, it had been reported at least historically, that urbanization in relation to almond area had only been relevant in areas where the conversion from dry farmed orchards to irrigated orchards was either infeasible or too costly (Aron 1988).
} 
averages of grid-point estimates interpolated from station data (NOAA, 2014)." The National Drought Mitigation Center defines that, "the PDSI is calculated based on precipitation and temperature data, as well as the local available water content of the soil" (2014). PDSI more specifically defined by the NOAA (2014):

This is the monthly value (index) that is generated indicating the severity of a wet or dry spell. This index is based on the principles of a balance between moisture supply and demand. Man-made changes were not considered in this calculation. The index generally ranges from -6 to +6 with negative values denoting dry spells and positive values indicating wet spells. There are a few values in the magnitude of +7 or -7 . PDSI values 0 to $-.5=$ normal; -0.5 to $-1.0=$ incipient drought; -1.0 to $-2.0=$ mild drought $;-2.0$ to $-3.0=$ moderate drought $;-3.0$ to $-4.0=$ severe drought; and greater than $-4.0=$ extreme drought. Similar adjectives are attached to positive values of wet spells. This is a meteorological drought index used to assess the severity of dry or wet spells of weather.

The variable to represent old tree stocks in the removals equation used lagged bearing data. As almond tree stocks age beyond a certain point they become less productive. Including a measure reflecting the declining capacity of older trees provides a proxy to represent an opportunity cost for replacement. As almond trees reach 20-25 years of age their productivity, begins to decline. To represent this older vintage lagged bearing area of $\mathrm{t}-20$ was used in the removals equation.

Macroeconomic data is used from the USDA's Economics Research Service (ERS) International Macroeconomic Data Set (USDA-ERS 2015). 


\subsection{Estimation of models}

Restricted maximum likelihood estimator (REML), or residual maximum

likelihood, was employed to estimate most equations in the structural models. REML was chosen over maximum likelihood (ML) as using ML with a normal distribution assumption can give a negative bias with small sample sizes (Kleinbaum et al. 2008). REML corrects for degrees of freedom, thereby adjusting for the potential downward bias of ML (Kleinbaum et al. 2008). REML was used to test specifications with the results validated on a single equation basis.

The primary exception where REML was not used was for the estimation of the expected net returns variable. A two stage least squares method was used to estimate the expectations approach with learning, where the first stage provides forecast errors used as an explanatory variable for the second stage as explained further below.

\subsubsection{Returns expectations model}

The expected profit was estimated in two stages in OLS. The expected profit proxy in this study used calculated average net returns per bearing acre. This series as detailed in the data section above was then incorporated into the expectations approach with learning ${ }^{6}$.

The results for the final specification of the expected returns had a priori expected signs and were statistically significant (Tables $3.1 \mathrm{a}$ and $3.1 \mathrm{~b}$ ). The modest improvement

\footnotetext{
${ }^{6}$ For additional model validation the returns approach was tested both with and without the water availability variable in both stages. The purpose of these tests was to determine whether the water availability had any statistically significant influence on expected returns. If it can be assumed that the water availability variable captures an influence on almond prices that would affect net returns on the revenue side it may show up as a significant variable influencing expected returns. In both tests the parameter for water availability was not statistically different from zero. The lack of statistical significance led me to not include the variable in the expected returns model
} 
in the R-square in the second stage and the statistically significance of the forecast errors suggests the promise of using this expectations approach.

Table 3.1a: First stage OLS results of expected returns

\begin{tabular}{lcccc} 
Variables & Coefficient & SE & P-value & Elasticity \\
\hline Lagged net returns & 1.215 & 0.117 & $<0.0001$ & 0.964 \\
& & & & \\
Intercept & 27.295 & 114.232 & 0.813 \\
\hline \multicolumn{5}{r}{} \\
\hline
\end{tabular}

Table 3.1b: Second stage OLS results of expected returns

\begin{tabular}{|c|c|c|c|c|}
\hline Variables & Coefficient & SE & P-value & Elasticity \\
\hline Lagged net returns & 1.099 & 0.115 & $<0.0001$ & 0.872 \\
\hline Lagged naïve forecast errors & -0.495 & 0.182 & 0.011 & -0.036 \\
\hline Intercept & 125.128 & 109.688 & 0.263 & \\
\hline R-square & \multicolumn{4}{|c|}{0.826} \\
\hline
\end{tabular}

\subsubsection{Planting model}

The REML regression results of the specification of the planting decision equations are represented in the Tables 3.2a and 3.2b. The log likelihood and AIC statistics are provided to compare the goodness of fit between the new specification and the traditional model (TM) that excluded the water variable. Both lower log likelihood and Akaike information criterion (AIC) numbers generally indicate better model fit (Akaike 1974) ${ }^{7}$.

\footnotetext{
${ }^{7} \mathrm{AIC}$ was included as it can be used as an alternative measure to log likelihood as AIC incorporates a penalty for increasing the number of estimated parameters. AIC therefore balances the trade-off of goodness of fit with complexity and allows for a measure of relative model quality between two similar models, hence AIC provides an alternative means for model selection.
} 
Table 3.2a: REML analysis of farmer investment decisions to plant in acres, traditional model (TM)

\begin{tabular}{|c|c|c|c|c|}
\hline Variables & Coefficient & SE & P-value & Elasticity* \\
\hline Lagged plantings in $\mathrm{t}-1$ & 0.714 & 0.112 & $<0.0001$ & 0.720 \\
\hline Deflated expected net returns with learning & 555.5 & 211.51 & 0.0136 & 0.173 \\
\hline Deflated lagged Walnut grower price & -4897.8 & 3606.23 & 0.1849 & -0.385 \\
\hline Intercept & 13221 & 7988.12 & 0.1087 & \\
\hline -2 Res Log Likelihood & 646.2 & $\mathrm{AIC}$ & 648.2 & \\
\hline
\end{tabular}

The TM plantings in Table 3.2a were estimated with the variables as specified in equation (4) excluding the variable for water availability. In this TM plantings model all parameters had a priori signs. The parameter for the walnut price as an opportunity cost to land had a high p-value. As others have pointed to walnuts as a potentially profitable alternative and as walnuts were the next largest tree nut crop by area in the region this variable was considered to be an economically important variable. Considering the sample size and that the parameter has the correct a priori sign, a one sided t-test would indicate that the walnut price was still significant at the $10 \%$ level. For these reasons the walnut price as a proxy for the opportunity cost to land was retained in both planting models.

Table 3.2b: REML analysis of farmer investment decisions to plant in acres including a variable for water availability

\begin{tabular}{lcccc} 
Variables & Coefficient & SE & P-value & Elasticity* $^{*}$ \\
\hline Lagged plantings in t-1 & 0.644 & 0.101 & $<0.0001$ & 0.649 \\
Deflated expected net returns with learning & 768.6 & 197.51 & 0.0006 & 0.239 \\
Deflated lagged Walnut grower price & -5042.3 & 3160.70 & 0.1219 & -0.396 \\
Palmer's drought severity index & 1959 & 627.09 & 0.0041 \\
Intercept & 14581 & 7014 & 0.0469 \\
\hline & 622.9 & AIC & 624.9 \\
\hline
\end{tabular}

*estimated

The new eco-economic specification with a variable to represent water availability incorporated all the variables from equation (4). Each estimated parameter in 
Table 3.2b similar to the TM again had the expected signs. Both statistical significance of the water variable (Palmer's drought severity index) and smaller log likelihood and AIC numbers imply improved quality of the new specification over the $\mathrm{TM}^{8}$.

\subsubsection{Uprooting model}

The TM for uprooting was estimated using REML. The TM estimated equation followed the specification of equation (5) excluding the new variable for water availability and the results are included in Table 3.3a. In the TM for uprooting, all parameters had the expected signs and were statistically significant.

\begin{tabular}{|c|c|c|c|c|}
\hline Variables & Coefficient & SE & P-value & Elasticity* \\
\hline Deflated expected net returns with learning & -260.1 & 77.917 & 0.0059 & -0.179 \\
\hline Lagged bearing area in $\mathrm{t}-20$ & 0.090 & 0.046 & 0.0750 & 0.262 \\
\hline Intercept & 16048 & 2997.11 & 0.0002 & \\
\hline -2 Res Log Likelihood & 260.3 & AIC & 262.3 & \\
\hline
\end{tabular}

*estimated

The new eco-economic specification with a variable to represent water availability incorporated all the variables from equation (5). Each estimated parameter in Table $3.3 \mathrm{~b}$ similar to the TM again had the expected signs and was statistically significant. Both statistical significance of the water variable (Palmer's drought severity

\footnotetext{
${ }^{8}$ Of interest are the relative magnitude of the elasticities with respect to expected almond returns and walnut prices. The higher estimated elasticity at the mean of the walnut price variable would be a concern if the profit proxy was also a deflated grower price, but in this case the profit proxy uses expected net returns instead. As the expected returns also subtract costs, which may make up about half of a returns variable, the net returns elasticity would then be approximately half of the price elasticity, which would be greater than the walnut price elasticity. To validate this I first, ran a regression using a naïve deflated almond grower price in the new specification and the estimated price elasticity was about 0.56 . Second, I calculated the ratio of historic net returns to historic gross returns and multiplied the 33 year average times the estimated elasticity in the new specification. This provided an implied elasticity of 0.406 . Third, I estimated expected gross returns using the two stage process that was used to estimate expected net returns. Then using the expected gross returns and expected net returns I calculated the ratio similar to the second test and this resulted in an implied elasticity of 0.418 . In each of these instances the implied elasticities were greater than the -0.396 elasticity of the walnut grower price as the potential profitable alternative to the land, or cross price elasticity, as expected.
} 
index) and smaller log likelihood and AIC numbers imply improved quality of the new specification over the TM.

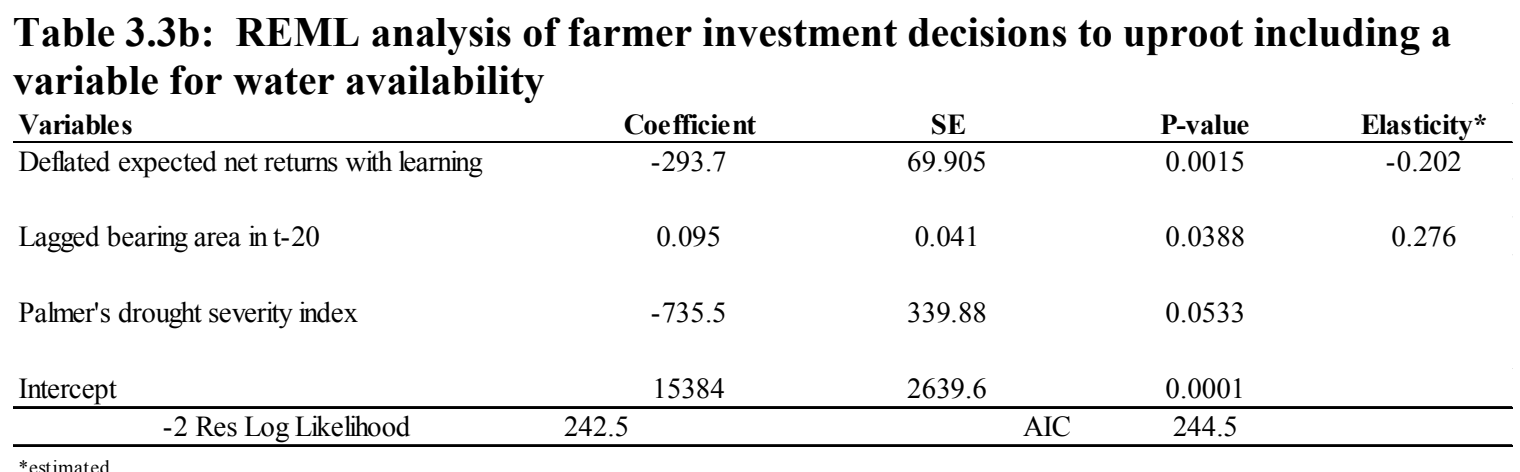

Not only did including the water availability variable improve statistical fit of the area equations, but the explanatory power and statistical significance of the other variables also increased. This influence is important as it lends credence to the idea that water availability adds information about observed almond producer area response decisions.

\subsubsection{Yield model}

The REML regression results of the final specifications of the yield equation are represented in the Tables $3.4 \mathrm{a}$ and $3.4 \mathrm{~b}$ below. The signs were consistent with conceptual expectations from equation (7). None of the three bearing area vintages or combinations thereof were included in the final equations as the results were inconsistent with expectations and in each case were not statistically different from zero. It is possible that this may be attributed to measurement errors of the data as vintages are based on annual survey data, as discussed previously. 
Table 3.4a: REML analysis of farmer yields, traditional model (TM)

\begin{tabular}{lcccc} 
Variables & Coefficient & SE & P-value & Elasticity* \\
\hline Trend & 91.8 & 22.86 & 0.001 & 1.301 \\
Lag Yield & -0.631 & 0.350 & 0.0900 & -0.626 \\
Yield t-1 minus Yield t-2 & 0.370 & 0.221 & 0.1134 & 0.009 \\
February Precipitation Index & -34.482 & 21.917 & 0.1352 & -0.065 \\
Intercept & 699.0 & 273.4 & 0.021 & \\
\hline & & & AIC & 261.9 \\
\hline *estimated & 259.9 & &
\end{tabular}

Table 3.4b: REML analysis of farmer yields including Palmer's drought severity index as a variable for water availability

\begin{tabular}{lcccc} 
Variables & Coefficient & SE & P-value & Elasticity* \\
\hline Trend & 85.37 & 25.84 & 0.0048 & 1.210 \\
Lag Yield & -0.442 & 0.373 & 0.2548 & -0.438 \\
Yield t-1 minus Yield t-2 & 0.265 & 0.232 & 0.2712 & 0.007 \\
Palmer's drought severity index & -198.95 & 101.343 & 0.0685 & -0.875 \\
Palmer's drought severity index squared & -11.26 & 6.01 & 0.0807 & \\
& & & & \\
Intercept & -381.7 & 509.0 & AIC & 256.3 \\
\hline
\end{tabular}

The deflated expected net returns as the profit proxy was also dropped in the final specification. Prices or returns has not been consistently included in the literature for empirical perennial yield equations. The parameter on the deflated expected net returns variable had varying signs across the models tested and in all tests it was not statistically different from zero.

As in the area investment equations, the water availability (Palmer's drought severity index) variable was statistically significant and had the expected sign. In both the TM and the new eco-economic specifications the water variables were statistically significant, although the PDSI had a lower p-value than the February precipitation index 
in the TM. Also, a reduced AIC in the new model indicates an improvement of model quality.

California has a distinct wet and dry season with irrigation water used when needed. Precipitation during the critical flowering month of February can reduce pollination efficacy, reducing yields (Alston et al. 1995). Thus, contrary to the experience for most rain-fed crops, an increase in rainfall at the wrong time can actually reduce almonds yields. As the wet season for California is a narrow timeframe between November and March, February precipitation is accounted for as an important portion of PDSI, even though the PDSI also accounts for accumulated effects of precipitation and temperatures over time. Despite this difference, this still gave both variables a similar influence on their respective models.

In the final yield model specification ${ }^{9}$ I used the PDSI as the water variable and included its quadratic to capture any offsetting influence from extreme drought years. In this test the PDSI was reduced by 7 in each year so to provide a consistent sign when squared. In this test the inclusion of the quadratic variable improved the performance of the yield model overall with the parameter for the quadratic variable being both statistically significant and having a negative sign, indicating a negative influence on yields when the PDSI was increasingly negative (Table 3.4b). As California almond

\footnotetext{
${ }^{9}$ Alternative specifications were examined to see if it is possible to distinguish a standard drier year, when reduced precipitation increases pollinator efficiency and yields, and an extreme or exceptional drought year, when the negative effects of drought may outweigh any pollination effect. A motivation to test this is in part from concern that during the most recent extreme drought when junior and even select senior water right holders have had surface water allocations constrained, that reduced on-farm access to irrigation water may have impacted yields.

The alternative specification included both the PDSI and February precipitation index. When both water variables were included the parameter for each ended up with the same sign. The parameters, $p$-values and subsequent elasticities of each were reduced, as often happens with correlated variables, so this approach was abandoned.
} 
producers are dependent on irrigation water ${ }^{10}$ it may be inferred from this variable that there exists a negative influence on aggregate almond yields during extreme drought years despite any counter benefit of dryness for pollination efficacy ${ }^{11}$.

The statistical significance of the lag yield and lag yield minus yield in $\mathrm{t}-2$ both were reduced from the TM. Given that the log likelihood and AIC numbers declined indicating improved model quality in this new specification and as the parameter estimates for all variables had the expected signs these two lag yield variables were retained.

\subsection{Forward looking analysis}

The model estimation results of the eco-economic framework showed a mixed influence of water availability on supply responses. The water availability variable was statistically significant in many of the model equations. In the planting and uprooting models the addition of the water variable improved the quality of the models as indicated by the smaller AIC numbers as well as increased explanatory power of the other variables. In the yield model where the PDSI was used in conjunction with its quadratic to help capture more extreme drought years, the yield model performed better than the TM using only February precipitation.

\footnotetext{
${ }^{10}$ An interesting potential future extension of this yield analysis may be to examine more micro-spatial yield changes at the county level to test whether water availability has impacts in counties where reliance on surface water irrigation sources is higher than groundwater sources.

${ }^{11}$ To examine this specification further, the influence of the PDSI was tested at different levels using the results of the estimated equations. It was observed that the combination of the PDSI and PDSI squared ceteris paribus represented a positive effect on yields as the PDSI declined along the whole spectrum of positive PDSI numbers, or wet conditions. This provided evidence that this specification was representative of the idea that pollination efficacy worsens during wetter years, or improves during drier years. It was also found that the effect on yields continued to improve on the negative spectrum until reaching -2 . Once the PDSI number dropped from -2 to -3 , the effect on yields turned negative and became increasingly negative as the PDSI declined. This provided evidence that reduced water availability begins to outweigh the positive influence of improved pollination efficacy as droughts become more extreme.
} 
A challenge to this examination is that this framework does not explicitly parse out what information is added from including the PDSI variable. It is possible that it actually represents a combination of factors affecting producer expectations. Such factors may include agronomic considerations for differences across vintages in wet or dry years, changing expectations of costs and revenues from differences in water needs, and potentially even adjustments to longer term profit expectations from concerns about future water availability and/or water prices. Despite the inability to explicitly define the underlying influence(s) that the water availability variable has on perennial producer supply response, it may be inferred that it adds information beyond the TM and captures an unmeasured or unobserved influence that water availability plays on farmers' expectations over time.

To test the impacts that water availability may have on producer expectations I developed a structural partial equilibrium model of the global almond market borrowing strongly from Maltsbarger (2017). The model incorporated parameter estimates from the proposed framework in this study and used estimated global supply, demand and price transmission parameter estimates as detailed in the Appendix (See table A.3.1 for world supply and demand, A.3.2 for price linkages and A.3.3 for US demand and ending stocks).

Using this forward looking model I developed two separate baseline scenarios with two additional scenarios as potential future alternatives where another extreme drought occurs. Each baseline was developed using exogenous variables from the USDA's International Macroeconomic Data Set (USDA-ERS 2015) with each representing a different possible future paradigm. In both of the baseline scenarios PDSI 
was set to zero. This means that in each year of the baseline scenarios the index neither represented a wet nor a dry year.

Both sets of scenarios incorporated the specifications and parameters estimates as proposed above using the PDSI in both the US area change equations and the yield equation. In each of the alternative drought scenarios, the PDSI variable takes the same values from $2011 / 12$ to $2015 / 16$ to mimic the historic drought with results compared to the baselines where the PDSI was set to zero. The purpose for using the recent drought related PDSI numbers is two-fold. First, using a recent historic drought provides a real world example of how an extreme drought has developed in this region. Using this example simplified selection of both the duration and variability of the PDSI. Second, as the risk of future droughts and their severity increases with the expected changing climate conditions, the recent extreme drought may be more common in the future (Cook, Ault and Smerdon 2015; Diffenbaugh, Swain and Touma 2015).

The goal of the two sets of scenarios was to obtain and compare estimates of how Californian almond producers may react under different assumptions within a global market model. The aim is to show changes that could occur relative to a baseline under an extreme drought scenario, recognizing that the model is limited to estimated parameters based on historic observed relationships and that the model cannot capture all uncertainties regarding future developments.

\subsubsection{PDSI scenarios}

The paradigm of the first set of scenarios, PDSI baseline and PDSI drought, represent a status quo outlook where water rights and regulations are similar in the future as they are today. The first purpose of a status quo analysis is to test the new eco- 
economic link specification in an out-of-sample manner to observe if the modeling framework responds as expected to changes in water availability. The second purpose is to compare the new eco-economic framework to a no water availability change influenced baseline. This comparison illustrates example of the responsiveness of the new eco-economic modeling framework in relation to a scenario that is assumed to have a similar output to the TM specification.

To implement the simulations, the first step was to solve the forward looking baseline scenario. The PDSI in the baseline was assumed to be zero beginning in 2016/17 and it remained zero through the projection period. Thus, the baseline assumes water availability is at normal levels, neither wet nor dry. By shifting PDSI to zero the underlying specification of the model does not change, but it eliminates any water availability effects in the modeling system. It is assumed that this shift influences the modeling system in such a manner that the results were similar, although not equivalent to what the TM may produce where no eco-economic variable is included in the specification.

For the alternative scenario the PDSI variable for 2019/20 through 2023/24 was set equal to its 2011/12-2015/16 values, and then returns to zero for the remaining years. The drought therefore begins in 2019/20 with a PDSI of -0.8 and is $-3.2,-5.4,-6.9$ and 4.4 in the subsequent years before returning to zero in $2024 / 25$. It is important to note that any year where the PDSI is negative 4 or more negative is considered an extreme drought year. From the proposed yield specification, slightly drier years generally have a positive impact on yields due to more favorable pollination efficacy during the flowering months of February and March, although as the PDSI becomes more negative the quadratic 
variable specification assists to capture the increasingly negative impact of water availability constraints on yields during more extreme drought years.

\subsubsection{PDSI simulation results}

When the influence of PDSI is assumed to be zero as in the baseline, any direct ESS influences of water into producer area and yields responses are also zero. When examining the yield impacts of the drought simulation it was observed that the shifts in yield responses were as expected. In the less-extreme drought years (PDSI between 0 to -

3) the drier years had a positive effect on yields for both 2019/20 and 2020/2021 as can be seen in Figure 3.3 below. Following the first two years of improved yields, the extreme drought conditions then had a negative impact on yields compared to the baseline for 2021/22 and 2022/23. In the last year of the drought, even though the PDSI was still in the extreme drought territory, the combination of being a modestly less extreme drought year combined with the biennial bounce from a much weaker 2022/23 yield drove the yield 2023/24 to be higher than the baseline. After the PDSI returned to zero in $2024 / 25$ the yields settled and converged back to less than a $1 \%$ difference relative to the baseline by $2025 / 26$. The lag responses in the specification to represent the biennial nature of almond yields had a modest effect, but kept the yield marginally different from the baseline. 


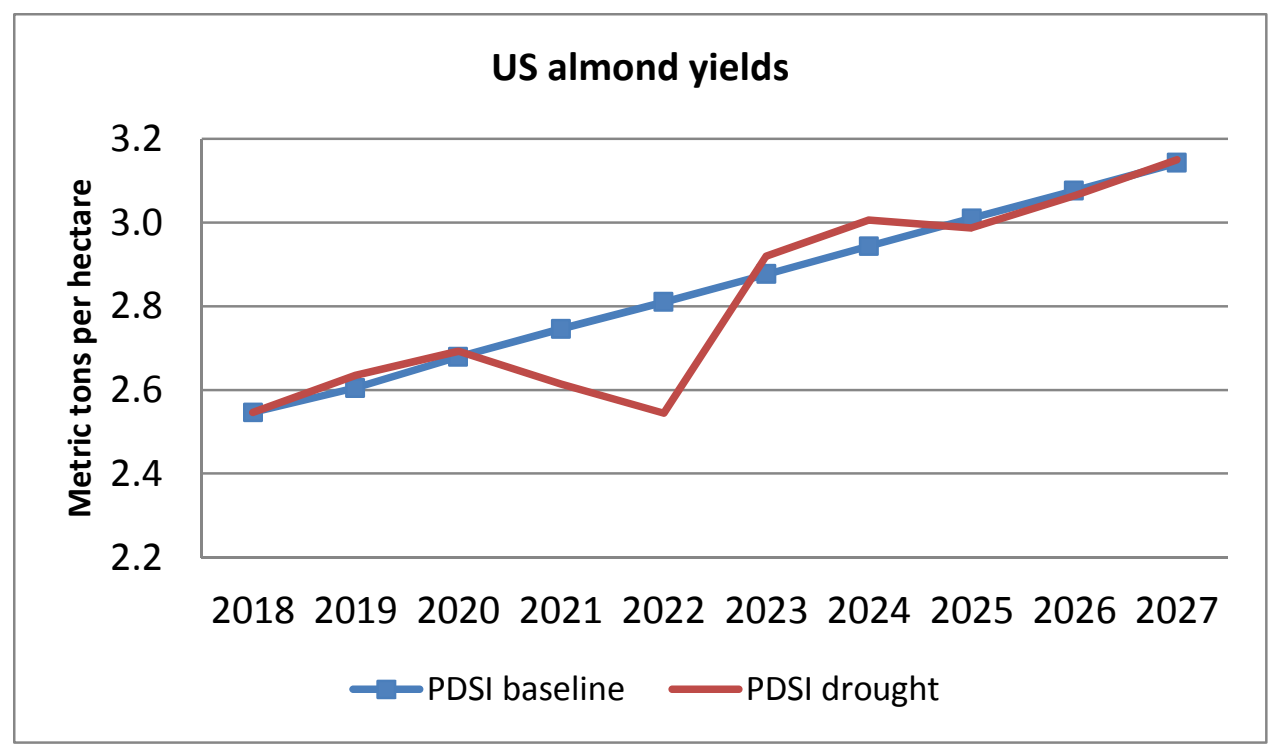

Figure 3.3: US almond yield comparison

The influence of planting and removal area changes combined to shift total bearing area as expected throughout the projection period following the initial year of drought. Following the eco-economic framework, ceteris paribus, a lower PDSI results in weaker planted area and stronger removals. It can be observed in Figure 3.4 below that bearing area shifted below the baseline as the PDSI was adjusted from a zero, or neutral level, into a persistent drought. Bearing area did not fully converge back to its respective baseline, although the difference between the two simulations narrowed considerably beyond the ten year mark following the final year of the simulated drought. 


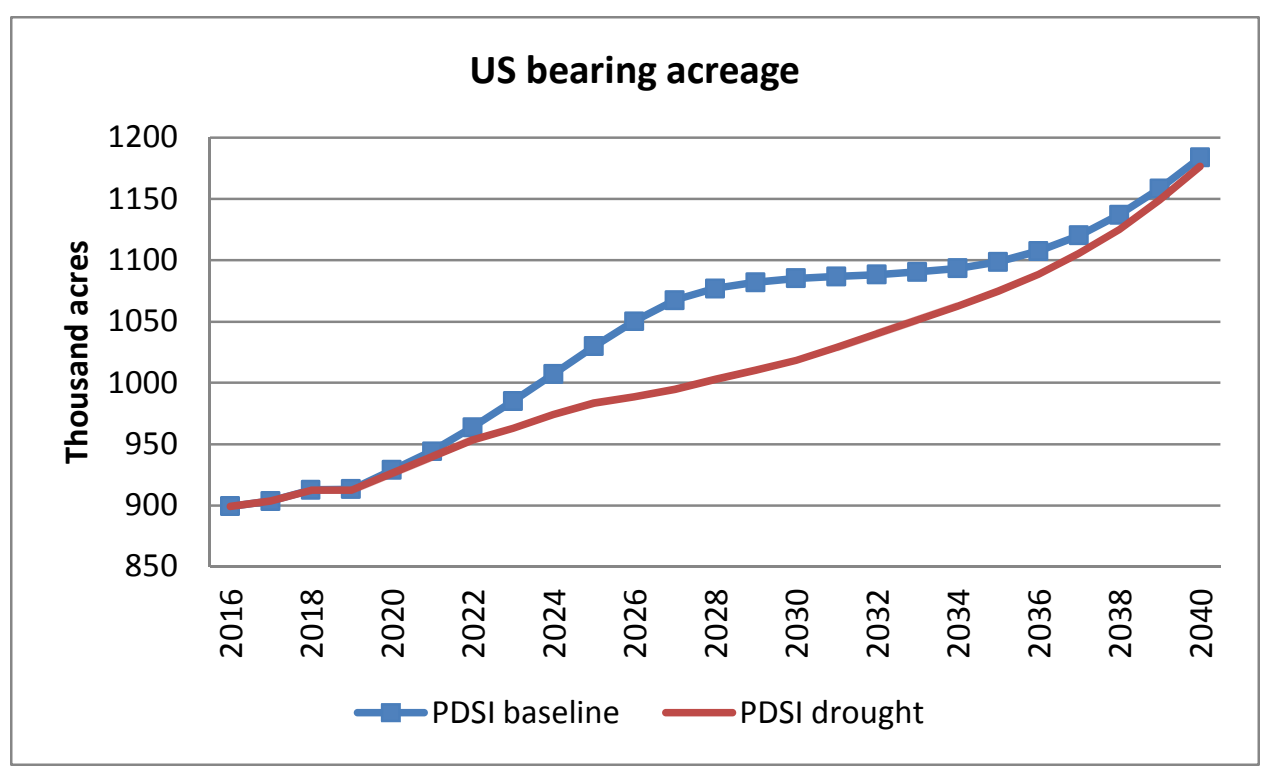

Figure 3.4: US almond bearing acreage comparison

US production was influenced by the combination of yield and area changes. In the first couple years of the simulation, while the drought was moderate, there was an improvement to US production from better yields. During the extreme drought years, weaker yields in concert with strong removals reduced US production as illustrated in Figure 3.5 below. The largest production difference relative to the baseline occurred in 2022/23 when both yield and removals also had their widest difference from the baseline. Following a return to near baseline trend yields within a couple years after the final year of the drought, longer-term production changes were attributed primarily to the changing area dynamics. 


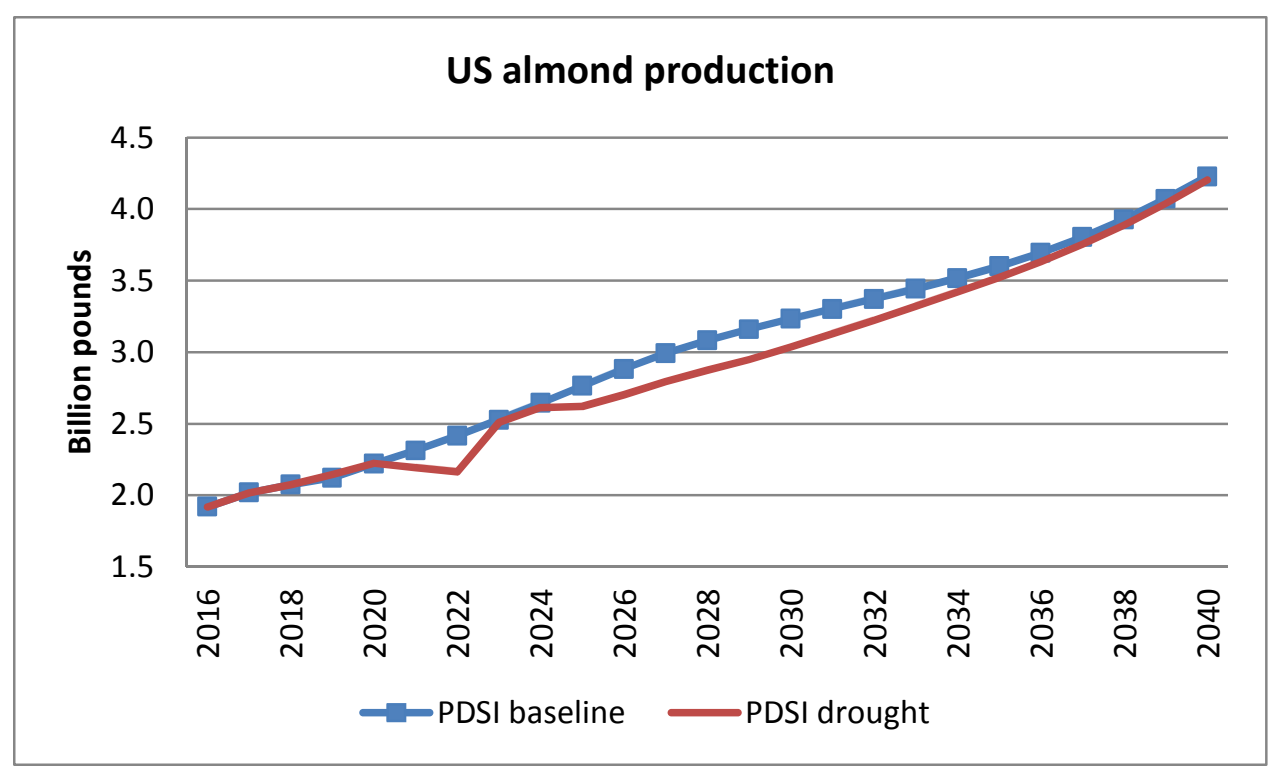

Figure 3.5: US almond production comparison

The price impacts of the simulation in Figure 3.6 illustrates how the inclusion of water availability added responsiveness as expected into the modeling system when water is constrained under an extended drought as opposed to when the influence of water availability is excluded. The price path in the drought simulation moved inversely to the changes in US almond production. As the US almond excess demand elasticity was found to be relatively inelastic in Maltsbarger (2017), the estimated impacts on prices are proportionally larger than the impacts on production. 


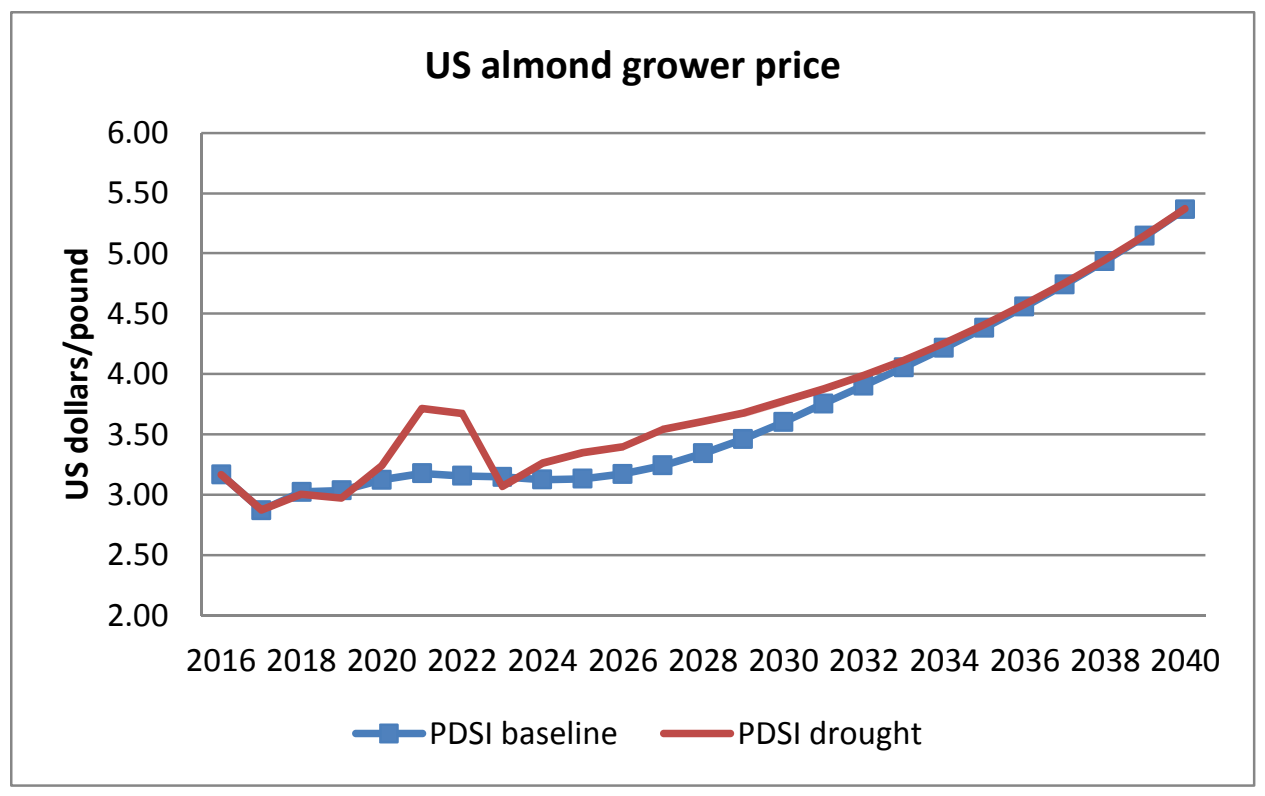

Figure 3.6: US almond grower price comparison

When comparing Figures 3.4, 3.5 and 3.6 it can be observed that the PDSI

drought scenario results eventually converges to the baseline. Removals were lower and plantings were higher than the baseline following the response of a higher price as the projection period drew closer to 2040. The magnitude of area difference fell to less than $1 \%$ from the baseline by 2036 for planted area, by 2035 for removed area, by 2039 for bearing area and by 2034 for price.

The scenario differences relative to the estimated baseline are summarized in Table 3.5 below. The differences in the tables are presented in both level and percent change terms. The PDSI drought scenario resulted in lower average area and higher average prices than in the baseline.

\subsubsection{Water price regime scenarios}

To take this forward looking analysis further a second set of scenarios was constructed. These scenarios assume a water pricing regime is established for Californian 
almond farmers. As California continues to increase regulations on water including ground water management (SGM 2015), it is possible that eventually the state will find that a water pricing regime is necessary. If it can be assumed that the water variable as proposed in the eco-economic framework in this paper is a proxy for the expected future cost of water to farmers, an interesting question would be to test if this framework may be modified to fit into a water pricing regime. Results can be examined to observe whether almond markets would react in a similar manner under the same simulated extreme drought.

Given the assumption that PDSI in the producer investment models for area including planting and removals is primarily representative of an expected cost of water, it may be incorporated as a cost of production. To operationalize the water costs into the modeling system two steps were taken. First, to shift away from the direct influence of the exogenous water variable in the area equations the PDSI was set to zero through the projection period. This removed the direct impact of PDSI on the area equations without fundamentally changing the specifications. The second step was to introduce a water price into the cost of production. For this the PDSI was incorporated as an explanatory variable to project water prices. These water prices were incorporated then as a cost into expected net returns with an assumed level of irrigation water use.

PDSI is assumed to have a supply side influence on water prices that becomes a part of the cost of producing almonds at a future point in time when the water price regime is implemented. In following this assumption I incorporated a reduced form water price model borrowing heavily from a combination of specifications from other studies (e.g. Michelsen, Booker and Person 2000; Brennan 2006; Brown 2006). For the water price scenario let water prices be 
(9) $W P_{t}=\theta_{o}+\theta_{1}$ Water $_{t}+\theta_{2} N R_{t-1}+\varepsilon_{t}$,

where water prices $W P_{t}$ is a series in dollar per acre-foot (AF) represented by historic average spot prices of voluntary water transfers (Donohew and Libecap 2010; West Water Research 2015). This is a reduced form specification where the supply of water is represented by Water ${ }_{t}$ using the PDSI as described in the data section and the value of water to agriculture is represented by lagged almond producer net returns per bearing acre. The parameter for water $\theta_{1}$ is expected to be negative as a higher PDSI number represents wetter conditions and higher supplies of water. The parameter $\theta_{2}$ for deflated, lagged net almond revenues $N R_{t-1}$ is expected to be positive as it represents the value of, or potential demand for irrigation water for an important agricultural use.

The water price model was estimated in OLS. The regression results are detailed below in Table 3.5. The signs across the parameters were consistent with a priori expectations and both coefficients were statistically significant.

Table 3.5: OLS results of water price model

\begin{tabular}{lcccc} 
Variables & Coefficient & SE & P-value & Elasticity \\
\hline Palmer's drought severity index & -14.149 & 7.370 & 0.066 & 0.102 \\
Lagged almond net returns & 9.897 & 1.851 & $<0.0001$ & 0.752 \\
Intercept & 19.324 & 24.872 & 0.444 & \\
\hline \multicolumn{5}{r}{0.637} \\
\hline
\end{tabular}

The R-square of 0.637 suggests an imperfect fit, but remained near the higher end of the water price literature reviewed (Michelsen, Booker and Person 2000; Brennan 2006; Brown 2006). As almonds are not the only user of water in California, a more detailed analysis of water pricing and water markets could prove valuable, but remains outside the scope of this research. 
Even though voluntary water transfer prices can only be considered a possible loose proxy for a cost of water, these prices make it possible to create an estimated forward looking water price series. In each of the Water price scenarios, the PDSI variable affects water prices and thus irrigation costs with the water price regime beginning the first year of the simulated drought in 2019/20 and persisting through the rest of the projection period. This water price is included as a cost of production thereby impacting net returns even beyond the end of the simulated drought. The difference is that in the baseline where the PDSI is set to zero, water availability essentially has no impact on water prices. There remains a price for water, but in the Water price baseline the projected water price changes are only influenced by changes from almond returns. For simplicity the level of irrigation water used was assumed to incorporate the same technology for all US production and remained flat across the projection period equaling average micro sprinkler, or low volume, irrigation needs on established bearing acres of 38 acre inches (3.17 acres feet) per year in total applied water (UCDAVIS 2015).

\subsubsection{Water price simulation results}

The yield results under the water price regime simulations were the same as in the PDSI simulations as the PDSI was assumed to effect tree productivity the same across the time period in both regimes. For simplicity it was also assumed that farmers would not change their water requirements across the different paradigms. Despite the likelihood that incorporating a water price regime may incentivize the use of more water saving technologies such as deficit irrigation techniques, it was not incorporated here, but remains a potential extension of this research. 
Figure 3.7 shows smaller impacts on bearing area in the water price scenarios than in the PDSI reported in Figure 3.4. In the water price scenarios the change of water availability has an impact through expected returns instead of a direct exogenous impact on area equations. When PDSI is an exogenous variable in the two area investment decisions, it has a direct influence on area when PDSI shifts. In contrast, when water is included as a cost of production through expected net returns the shift in costs is more muted as it is estimated to have a proportionally smaller impact on production costs and net returns.

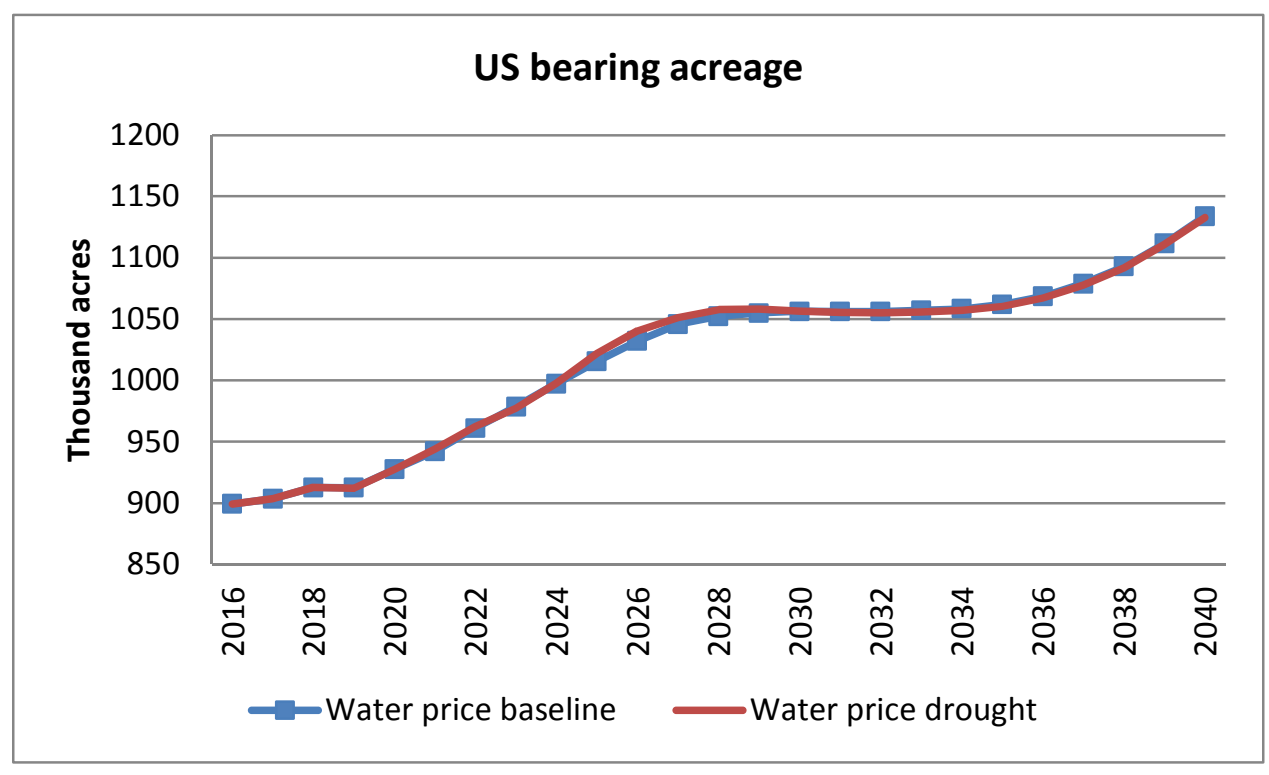

Figure 3.7: US almond planting acreage comparison

Similar to the PDSI scenarios, bearing acreage (Figure 3.7) under the water price regime did not completely converge to the baseline path by 2040 , but continued towards convergence as removals are lower and plantings are higher than its baseline following the response of a marginally higher price through 2040 . The magnitude of area difference 
in the water price simulations fell to less than $1 \%$ from the baseline by 2030 for planted area and by 2027 for removed area.

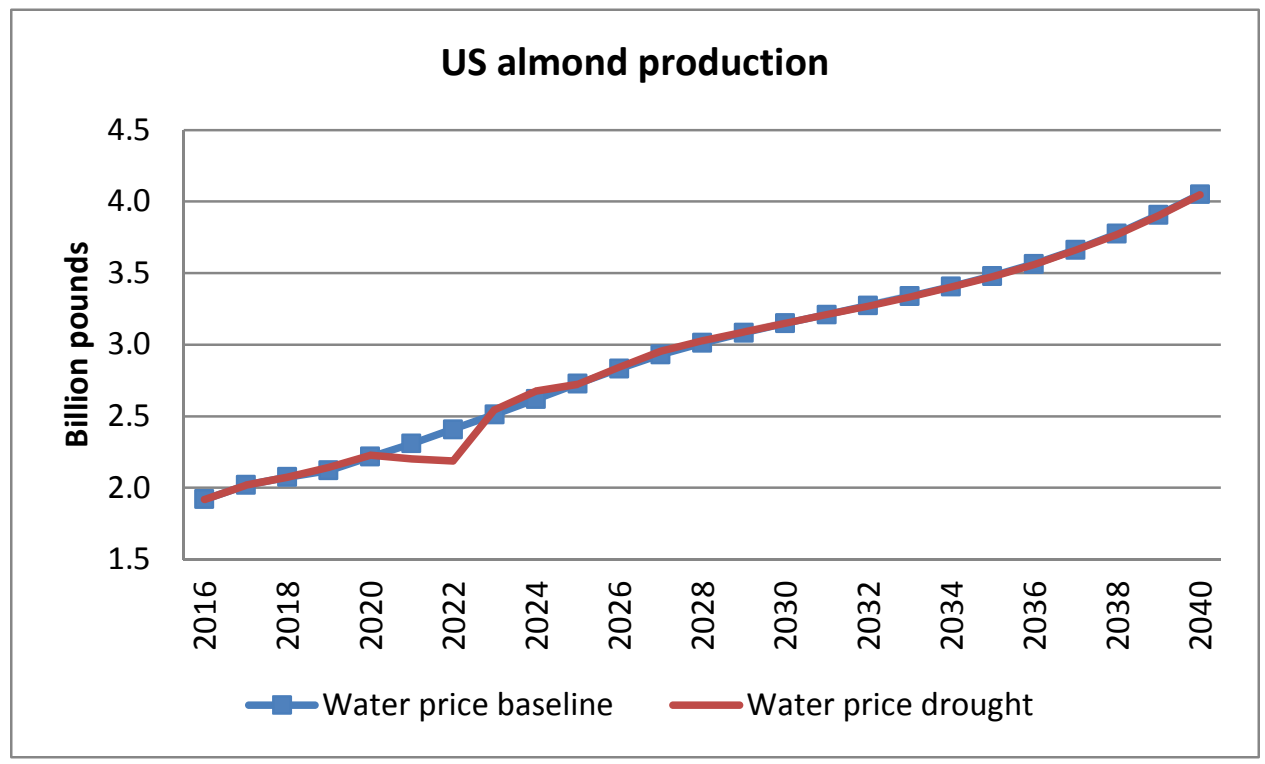

Figure 3.8: US almond planting production comparison

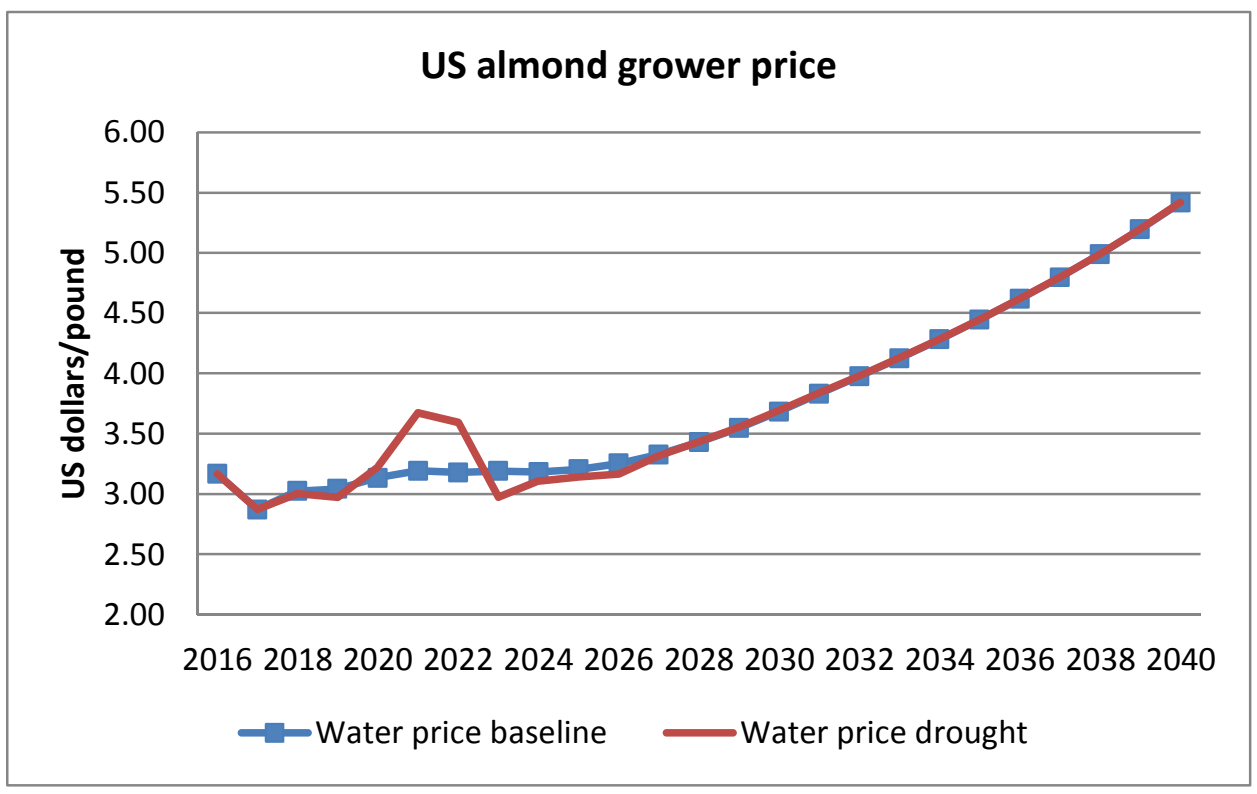

Figure 3.9: US almond grower price comparison 
The direction of price response in this simulation remained as expected. The nonextreme drought years (PDSI between 0 to -4 ) had a positive impact on yields the first couple of years of the simulated drought, increasing US production and reducing prices. Following the weaker price combined with extreme drought conditions that negatively impacted yields, prices rebound through the end of the simulated five year drought. After the return to a modestly higher yield in 2023/24, the price in the Water price drought simulation declined. The area changes were much more muted in the Water price drought simulation than in the PDSI drought simulation.

Scenario differences relative to the estimated baseline are reported in Table 3.7. The differences in the tables are presented in both level and percent change terms. On average across the projection period, prices effects were higher in the Water price drought scenario with average bearing area changes only modestly different from zero but still higher as expected with a higher average price. 
Table 3.6: US almond yield, area, production and price differences under a simulated extreme drought scenario relative to the PDSI baseline

\begin{tabular}{|c|c|c|c|c|c|c|c|c|c|c|c|c|c|c|}
\hline Supply effects & & 2019 & 2020 & 2021 & 2022 & 2023 & 2024 & 2025 & 2026 & 2027 & 2028 & 2029 & 2030 & $\begin{array}{l}\text { 2019-2040 } \\
\text { average }\end{array}$ \\
\hline \multirow[t]{2}{*}{ Yield } & lb./acre & 0.03 & 0.01 & -0.13 & -0.27 & 0.04 & 0.06 & -0.02 & -0.01 & 0.01 & 0.00 & 0.00 & 0.00 & -0.01 \\
\hline & Percent & $1.1 \%$ & $0.5 \%$ & $-4.8 \%$ & $-9.5 \%$ & $1.5 \%$ & $2.1 \%$ & $-0.7 \%$ & $-0.4 \%$ & $0.3 \%$ & $0.1 \%$ & $-0.1 \%$ & $0.0 \%$ & $-0.4 \%$ \\
\hline \multirow[t]{2}{*}{ Bearing area } & 1000 Acres & -0.9 & -2.5 & -4.3 & -10.5 & -22.1 & -33.2 & -46.1 & -61.5 & -72.6 & -74.0 & -71.9 & -66.8 & -33.1 \\
\hline & Percent & $-0.1 \%$ & $-0.3 \%$ & $-0.5 \%$ & $-1.1 \%$ & $-2.2 \%$ & $-3.3 \%$ & $-4.5 \%$ & $-5.9 \%$ & $-6.8 \%$ & $-6.9 \%$ & $-6.6 \%$ & $-6.2 \%$ & $-3.1 \%$ \\
\hline Production & $\begin{array}{l}\text { Million lbs. } \\
\text { Percent }\end{array}$ & $\begin{array}{r}22 \\
1.0 \%\end{array}$ & $\begin{array}{r}5 \\
0.2 \%\end{array}$ & $\begin{array}{r}-121 \\
-5.2 \%\end{array}$ & $\begin{array}{r}-252 \\
-10.4 \%\end{array}$ & $\begin{array}{r}-20 \\
-0.8 \%\end{array}$ & $\begin{array}{r}-33 \\
-1.2 \%\end{array}$ & $\begin{array}{r}-143 \\
-5.2 \%\end{array}$ & $\begin{array}{r}-180 \\
-6.2 \%\end{array}$ & $\begin{array}{r}-196 \\
-6.6 \%\end{array}$ & $\begin{array}{r}-210 \\
-6.8 \%\end{array}$ & $\begin{array}{r}-212 \\
-6.7 \%\end{array}$ & $\begin{array}{r}-199 \\
-6.2 \%\end{array}$ & $\begin{array}{r}-108 \\
-3.5 \%\end{array}$ \\
\hline \multicolumn{15}{|l|}{ Price effects } \\
\hline US grower price & $\begin{array}{l}\text { US\$/lb. } \\
\text { Percent }\end{array}$ & $\begin{array}{r}-0.06 \\
-2.1 \% \\
\end{array}$ & $\begin{array}{r}0.12 \\
3.8 \% \\
\end{array}$ & $\begin{array}{r}0.54 \\
17.0 \% \\
\end{array}$ & $\begin{array}{r}0.52 \\
16.4 \% \\
\end{array}$ & $\begin{array}{r}-0.08 \\
-2.4 \% \\
\end{array}$ & $\begin{array}{r}0.14 \\
4.4 \% \\
\end{array}$ & $\begin{array}{r}0.22 \\
6.9 \% \\
\end{array}$ & $\begin{array}{r}0.22 \\
7.1 \% \\
\end{array}$ & $\begin{array}{r}0.30 \\
9.2 \% \\
\end{array}$ & $\begin{array}{r}0.27 \\
8.0 \% \\
\end{array}$ & $\begin{array}{r}0.21 \\
6.2 \% \\
\end{array}$ & $\begin{array}{r}0.17 \\
4.8 \% \\
\end{array}$ & $\begin{array}{r}0.13 \\
4.0 \% \\
\end{array}$ \\
\hline
\end{tabular}

$\ddot{\circ}$

Table 3.7: US almond yield, area, production and price differences under a water pricing regime relative to a water price baseline

\begin{tabular}{|c|c|c|c|c|c|c|c|c|c|c|c|c|c|c|}
\hline Supply effects & & 2019 & 2020 & 2021 & 2022 & 2023 & 2024 & 2025 & 2026 & 2027 & 2028 & 2029 & 2030 & $\begin{array}{c}\text { 2019-2040 } \\
\text { average }\end{array}$ \\
\hline \multirow{2}{*}{ Yield } & lb./acre & 0.03 & 0.01 & -0.13 & -0.27 & 0.04 & 0.06 & -0.02 & -0.01 & 0.01 & 0.00 & 0.00 & 0.00 & -0.01 \\
\hline & Percent & $1.1 \%$ & $0.5 \%$ & $-4.8 \%$ & $-9.5 \%$ & $1.5 \%$ & $2.1 \%$ & $-0.7 \%$ & $-0.4 \%$ & $0.3 \%$ & $0.1 \%$ & $-0.1 \%$ & $0.0 \%$ & $-0.4 \%$ \\
\hline \multirow[t]{2}{*}{ Bearing area } & 1000 Acres & -0.4 & 0.0 & 1.6 & 1.3 & -1.2 & 0.3 & 6.3 & 8.3 & 5.5 & 5.4 & 3.2 & 0.3 & 0.9 \\
\hline & Percent & $0.0 \%$ & $0.0 \%$ & $0.2 \%$ & $0.1 \%$ & $-0.1 \%$ & $0.0 \%$ & $0.6 \%$ & $0.8 \%$ & $0.5 \%$ & $0.5 \%$ & $0.3 \%$ & $0.0 \%$ & $0.1 \%$ \\
\hline \multirow[t]{2}{*}{ Production } & Million lbs. & 23 & 11 & -107 & -225 & 34 & 57 & -4 & 11 & 23 & 17 & 7 & 1 & -9 \\
\hline & Percent & $1.1 \%$ & $0.5 \%$ & $-4.6 \%$ & $-9.3 \%$ & $1.4 \%$ & $2.2 \%$ & $-0.1 \%$ & $0.4 \%$ & $0.8 \%$ & $0.6 \%$ & $0.2 \%$ & $0.0 \%$ & $-0.4 \%$ \\
\hline \multicolumn{15}{|l|}{ Price effects } \\
\hline \multirow[t]{2}{*}{ US grower price } & US\$/lb. & -0.07 & 0.09 & 0.48 & 0.41 & -0.22 & -0.07 & -0.06 & -0.09 & -0.01 & 0.00 & 0.01 & 0.01 & 0.02 \\
\hline & Percent & $-2.3 \%$ & $2.9 \%$ & $15.1 \%$ & $13.1 \%$ & $-6.8 \%$ & $-2.3 \%$ & $-1.9 \%$ & $-2.7 \%$ & $-0.3 \%$ & $0.0 \%$ & $0.2 \%$ & $0.3 \%$ & $0.7 \%$ \\
\hline
\end{tabular}




\subsubsection{Paradigm comparison}

Examining the US grower price results for the drought scenarios across the two different forward looking paradigms below in Figure 3.10 illustrates that the simulated drought had strikingly similar impacts under both approaches. Despite different impacts on area (Tables 3.6 and 3.7) between the two paradigms, the level and direction of change in the top line US grower price followed a similar pattern. The challenge remains that even though the top line price results between the two regimes followed a similar path, it does not provide clear evidence that the eco-economic variable for water availability is solely an unobserved, expected water price. However, the results do suggest that the inclusion of an eco-economic variable provides additional information not captured by those variables traditionally used for perennial supply response models.

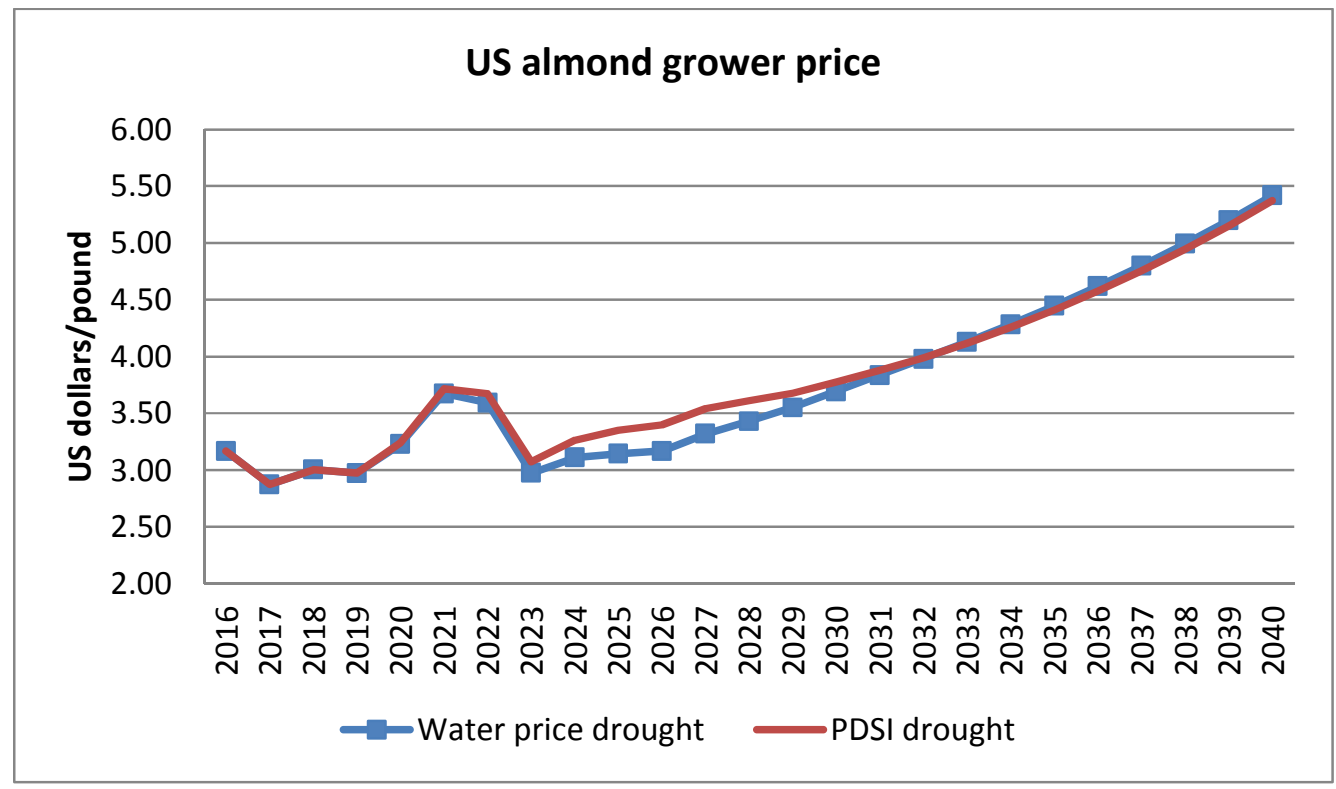

Figure 3.10: US almond grower price drought paradigm comparison 


\subsection{Conclusion}

The traditional approach to modeling perennial area investment decisions that ignores any explicit influences from ESS is insufficient in that it fails to represent relevant dynamics of producer response when a critical ESS is threatened. Results from estimating the model developed here found evidence that a measure of water availability has impacts on California almond production that are not explained by the types of economic variables typically used to model perennial crop supply.

The inclusion of an exogenous variable to represent water availability as a critical ESS to California almond producers enhanced model fit beyond that of the traditional model. In the forward looking analysis it was observed that the new eco-economic framework provided a more responsive result from the influence of a constrained ESS than when changes to ESS are not included in the investment equations. An important implication and potential extension for future research is the ability to incorporate long term climate scenarios that may directly impact ESS availability critical to agricultural production. Inclusion of an explicit variable representing this ESS in perennial investment decisions provides for more variable rates of investment leading to expansion or contraction of area under environmentally linked scenarios. With this knowledge we may better represent land use changes over time in the face of the ecosystem threats.

As the state of California continues its work to develop additional rules to regulate groundwater, water availability and access to water as it exists currently for California almond producers is unlikely to remain fixed. Uncertainty surrounding water availability and the cost of water in an industry dependent on irrigation water provided a unique opportunity to learn more about the influences of a critical ESS on perennial 
producer responses. The integration of forward looking analysis with either an exogenous ESS variable or an endogenously solved ESS price creates a springboard for more indepth research applying eco-economic analysis across other perennial crops wherever or whenever our changing environment may constrain critical ESS either by availability or cost.

\subsection{References}

Agricultural \& Resource Economics UCDAVIS. (1980-2012). Retrieved November 2014, from UC Davis Cost Studies: http://coststudies.ucdavis.edu/archived.php

Akaike, H. (1974). A New Look at the Statistical Model Identification. IEEE transactions on automatic control, 19(6), 716-723.

Akiyama, T., \& Trivedi, P. K. (1987). Vintage Production Approach to Perennial Crop Supply. Journal of Econometrics, 36, 133-161.

Alston, J. M., Carman, H. F., Christian, J. E., Dorfman, J., Murua, J.-R., \& Sexton, R. J. (1995, February). Optimal Reserve and Export Policies for the California Almond Industry: Theory, Econometrics and Simulations. Giannini Foundation Monograph, 42, 1-130.

Alston, J. M., Freebairn, J. W., \& Quilkey, J. J. (1980). A Model of Supply Response in The Australian Orange Growing Industry. Australian Journal of Agricultural and Resource Economics, 24(3), 248-267.

Arnade, C., \& Cooper, J. (2013). Price Expectations and Supply Response. 2013 Agricultural \& Applied Economics Association's Annual Meeting, (pp. 1-31). Washington, D.C.

Aron, R. H. (1988). The Changing Location of California Almond Production. California Geographical Society, 28, 69-94.

Bateman, M. J. (1965). Aggregate Regional Supply Functions for Ghanian Cocoa 194662. Journal of Farm Economics, 50, 384-401.

Boxall, B. (2017, April 7). Gov. Brown Declares California Drought Emergency is Over. Los Angeles Times.

Bray, M. (1982). Learning, Estimation, and the Stability of Rational Expectations. Journal of Economic Theory, 26, 318-339. 
Brennan, D. (2006). Water Policy reform in Australia: Lessons from the Victorian Seasonal Water Market. The Australian Journal of Agricultural and Resource Economics, 50, 403-423.

Breusch, T. S. (1978). Testing for Autocorrelation in Dynamic Linear Models. Australian Economic Papers, 17(31), 334-355.

Brewer, J., Glennon, R., Ker, A., \& Libecap, G. (2008). 2006 Presidential Address Water Markets in the West: Prices, Trading and Contractual Forms. Economic Inquiry, 46(2), 91-112.

Brown, T. C. (2006). Trends in Water Market Activity and Price in the Western United States. Water Resources Research, 42, 1-14.

Bushnell, P. G., \& King, G. A. (1986). The Domestic and Export Markets for California Almonds. University of California, Agricultural and Resource Economics. Giannini Foundation.

California Department of Conservation. (2016). Farmland Conversion Reports. California. Retrieved from http://www.conservation.ca.gov/dlrp/fmmp/products/Pages/ReportsStatistics.aspx

Carman, H. F. (1981). Income Tax Reform and California Orchard Development. Western Journal of Agricultural Economics, 165-180.

Chambers, R. G., \& Just, R. E. (1981). Effects of Exchange Rate Changes on US Agriculture: A Dynamic Analysis. American Journal of Agricultural Economics, 63(1), 32-46.

Chavas, J.-P., Pope, R. D., \& Kao, R. S. (1983, July). An Analysis of the Role of Futures Prices, Cash Prices and Government Programs in Acreage Response. Western Journal of Agricultural Economics, 27-33.

Colman, D. (1983). A Review of the Arts of Supply Response Analysis. Review of Marketing and Agricultural Economics, 51(3), 201-230.

Cook, B. I., Ault, T. R., \& Smerdon, J. E. (2015). Unprecedented 21st Century Drought Risk in the American Southwest and Central Plains. Science Advances, 1(1).

Devadoss, S., \& Luckstead, J. (2010). An Analysis of Apple Supply Response. International Journal of Production Economics, 124, 265-271.

Devadoss, S., \& Meyers, W. H. (1990). Variability in Wheat Export Demand Elasticity: Policy Implications. Agricultural Economics, 4, 381-394. 
Diffenbaugh, N. S., Hertel, T. W., Sherer, M., \& Verma, M. (2012, July). Response of Corn Markets to Climate Volatility Under Alternative Energy Futures. Nature Climate Change, 2, 514-518.

Diffenbaugh, N. S., Swain, D. L., \& Touma, D. (2015). Anthropogenic Warming has Increased Drought Risk in California. PNAS, 112(13), 3931-3936.

Donohew, Z., \& Libecap, G. (2010). California Water Transfer Records. Retrieved 2015, from bren.ucsb.edu: http://www.bren.ucsb.edu//news/water_transfers.htm

Dorfman, J. H., \& Heien, D. (1989). The Effects of Uncertainty and Adjustment Costs on Investment in the Almond Industry. The Review of Economics and Statistics, 71(2), 263-274.

Dorfman, J., Dorfman, M., \& Heien, D. (1988). Causes of Almond Yield Variations. California Agriculture, 42(5), 27-28.

Elnagheeb, A. H., \& Florkowski, W. J. (1993, July). Modeling Perennial Crop Supply: An Illustration from the Pecan Industry. Journal of Agricultural and Applied Economics, 25, 187-196.

Espadafor, M., Orgaz, F., Testi, L., Lorite, I. J., \& Villalobos, F. J. (2015). Transpiration of Young Almond Trees in Relation to Intercepted Radiation. Irrigation Science, 33(4), 265-275.

French, B. C., \& Bressler, R. G. (1962). The Lemon Cycle. Journal of Farm Economics, 44(4), 1021-1036.

French, B. C., \& Matthews, J. L. (1971). A Supply Response Model for Perennial Crops. American Journal of Agricultural Economics, 53, 478-490.

French, B. C., King, G. A., \& Minami, D. D. (1985). Plantings and Removals Relationships for Perennial Crops: An Application of Cling Peaches. American Journal of Agricultural Economics, 67, 215-223.

Gardner, B. L. (1976). Futures Prices in Supply Analysis. American Journal of Agricultural Economics, 58(1), 81-84.

Gleick, P. H. (1998). Water in Crisis: Paths to Sustainable Water Use. Ecological Applications, 8(3), 571-579.

Goldhammer, D. A., Fereres, E. \& Salinas, M. (2003). Can Almond Trees Directly Dictate Their Irrigation Needs? California Agriculture, 57(4), 138-143.

Goldhammer, D. A., \& Smith, T. E. (1995). Single-season Drought Irrigation Strategies Influence Almond Production. California Agriculture, 49(1), 19-22. 
Goldhammer, D. A., Viveros, M., \& Salinas, M. (2006). Regulated Deficit Irrigation in Almonds: Effects of Variations in Applied Water and Stress Timing on Yield and Yield Components. Irrigation Science, 24, 101-114.

Grafton, R. Q., Libecap, G., McGlennon, S., Landry, C., \& O'Brien, B. (2011). An Integrated Assessment of Water Markets: A Cross-Country Comparison. Review of Environmental Economics and Policy, 5(2), 219-239.

Griffin, D., \& Anchukaitis, K. J. (2014). How Unusual is the 2012-2014 California Drought? Geophysical Research Letters, 41(24), 9017-9023.

Harter, T., \& Dahlke, H. E. (2014). Out of Sight but Not Out of Mind: California Refocuses on Groundwater. California Agriculture, 68(3), 54-55.

Hartley, M. J., Nerlove, M. \& Peters, K. (1987). An Analysis of Rubber Supply in Sri Lanka. American Journal of Agricultural Economics, 69, 755-761.

Heim, R. (2014, September 30). Weekly Weather and Crop Bulletin. Retrieved September 30, 2014, from U.S. Drought Monitor: http://droughtmonitor.unl.edu/

Hommes, C. H. (2009). Bounded Rationality and Learning in Complex Markets. In J. B. Rosser (Ed.), Handbook of Research on Complexity (p. 37). Cheltenham: Elgar.

Houck, J. P., \& Gallagher, P. W. (1976). The Price Responsiveness of U.S. Corn Yields. American Journal of Agricultural Economics, 58(4), 731-734.

Howitt, R. E., MacEwan, D., Medellin-Azuara, J., Lund, J. R., \& Sumner, D. A. (2015). Economic Anaysis of the 2015 Drought for California Agriculture. University of California-Davis. Davis, CA: Center for Watershed Sciences.

Kalaitzandonoakes, N., \& Shonkwiler, J. S. (1992). A State-space Approach to Perennial Crop Supply Analysis. American Journal of Agricultural Economics, 74, 343352.

Kleinbaum, D. G., Kupper, L. L., Nizam, A., \& Muller, K. E. (2008). Applied Regression Analysis and Other Multivariable Methods (Fourth ed.). Belmont, CA, USA: Brooks/Cole, Cengage Learning.

Laajimi, A., Guesmi, A., Mahfoudhi, A., \& Dehibi, B. (2008). Analyzing Supply Response of Fruit Tree Products in Tunisia: The Case of \{eaches. Agricultural Economics Review, 9(1), 24-33.

Lapsely, J. T. (2010). Looking Forward: Imagining the Market for California Wine in 2030. Agricultural and Resource Economics Update, 12-15. 
Lucas, R. E. (1975). An Equilibrium Model of the Business Cycle. The Journal of Political Economy, 83, 1113-1144.

Maltsbarger, R. D. (2017). Excess Demand Elasticity of US Almonds. In Unpublished doctoral dissertation. University of Missouri-Columbia, Missouri.

Michelsen, A. M., Booker, J. F., \& Person, P. (2000). Expectations in Water-right Prices. International Journal of Water Resources Development, 16(2), 209-219.

Muth , J. F. (1961). Rational Expectations and the Theory of Price Movements. Econometrica, 29, 315-335.

National Oceanic and Atmospheric Administration Satellite and Information Service. (1981-2014). Retrieved November 2014, from Divisional output indices: www7.ncdc.noaa.gov/CDO/CDODivisionalSelect.jsp

Nerlove, M. (1956). Estimates of the Elasticities of Supply of Selected Agricultural Commodities. Journal of Farm Economics, 38(2), 496-509.

Nerlove, M. (1958). Adaptive Expectations and Cobweb Phenomena. The Quarterly Journal of Economics, 72(2), 227-240.

Nerlove, M. (1958). Distributed Lags and Estimation of Long-Run supply and Demand Elasticities: Theoretical Considerations. Journal of Farm Economics, 40(2), 301311.

Nerlove, M. (1979). The Dynamics of Supply: Retrospect and Prospect. American Journal of Agricultural Economics, 61(5), 874-888.

Paarlberg, P. (1983). Endogenous Policy Formation in the Imperfect World Wheat Market (Vol. PhD. Dissertation). Purdue University.

Provencher, B., \& Burt, O. (1993). The Externalities Associated with the Common Property Expoitation of Groundwater. Journal of Environmental Economics and Management, 24, 139-158.

Randall, A. (1987). Resource Economics: An Economic Approach to Natural Resource and Environmental Policy (2nd ed.). New York: John Wiley and Sons.

Rodriguez, R. (2014, January 18). San Joaquin Valley Farmers Take Drastic Measures to Deal with Drought. FresnoBee.com.

Schoengold, K., \& Zilberman, D. (2007). The Economics of Water, Irrigation and Development. In R. Evenson, \& P. Pingali (Eds.), Handbook of Agricultural Economics (Vol. 3, pp. 2939-2986). Elsevier B.V. 
SGM Sustainable Groundwater Management. (2015). Retrieved from CA.gov: http://www.water.ca.gov/groundwater/sgm/index.cfm

Shumway, R. C., \& Chang, A. A. (1980, December). Supply Response of Texas Field Crops: An Evaluation of the CET Linear Supply Model. Western Journal of Agricultural Economics, 5, 149-164.

Sumner, D. A., Matthews, W. A., Medellin-Azuara, J., \& Bradley, A. (2014). The Economic Impacts of the California Almond Industry. University of California Agricultural Issues Center.

Tsur, Y., \& Zemel, A. (2004). Endangered Aquifers: Groundwater Management Under Threats of Catastrophic Events. Water Resources Research, 40.

U.S. Department of Agriculture. (2015). Economic Research Service (ERS). Retrieved 2016, from International Macroeconomic Data Set: http://www.ers.usda.gov/dataproducts/international-macroeconomic-data-set/

U.S. Department of Agriculture. (2015). National Agricultural Statistics Service (NASS). Retrieved 2016, from Quick_Stats: https://www.nass.usda.gov/Quick_Stats/

U.S. Department of Agriculture. (2016). Foreign Agricultural Service (FAS). Retrieved 2016, from PS\&D: https://apps.fas.usda.gov/psdonline/

U.S. Department of Agriculture, f. o. (2014, June). National Agricultural Statitics Service (NASS) Pacific Regional Field Office. (R. Maltsbarger, Interviewer)

West Water Research, LLC. (2015, Q3). Water Market Insider. Retrieved from waterexchange.com.

Wickens, M. R., \& Greenfield, J. N. (1973). The Economics of Agricultural Supply: An Application to the World Coffee Market. Review of Economics and Statistics, 55, 433-440.

Yadollahi, A., Arzani, K., Ebadi, A., Wirthensohn, M., \& Karimi, S. (2011). The Response of Different Almond Genotypes to Moderate and Severe Water Stress in Order to Screen for Drought Tolerance. Scientia Horticulturae, 129, 403-413. 


\subsection{Appendix}

Table A.3.1: World almond demand and supply parameter estimates

\begin{tabular}{|c|c|c|c|c|c|c|c|c|c|}
\hline & Australia & Canada & China & $\begin{array}{c}\text { European } \\
\text { Union }\end{array}$ & Hong Kong & Iran & Japan & Turkey & $\begin{array}{l}\text { Rest of } \\
\text { World }\end{array}$ \\
\hline $\begin{array}{l}\text { Demand Equation } \\
\text { ln almond price }\end{array}$ & $\begin{array}{c}-0.192 * * * \\
(0.037)\end{array}$ & $\begin{array}{c}-0.267 * * * \\
(0.045)\end{array}$ & $\begin{array}{c}-0.009 * * * \\
(0.005)\end{array}$ & $\begin{array}{c}-0.142 * * \\
(0.059)\end{array}$ & $\begin{array}{c}-0.150 * * * \\
(0.047)\end{array}$ & $\begin{array}{l}-0.148 \\
(0.589)\end{array}$ & $\begin{array}{l}-0.119 \\
(0.164)\end{array}$ & $\begin{array}{c}-0.099 * * * \\
(0.035)\end{array}$ & $\begin{array}{l}-0.088 \\
(0.138)\end{array}$ \\
\hline ln GDP/capita & $\begin{array}{c}3.481 * * * \\
(0.247)\end{array}$ & $\begin{array}{c}0.975^{*} \\
(0.68)\end{array}$ & $\begin{array}{r}0.417 * * \\
(0.038)\end{array}$ & $\begin{array}{l}0.51 * * * \\
(0.103)\end{array}$ & $\begin{array}{c}6.874 * * * \\
(1.23)\end{array}$ & $\begin{array}{c}2.55 \\
(2.916)\end{array}$ & $\begin{array}{c}0.989 \\
(0.757)\end{array}$ & $\begin{array}{c}1.009 * * * \\
(0.233)\end{array}$ & $\begin{array}{c}2.854 * * * \\
(0.252)\end{array}$ \\
\hline $\ln$ trend & - & $\begin{array}{c}0.816^{* * *} \\
(0.237)\end{array}$ & - & - & - & $\begin{array}{l}-1.085 \\
(3.172)\end{array}$ & - & - & - \\
\hline Intercept & $\begin{array}{c}-26.479 * * * \\
(2.787)\end{array}$ & $\begin{array}{l}-2.240 \\
(6.644)\end{array}$ & $\begin{array}{c}6.603 * * * \\
(0.388)\end{array}$ & $\begin{array}{l}7.87 * * * \\
(1.034)\end{array}$ & $\begin{array}{c}-57.539 * * * \\
(11.623)\end{array}$ & $\begin{array}{l}-6.522 \\
(13.69)\end{array}$ & $\begin{array}{l}-0.049 \\
(7.657)\end{array}$ & $\begin{array}{c}1.657 \\
(2.202)\end{array}$ & $\begin{array}{c}-10.421 * * * \\
(1.905)\end{array}$ \\
\hline \multicolumn{10}{|l|}{ Supply Equation } \\
\hline ln almond price $\mathrm{t}-1$ & $\begin{array}{c}0.213 * * \\
(0.1)\end{array}$ & - & $\begin{array}{l}0.070^{*} \\
(0.049)\end{array}$ & $\begin{array}{c}0.144 \\
(0.149)\end{array}$ & - & $\begin{array}{c}0.307 \\
(0.743)\end{array}$ & - & $\begin{array}{c}0.052 \\
(0.105)\end{array}$ & $\begin{array}{l}0.259 * \\
(0.181)\end{array}$ \\
\hline In almond price $\mathrm{t}-\mathrm{k}^{++}$ & $\begin{array}{c}0.038 \\
(0.114)\end{array}$ & - & $\begin{array}{l}0.115^{* *} \\
(0.047)\end{array}$ & $\begin{array}{r}0.155++ \\
(0.122)\end{array}$ & - & $\begin{array}{c}0.132 \\
(0.612)\end{array}$ & - & $\begin{array}{r}0.029++ \\
(0.109)\end{array}$ & $\begin{array}{c}0.151 \\
(0.180)\end{array}$ \\
\hline In lagged production & $\begin{array}{c}0.46^{* *} \\
(0.26)\end{array}$ & - & $\begin{array}{c}0.476 * * * \\
(0.163)\end{array}$ & $\begin{array}{c}0.076 \\
(0.254)\end{array}$ & - & $\begin{array}{c}0.16 \\
(0.58)\end{array}$ & - & $\begin{array}{l}0.42 * * \\
(0.228)\end{array}$ & $\begin{array}{c}-0.044 \\
(0.235)\end{array}$ \\
\hline ln trend ${ }^{+}$ & $\begin{array}{c}0.0845^{* *+} \\
(0.037)\end{array}$ & - & $\begin{array}{c}0.029 * * *+ \\
(0.008)\end{array}$ & $\begin{array}{c}-0.012^{* * *+}+ \\
(0.004)\end{array}$ & - & $\begin{array}{c}1.555 \\
(3.276)\end{array}$ & - & $\begin{array}{c}0.041^{* * *+} \\
(0.016)\end{array}$ & $\begin{array}{c}1.635^{* * *} \\
(0.384)\end{array}$ \\
\hline Intercept & $\begin{array}{c}2.301 * * \\
(1.263)\end{array}$ & - & $\begin{array}{c}3.57 * * * \\
(1.344)\end{array}$ & $\begin{array}{c}10.91^{* * *} \\
(3.445) \\
\end{array}$ & - & $\begin{array}{c}2.112 \\
(11.749)\end{array}$ & - & $\begin{array}{c}4.524 * * \\
(1.883)\end{array}$ & $\begin{array}{c}6.014 * * * \\
(2.143)\end{array}$ \\
\hline
\end{tabular}

Notes: Standard error is in parentheses. R-square is not available for equations estimated with restricted maximum likelihood estimator. The asterisks $* * *, * * *$ denote statistical significance at the $1 \%, 5 \%$ and $10 \%$ levels respectively. + denotes trend instead of $\ln$ trend; ++ denotes $\mathrm{t}-\mathrm{k}$ where $\mathrm{k}=4$ except for European Union where $\mathrm{k}=5$ and Turkey where $\mathrm{k}=3$. 
Table A.3.2: World almond price linkage parameter estimates

\begin{tabular}{|c|c|c|c|}
\hline & ln U.S. Price & ln Lagged Own Price & Intercept \\
\hline Australia & $0.441 * * *(0.058)$ & - & $1.351 * * *(0.350)$ \\
\hline Canada & $0.962 * * * \quad(0.198)$ & - & $0.011 \quad(0.792)$ \\
\hline China & $1.007 * * * \quad(0.119)$ & - & -0.087 \\
\hline European Union & $0.959 * * *(0.080)$ & - & $-1.077 * *(0.294)$ \\
\hline Hong Kong & $1.422 * * *(0.113)$ & - & $-1.816 * * *(0.446)$ \\
\hline Iran & $1.184 \quad(0.756)$ & - & $0.032 \quad(2.915)$ \\
\hline Japan & $1.401 * * *(0.143)$ & - & $-1.772 * * *(0.557)$ \\
\hline Turkey & $0.445 * \quad(0.282)$ & $0.530 * *(0.159)$ & $-0.089 \quad(1.461)$ \\
\hline Rest of World & $0.949 * * *(0.087)$ & - & $(0.345)$ \\
\hline
\end{tabular}

Notes: Standard error is in parentheses. R-square is not available for equations estimated with restricted maximum likelihood estimator.

二 The asterisks $* * *, * *, *$ denote statistical significance at the $1 \%, 5 \%$ and $10 \%$ levels, repsecitvely. All prices are in real term in US dollars.

\section{Table A.3.3: US parameter estimates}

\begin{tabular}{llcc}
\hline Equation & Variable name & Coefficient estimate & Elasticity at mean \\
\hline Consumption per capita & Intercept & 0.16 & -0.291 \\
& Deflated US almonds grower price & $-6.7^{* *}$ & 0.048 \\
& Deflated US walnuts grower price & 2.4 & 0.682 \\
& real GDP per capita & $0.0000077^{* *}$ & 0.215 \\
& Shift trend beginning 2004 & $0.051^{* *}$ & \\
Ending stocks & Intercept & $29799^{*}$ & -0.155 \\
& Deflated US almonds grower price & -672908 & 1.277 \\
& US almond production & $0.27^{* *}$ & -0.881 \\
& US almond production t+1 & $-0.18^{* *}$ & 0.417 \\
\hline
\end{tabular}

*: Statistically significant at 0.05 level

**: Statistically significant at 0.01 level 
Table A.3.4: US almond area thousands of acres

\begin{tabular}{|c|c|c|c|}
\hline \multicolumn{2}{|c|}{ Bearing area } & Planted area & Removed area* \\
\hline 1980 & 327.0 & & \\
\hline 1981 & 326.0 & 39.1 & \\
\hline 1982 & 339.0 & 24.3 & \\
\hline 1983 & 360.0 & 9.4 & \\
\hline 1984 & 381.0 & 9.6 & \\
\hline 1985 & 409.0 & 9.8 & \\
\hline 1986 & 416.0 & 7.6 & \\
\hline 1987 & 417.0 & 10.9 & \\
\hline 1988 & 419.0 & 16.1 & \\
\hline 1989 & 411.0 & 17.8 & \\
\hline 1990 & 411.0 & 23.1 & \\
\hline 1991 & 405.0 & 13.6 & \\
\hline 1992 & 401.0 & 13.2 & \\
\hline 1993 & 413.0 & 20.0 & \\
\hline 1994 & 433.0 & 31.7 & \\
\hline 1995 & 418.0 & 36.7 & \\
\hline 1996 & 428.0 & 35.1 & \\
\hline 1997 & 442.0 & 38.5 & \\
\hline 1998 & 460.0 & 47.8 & \\
\hline 1999 & 485.0 & 36.6 & 15.8 \\
\hline 2000 & 510.0 & 26.3 & 21.7 \\
\hline 2001 & 530.0 & 20.9 & 25.2 \\
\hline 2002 & 545.0 & 18.5 & 23.2 \\
\hline 2003 & 550.0 & 21.6 & 21.4 \\
\hline 2004 & 570.0 & 47.4 & 17.9 \\
\hline 2005 & 590.0 & 68.4 & 10.5 \\
\hline 2006 & 610.0 & 59.2 & 17.1 \\
\hline 2007 & 640.0 & 30.8 & 14.6 \\
\hline 2008 & 710.0 & 33.1 & 25.6 \\
\hline 2009 & 750.0 & 27.9 & 19.4 \\
\hline 2010 & 770.0 & 25.3 & 16.2 \\
\hline 2011 & 800.0 & 25.9 & 12.9 \\
\hline 2012 & 820.0 & 19.7 & 11.8 \\
\hline 2013 & 840.0 & 22.0 & 9.3 \\
\hline 2014 & 870.0 & 19.9 & 17.8 \\
\hline
\end{tabular}

* Calculated from annual California almond acreage reports summing declining vintages each year. 


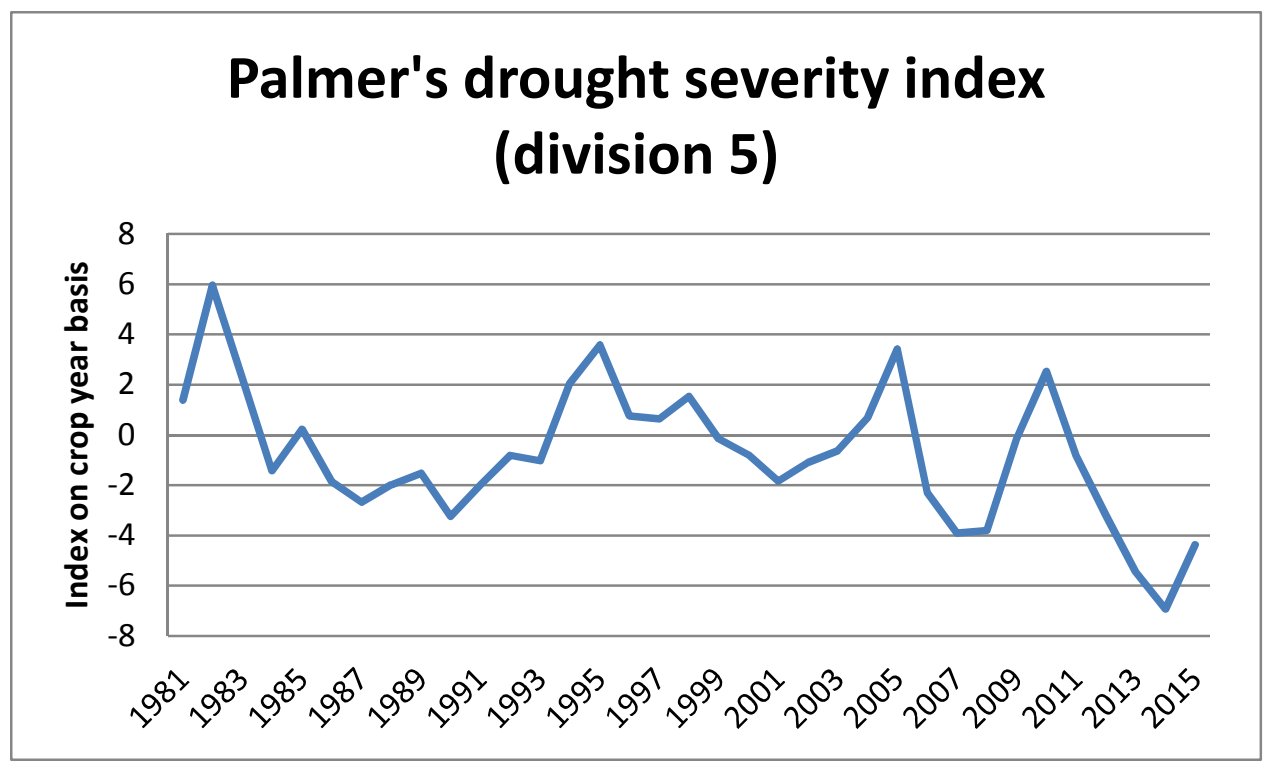

Figure A.3.1: Palmer's drought severity index for division 5 on a US almond crop year basis 


\section{ECONOMIC VALUATION OF THREATENED ECOSYSTEM SERVICES: US ALMOND FARMERS FACING COLONY COLLAPSE DISORDER AND EXTREME DROUGHT}

This study investigates the producer welfare impacts of colony collapse disorder (CCD) and extreme drought on US almond producers. Commercial pollinator service fees for US almond producers have skyrocketed since 2005. This shift in fees has been linked to $\mathrm{CCD}$, which increased bee colony mortality. Many valuation methods have been used to estimate the importance of pollinators, but none of these methods has effectively captured the economic impact of CCD on a specific market entirely dependent on commercial pollination services. In concert with the ongoing CCD phenomenon, California experienced a drought event between winter 2011/12 and spring 2017, with large portions of the state in an extreme drought. The drought increased concerns about water availability and water quality as limited surface water increased dependence on more and deeper groundwater irrigation wells. The US almond industry is dependent on irrigation water, especially during the distinct dry season.

A model incorporating the influence of both $\mathrm{CCD}$ and extreme drought on Californian almond producer behavior was used to estimate producer welfare impacts of threatened ecosystem services on a specific agricultural sector dependent on both. Extreme drought reduced production leading to higher almond price and a positive impact on producer surplus, whereas CCD increased farmers' costs and negatively impacted producer surplus. The net influence of drought and CCD from 2005/06 through 2015/16 was to increase US almond farmers’ producer surplus by $\$ 656$ million. 


\subsection{Introduction}

The economic implications and valuation of ecosystem service(s) (ESS) continue to be the subject of debate. In order to formulate effective policies to address threatened ESS, the economic impacts must be identified. This paper is a preliminary effort to examine the economic influences that two threatened ESS have had on a specific agricultural industry dependent on both by estimating the producer welfare impacts under a counterfactual simulation.

Pollination from commercial honeybee colony services and quality water from irrigation systems are both critical ESS and integral to United States' (US) almond production. US almonds are produced solely in the Central Valley region of California. This region spans from the foothills of the Sierra Nevada Mountains down towards the coastal region, and ranges about 40 to 60 miles wide and about 450 miles long from North to South. The area has provided on average over $90 \%$ of world almond exports across the last decade (USDA-ERS 2015). Almonds are also a valuable addition throughout the value chain for the state's economy. For example, the University of California Agricultural Issues Center estimated that the value of the California almond industry in 2014 was $\$ 21.5$ billion (Sumner et al. 2014). The Central Valley is known for its Mediterranean style climate experiencing distinct wet and dry seasons. Agricultural production for annual, forage and perennial crops must have yearly precipitation supplemented through irrigation to not only thrive but to survive during the drier months between April and October.

To accomplish this feat Californian water needs are provided through a complex system of surface water reservoirs, canals and aqueducts from rivers and lakes, 
supplemented with groundwater wells. As population, industry and agriculture has expanded in California, the demand for quality water has also continued to expand. Clean water is also required for environmental protection. The drought that began to develop in the winter of 2011/12 threatened this ESS. The drought was classified by the US Drought Monitor (USDA-NDMC 2017) as an extreme or even an exceptional drought lasting five years that encompassed the majority of the Central Valley.

The persistent extreme drought limited surface water availability with subsequent restrictions of water allocations enacted through governmental limitations on residential use and surface water use for agricultural irrigation. This led to increased drilling of a combination of new groundwater wells and deeper groundwater wells to compensate for decreased surface water access (Heim 2014). Meanwhile, the Californian state government in 2014 passed the Sustainable Groundwater Management Act, which is set to more clearly define and regulate groundwater use, especially "to bring water basins in a state of overdraft into balance" (SGM 2015). The implementation was delayed until 2020, increasing uncertainty about future groundwater access (SGM 2015). It had also been reported that some almond farmers responded to the drought event by removing older, less productive orchard vintages to decrease more immediate water needs (Rodriguez 2014; Harter \& Dahlke 2014).

In addition to water concerns there has been the ongoing issue of colony collapse disorder (CCD). Since its beginnings in 2005, CCD has dramatically increased honeybee colony losses and led to skyrocketing pollination service fees to the almond industry (Carman 2011). Commercial honeybee colonies are used by US almond producers to provide necessary pollination services during the flowering months of February and March. The importance of commercial pollination services to the US almond industry is 
two-fold. First, early flowering of almonds in the Central Valley of California begins in February, when many wild pollinators are still coming out of diapause in the region. Without commercial pollinators imported to the state, pollination during the early bloom would be less impactful, limiting tree productivity. Second, the monoculture of large US almond orchards limits wild pollinator habitat and forage area, reducing their ability to effectively pollinate the whole of the Californian almond industry.

Early blooming and the monoculture environment create an industry dependent on commercial pollinator services. For example, California almond producers are said to be $100 \%$ dependent on honeybees (Morse and Calderone 2000), so a sufficient supply of commercial pollinators is extremely important for California as the leading global producer of almonds. During the era of CCD, the commercial honeybee services industry has worked to offset their ongoing annual losses. The market has adjusted and beekeepers have been able to maintain and even increase the aggregate colony numbers from the 2004 level pre-CCD (USDA-NASS 2015).

For the ten years prior to $\mathrm{CCD}$ the annual average fee increase per colony for almond pollination services in California was about 5\% a year. With the onset of CCD the fees grew $35 \%$ in the first year, 2005 , with another $93 \%$ jump in 2006 , and with oscillating but historically high fees ever since. In 2014, almond fees reached a record of $\$ 177$ per colony as illustrated in appendix Figure A.4.1 (CSBA 2016).

With two threatened ESS in an industry dependent on both, the California almond industry provided a unique case to examine the economic impacts of threatened ESS. An econometrically estimated partial equilibrium model of the global almond industry was developed and used to evaluate a counter factual historical scenario. This scenario was 
used to quantify the producer welfare impacts that CCD and extreme drought have had on the global leading producer of almonds.

\subsection{Relevant historic scenario}

To assess the impacts from the threatened ESS, it requires a comparison of the observed economic outcomes for indicators such as production, revenues and costs against a benchmark that is not observed. This unobserved benchmark reflects the situation that would have resulted in the absence of these ecosystem threats. When considering various ESS valuation methods, it is challenging to choose one single method as ESS are multidimensional in nature. There is also no consensus on how to evaluate farm-level impacts.

One of the more promising methods is the use of experimental yield trials. Yields may be impacted by not only pollination services but also available water, so yield trials may be helpful in evaluating productivity impacts of a specific ESS. Yield trials can provide an upper or lower bound on yield impacts for economic analysis. There is one relevant challenge to this method. Yield trials are generally, "not designed to minimize unit costs or maximize profits" (p. 3, Alston, Kalaitzandonakes \& Kruse 2014). So, when using yield experiments the use of inputs and the associated costs and revenues may not be representative of actual farmer behavior. When this occurs, using yield impacts alone may lead to over- or under-estimated impacts of threatened ESS.

An alternative valuation method is to consider how producers might adjust practices and expenses to avoid or mitigate the effects of threatened ESS on production. The current ESS threat from CCD increased commercial pollination service fees (Carmen 2011). This increase in cost led some almond producers to supplement commercial 
pollination services. Strategies included increasing pollinator habitat for wild and/or onfarm domestic honeybee colonies and adding supplemental almond pollen in honey bee hives to improve cross-varietal pollination (Kremen et al. 2008). Each of these strategies likely increased the variable costs associated with pollination. Also, when faced with the extreme drought and reductions in available supply of surface water, farmers have deepened groundwater wells or dug new ones and have pushed out older less productive orchard vintages to decrease water needs (Rodriguez 2014; Harter \& Dahlke 2014; Heim 2014).

Given the examples of producer behavior above it is not a surprise that producers will adjust and attempt to choose an optimal input mix in view of relative prices and availabilty of alternative input options. Producers seek to minimize costs per unit produced, but costs will often increase when ESS are threatened. Changes in these costs will therefore affect investment and farm management decisions that influence production.

By assuming that farmers will make profit maximizing decisions, a counterfactual scenario may be developed that estimates impacts of changes in ecological and economic (eco-economic) variables. This allows a simulation of what almond production and market conditions would have been in the absence of the ecosystem threats.

A conventional supply and demand framework can be used to estimate impacts of drought and CCD. When using this framework, supply and demand shifts can be modeled either exogenously or endogenously depending on the objective of the study. When considering a single-commodity market model, the elimination of threats to ESS would cause the commodity supply to shift out. Given a static demand curve, this would lead to an increase in both quantity produced and consumed at a reduced price level. Changes in 
both producer and consumer surplus from this increase in supply can be evaluated using Marshallian measures. The distribution of welfare change will depend on the size of the shift and the elasticities of the supply and demand curves. Additional factors of analysis may have second-order effects on the measures of surplus change, and could have implications for the distribution of welfare changes between producers and consumers.

A traditional supply and demand system of equations assumes that competition exists in the market for the commodity of concern and there is an absence of any significant market distortions. The US and global market for almonds and related commodities are subject to domestic and border policies, but it is assumed that these policies cause only limited distortions in domestic production and consumption.

The competitive domestic partial equilibrium model can also be expanded to consider domestic supply and demand in foreign markets. This provides the detail behind changes in US trade and makes it possible to determine impacts on other countries. It is also possible to expand the single-market model to consider cross-commodity impacts.

\subsection{Modeling economic impacts}

To estimate the economic impacts to producers from CCD and drought across the period from crop year 2005/06 to 2015/16, a detailed market simulation model was developed to capture global interrelationships among major almond producers and consumers. The modeling system allows for the estimation of price effects and changes in US land use. The model is calibrated so that a baseline simulation replicates the actual historic values of supply, demand, trade and stocks. The alternative scenario represents a world where California did not face CCD or the recent extreme drought event. The resulting counterfactual prices, quantities, area, stocks, imports, exports and other 
indicators may then be compared to actual historic values to estimate the effects of these threatened ESS. The consequent differences between this counterfactual scenario and actual observed outcomes are used to estimate the welfare changes to producer surplus.

\subsubsection{Model structure}

The model is a partial equilibrium model of the global almond market. Separate supply and demand equations are developed for ten countries and/or regions, including the United States (US), Australia, Canada, China, the European Union, Hong Kong, Iran, Japan, Turkey and a Rest of World aggregate.

The model framework is similar to that historically used by the Food and Agricultural Policy Research Institute (FAPRI) (Devadoss et al. 1989; FAPRI 2004; Kruse 2003; Brown et al. 2009). The model structure follows the traditional manner in which supply and demand factors are represented. The supply of almonds is the sum of production, imports and beginning stocks. Annual almond demand for a country is the sum of domestic consumption, exports and ending stocks.

In this modeling framework price serves as the rationing mechanism for equating supply to demand. "Market clearing identities" (e.g. net exports equal production plus beginning stocks minus domestic use and ending stocks) ensure the supply and demand balance for a given country (Brown et al. 2009).

Production for the US is determined by separate structural equations for area planted, removals and yield, whereas production for other countries is determined by a single estimated equation. On the demand side, domestic consumption, or more generally domestic disappearance, is estimated as well as ending stocks for the US. The model incorporated parameter estimates for area, yield, supply, demand and price linkages as 
detailed in the Appendix (See Tables A.4.1 for global supply and demand, A.4.2 for price transmission and A.4.3 for US equations). The explicit inclusion of exogenous variables for water availability in the US equations is detailed in the Appendix in Table A.4.3 and examined further in Maltsbarger (2017a).

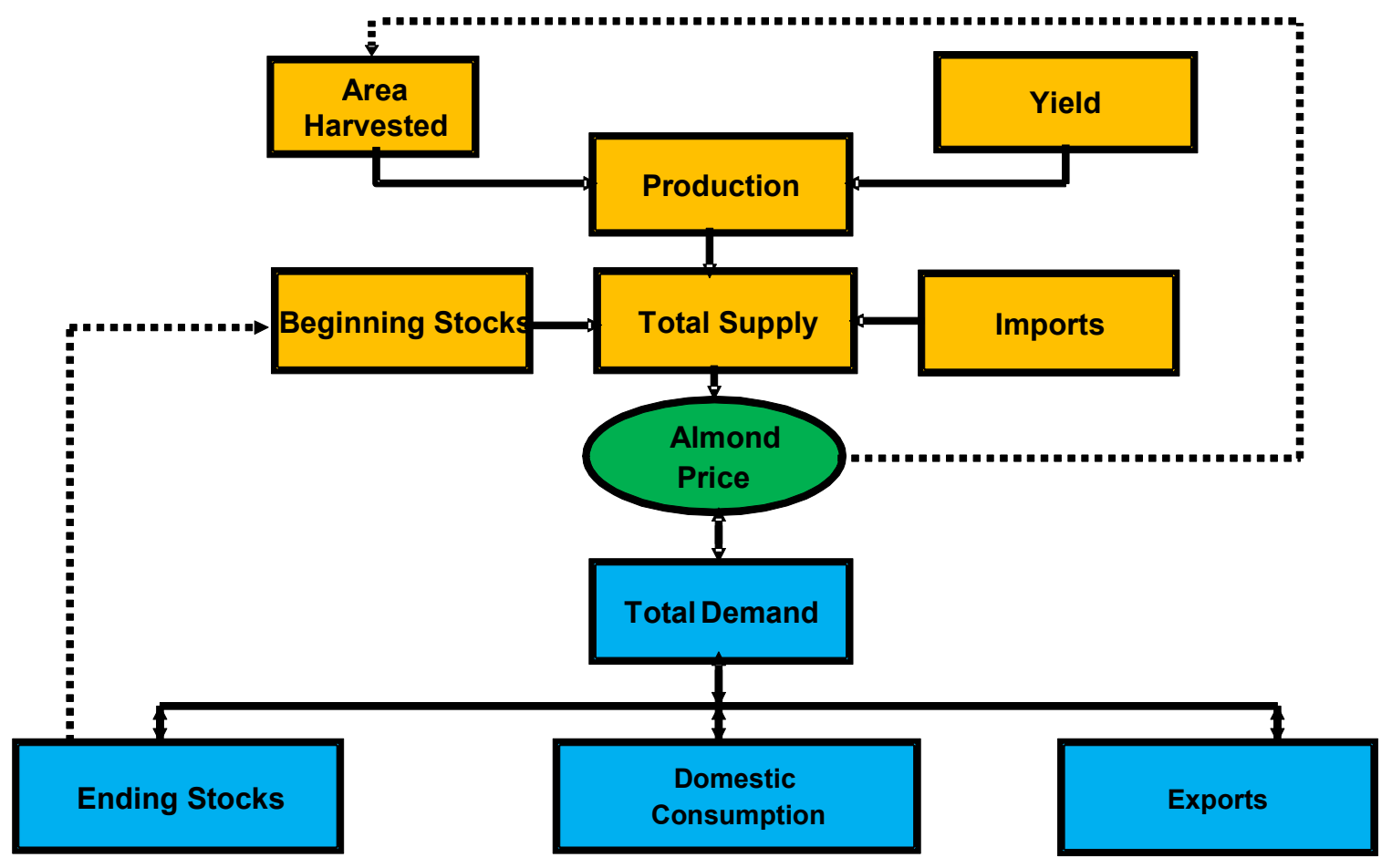

Figure 4.1: Flow diagram for the model

The structure of the almond model for a single country is represented in Figure 4.1. Country models are linked by trade where the resultant equilibrium world indicator price is the one that results in a balance between the net exports of the residual supplying country (in this case, the United States) and the net imports of all the other modeled countries and regions. 
Figure 4.2 below shows how the models are linked across countries. Beginning at the top-center of Figure 4.2 with the residual supplying country model, the model diagram starts with an assumption about the level of exports from this country. This price in the residual supply country is considered to be the world price. The world price is then translated into the local currency of each country using exchange rates, and price linkage equations that also consider any tariffs or other trade measures, transportation costs and other factors. As long as the country has reasonably open trade without any effective quantitative trade restrictions (such as import quotas), and the commodity is reasonably homogenous, the domestic price is simply a function of the world price. In none of the countries modeled here are there any significant quantitative restrictions on almond trade, so simple price-linkage equations are adequate. Domestic supply and demand in each country is a function of the domestic price, and net trade is the difference between domestic supply and demand. The net position of the country may be positive or negative depending on whether the country is a net exporter or net importer.

Once a net trade position for each country is determined for a given world price, the net positions across all countries are summed to form a new net export position for the residual supplier. The new trade position results in a new price for the residual supplier, which can then be transmitted again to all the countries, thus starting the iterative process again. These iterations continue until the model converges to where supplies equal demand worldwide as illustrated in Figure 4.2. One result of using a net trade position is that the need to estimate both import and export equations is removed. 


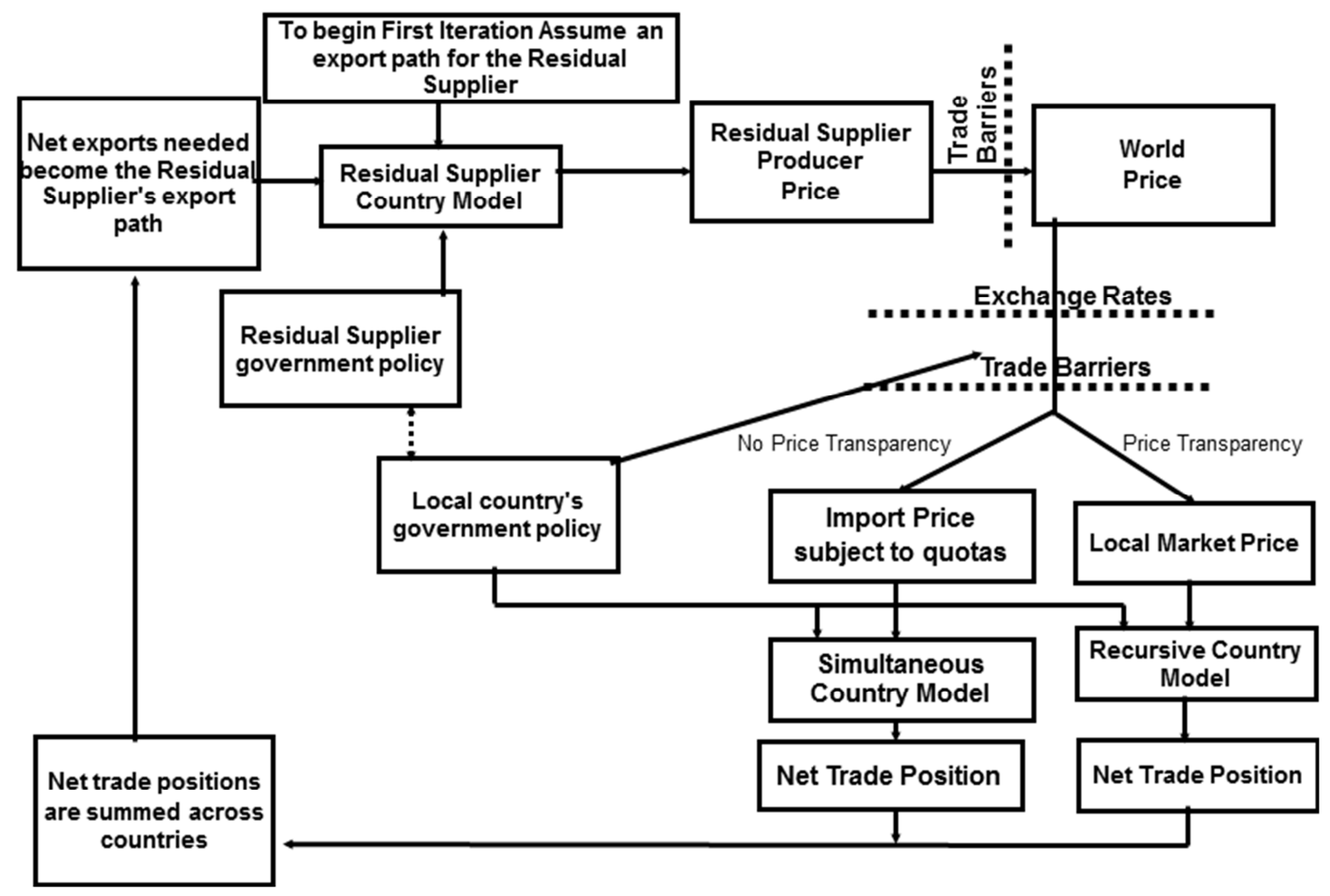

\section{Figure 4.2: Structural linkages across countries}

Source: Kruse, 2003

\subsubsection{Endogenizing pollination fees}

The model developed in Maltsbarger (2017a) included variables representing water availability that included the effect of drought, but it did not include and endogenize pollination fees to capture the impacts of CCD. The market-wide impacts of CCD on almond supply are directly related to the farm-level decisions made by Californian almond producers. Therefore, to measure the market-wide economic impacts, the farm-level impacts are first quantified. However, this is not straightforward as a counterfactual alternative (what would have happened if farmers did not face threatened ESS) and may not be easy to infer from observed data. 
One way to represent CCD in the model is called the stocking rate approach. This approach makes use of the hive stocking rate as a proxy to move from the bee to production and then to value. The stocking rate approach relies on findings from Cheung (1973) that the rental market for pollination bees is an efficient market. From this result, it becomes possible to use the number of rented hives (the link between the bee and production) and the rental fee for each hive (the link between production and value) to determine the value of bees (Muth \& Thurman 1995; Rucker, Thurman \& Burgett 2012). This framework illustrates that pollination is an input in the production of a crop, and it looks at the value-added from a specific input as a measure by how much farmers would be willing to pay for that input. This framework is based on the assumption that the value of pollination is best measured by the market price and can be observed by the rental rates. Assuming that the stocking rate approach is valid, it is used to estimate the relationship of rental rates using observed pollination services fees over time and applicable explanatory variables.

Following the stocking rate approach, the conceptual model for pollination service fees was estimated as a reduced form equation. This model is a function of a variety of relevant supply and demand related explanatory variables related to commercial honeybees following previous research (Ward, Whyte, \& James 2010; Carman 2011; Rucker, Thurman \& Burgett 2012). Let the almond pollination fees be (1) $P F_{t}=\theta_{o}+\theta_{1}$ APr $_{t}+\theta_{2} \operatorname{HPr}_{t}+\theta_{3} B_{t}+\theta_{4}$ Varroa $_{t}+\theta_{5} C C D_{t}+\theta_{6}$ Bpop $_{t}+\varepsilon_{t}$, where the $\theta$ s are the parameters to be estimated. This specification for almond pollination fees, $P F_{t}$ includes consideration for the US grower price of almonds, $A P r_{t}$, the price for honey, $\operatorname{HPr}_{t}$, almond bearing area, $B_{t}$, an indicator variable for years of Varroa mite infestation, Varroa $_{t}$, an indicator variable for years during $C C D, C C D_{t}$, and finally 
honeybee colony population, $B p o p_{t}$. These explanatory variables have been used in differing empirical models, and each has been shown to have economic importance or statistical significance at least once in previous research ${ }^{12}$.

The parameters for the explanatory variables were expected to have mixed signs largely dependent on whether they are a demand or supply side factor. The first parameter $\theta_{1}$ is for almond prices and was expected to have a positive sign. As increased almond prices increase the value of almond production and thus of pollination services. The second parameter $\theta_{2}$ for the price of honey was expected to have a negative sign. Beekeepers contractually get to keep all of the honey generated as coproduct when pollination services are provided. Higher honey prices increase beekeeper revenue, so they can afford to charge less for pollination services. The sign on the third parameter $\theta_{3}$ for the almond bearing area was expected to be positive. As bearing area increases the demand for more colonies to pollinate the trees on those acres also increases. The expected signs for Varroa mite infestation $\theta_{4}$ and $\operatorname{CCD} \theta_{5}$ were both expected to be positive as each represents a threat to honeybee populations thereby potentially decreasing the supply of bees available in the representative years. The last parameter $\theta_{6}$ for honeybee population is expected to be negative as it has an inverse relationship to pollination fees. A reduction in the numbers of colonies is expected to limit the supply of bees available for pollination services.

\footnotetext{
${ }^{12}$ Interestingly, no competing crop pollination fees such as plums or early cherries, which both have overlapping pollination timing with almonds have been included as a cross price in previous examinations. It has been reported that, "pollination revenue from almonds made up more than $90 \%$ of California pollination and more than $80 \%$ of all pollination income nationwide" (Lee et al. 2017, p. 2). With almonds representing the majority of pollination fees in California, it is assumed that competition from these other crops with overlapping pollination timing are minor and have provided little in the way of competition for commercial pollinators for almonds. These other pollination fees, similar to previous studies were therefore ignored as economically important explanatory variables for this examination.
} 
Generally, contracted pollinators produce sellable honey from what is collected during the pollination window for each crop. This honey is an added benefit to the commercial pollination services as mentioned above in addition to the pollination fee. However, for almonds the honey produced is bitter and is not a sellable product. Consequently, honey prices have either been ignored or dropped in the model specifications (Ward, White \& James 2010; Carman 2011) or shown to be statistically insignificant (Rucker, Thurman \& Burgett 2012). In this examination honey prices were also found to be statistically insignificant and decreased the explanatory power of one or more variables when included and was dropped from the final specification.

In pre-testing, the honeybee population variable was also found to be statistically insignificant, and it also reduced the explanatory power of the other variables. In part this may be attributed to the fact that the indicator variables for Varroa mite infestation and CCD have colony supply affects. Also, it is important to point out that even though CCD had a negative impact on total colony populations between 2005-2008, colony numbers have increased since 2008 (USDA-NASS 2015). The resilience of total colony population numbers even during years of higher colony mortality from $\mathrm{CCD}$, may be attributed to the ability of commercial beekeepers to aggressively offset colony losses through common methods of splitting and creating new hives (Rucker \& Thurman 2012). Also, as annual colony numbers are the result of endogenously determined factors, the supply of honeybees, or annual colony totals, do not necessarily only represent the impacts or costs of higher mortality but also revenues associated with combined pollination fees and honey returns, it was therefore expected that using it as an explanatory variable may not be useful in this context. Despite this expectation the inclusion of honey bee colonies was tested as an alternative specification as it was included in one almond pollination fee 
model (Ward, White \& James 2010), although their resultant p value was 0.0897 , which may not have met other authors' statistical significance thresholds.

During estimation the almond price was found to be statistically insignificant. It is possible that the cause for this is that a fixed number of colonies are necessary to sufficiently pollinate orchards, and that the de facto stocking density is relatively stable over time. Evidence from tests by Rucker, Thurman \& Burgett (2012) implied that stocking densities are constant by commodity with respect to crop prices. Also, across costs of production surveys for almonds from the Agricultural and Resource Economics Department at UC Davis (UCDAVIS 2015) it was consistently assumed that between 2 and 3 hives were necessary to pollinate mature orchards implying a relatively stable stocking density over time. As almond prices were statistically insignificant and as it was assumed that the stocking density for almonds was relatively stable and this variable was dropped in the final specification.

One challenge with parsing out the influence of CCD and Varroa mite infestation on pollination fees is that surveys measuring winter colony losses by the USDA did not start until winter 2006/2007. This is up to two winters after CCD began having an influence on colonies and pollination fees and numerous years after the beginning of the impact of Varroa mites. The series for winter losses is thereby truncated and not necessarily representative of either the Varroa mite issue or CCD related mortality. This limited the efficacy of testing a continuous variable to measure the historical influence on pollination fees.

Despite the weakness of the winter loss data, this data series was still tested in an alternative specification, where the years prior to the survey were assumed to have an average reported loss of $14 \%$ (Burgett et al. 2009). When this series for winter losses was 
included, the coefficient on the indicator variable for Varroa mites had an unexpected negative sign and was statistically insignificant. It is likely that a longer time series representing colony losses would be the most effective at representing the impacts of Varroa mites and CCD on pollination fees, although without this complete time series the final specification used here was similar to Rucker, Thurman \& Burgett (2012) where indicator variables were used to proxy both.

It is important to note that CCD in regression results in Table 4.1 below was represented as two separate indicator variables instead of one. The indicator for 2005 captured the more modest impact at the beginning of CCD on almond pollination fees, whereas the second indicator variable for 2006 through the 2015 represented the larger impact. It is possible that the average almond pollination fee did not rise as dramatically in the first year of CCD as some rental contracts may have already been negotiated, or perhaps colony mortality was not as extreme but still above average in the first winter.

\section{Table 4.1: OLS analysis of almond pollination fees}

\begin{tabular}{lcccc}
\hline Variables & Coefficient & SE & P-value & Elasticity* \\
\hline Almond bearing area & 0.107 & 0.011 & $<0.0001$ & 0.836 \\
Varroa mite indicator 1991-2015 & 5.989 & 2.005 & 0.0055 & 0.061 \\
CCD indicator 2005 & 20.012 & 4.668 & $<0.0001$ & 0.008 \\
CCD indicator 2006-2015 & 83.910 & 3.875 & $<0.0001$ & 0.342 \\
Intercept & -16.824 & 4.579 & 0.0009 & \\
\hline R-square & & & & \\
\hline
\end{tabular}

The pollination fee model was estimated in OLS. The regression results for the final specification of almond pollination fees are reported in Table 4.1. Coefficients in all explanatory variables had the expected signs and were statistically significant. The R- 
square of 0.995 suggested a strong fit, and was at the high side of pollination fee literature reviewed ${ }^{13}$.

\subsubsection{Calculating producer welfare}

The conceptual model used to calculate producer welfare impacts follows that of Just, Hueth and Schmitz (2004). The conceptual model equates producer welfare with producer surplus. Producer surplus can be calculated a number of ways. The simplest method measures the profit change when a price and quantity shift occur.

Theoretically, it is assumed that marginal costs are perfectly measurable. For the case of the US almond industry this is not the reality. Costs and returns surveys provide a number of costs associated with producing almonds. These surveys include variable production costs as well as diverse capital investment costs, and generate estimates of average costs for a representative farm. True marginal costs for the firm are not measured, but a method provided by Just, Hueth and Schmitz (2004) can measure producer welfare under a price change using average variable costs for the representative firm. This producer welfare calculation equates producer surplus with a quasirent calculation. Quasirent is measured by subtracting total variable costs (TVC) from total revenue (TR).

\footnotetext{
${ }^{13}$ Additional tests were executed including incorporating a trend when using the nominal almond pollination fees as the dependent variable and using deflated almond pollination fees. The final specification had the best combination of fit and statistical significance across explanatory variables.
} 


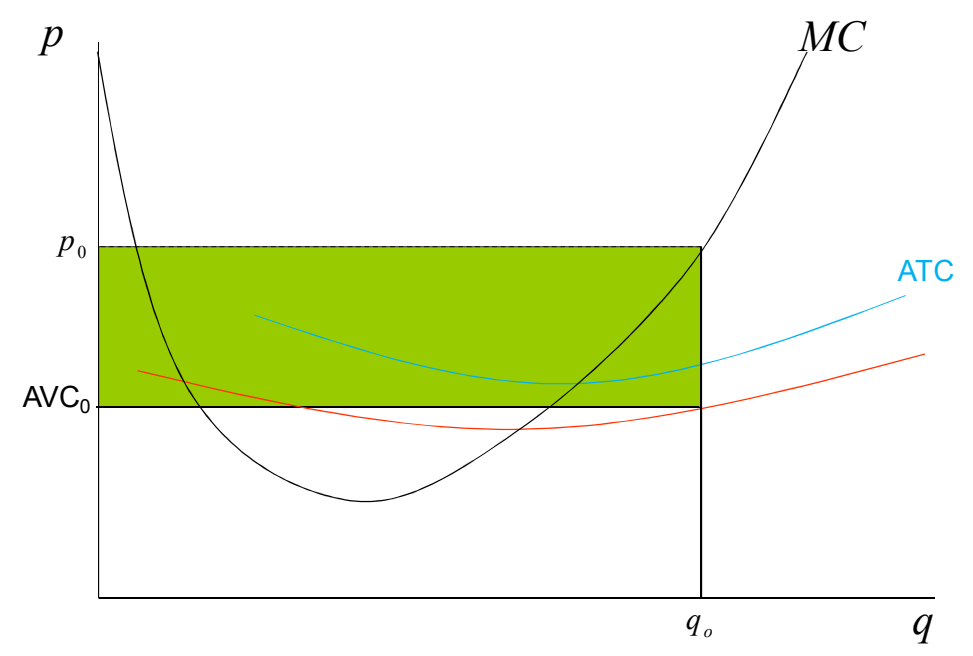

Figure 4.3: Calculating quasirent/producer surplus using average variable costs

In Figure 4.3 total revenue is equal to the price at $\mathrm{p}_{\mathrm{o}}$ multiplied by the quantity at $\mathrm{q}_{\mathrm{o}}$ with TVC being equal to average variable costs (AVCo) also multiplied by the quantity at $\mathrm{q}_{\mathrm{o}}$. Subtracting TVC from TR is represented in the shaded area.

Using this calculation for producer welfare (e.g. quasirent, producer surplus) the producer surplus for separate states can be calculated. Comparing these states provides estimates of the positive or negative shift in producer welfare. Following this approach the welfare change will be calculated for the counterfactual scenario in comparison to the historical state. Let the change in producer welfare measure be (2a) $\Delta P S=\left\{\left(P_{1}\right) Q_{1}-\left(V C_{1}\right) Q_{1}\right\}-\left\{\left(P_{0}\right) Q_{0}-\left(V C_{0}\right) Q_{0}\right\}$, where the change in producer surplus $\triangle P S$ is the difference between the counterfactual scenario's producer surplus and the baseline producer surplus. The producer surplus for each state is the difference of total average costs from total revenue where $P_{1}$ is the counterfactual price, $P_{0}$ is the actual price, $Q_{1}$ is the counterfactual production quantity, 
$Q_{0}$ is the actual production quantity, $V C_{1}$ is the counterfactual average variable costs and $V C_{0}$ is the actual average variable costs.

The data sources used as detailed in the next section both provided revenue and costs on a per acre basis. To illustrate this idiosyncrasy of the data, equation (2a) is transformed into (2b). To capture total producer surplus change using per acre revenue and per acre costs let the change in producer welfare be (2b) $\Delta P S=\left[\left\{\left(P_{1}\right) Y l d_{1}-\left(V C_{1}\right)\right\} * B A_{1}\right]-\left[\left\{\left(P_{0}\right) Y l d_{0}-\left(V C_{0}\right)\right\} * B A_{0}\right]$, where the change in producer surplus $\triangle P S$ is the difference of the counterfactual scenario's producer surplus from the baseline producer surplus. The producer surplus for each state is the difference of total average costs from total revenue where $P_{1}$ is the counterfactual price per unit of weight, $P_{0}$ is the actual price per unit of weight, $Y l d_{1}$ is the counterfactual production quantity per bearing acre, $Y l d_{0}$ is the actual production quantity per bearing acre, $B A_{1}$ is the counterfactual total bearing acres, $B A_{0}$ is the actual total bearing acres, $V C_{1}$ is the counterfactual average variable costs per acre and $V C_{0}$ is the actual average variable costs per acre.

A weakness in the application of this approach is that as quantities change variable costs per unit should also change. As illustrated in Figure 4.3 the red line, representing average costs, would at varying quantities shift higher or lower along the line. The average costs given by the data source provide only snapshots of average costs across time at unreported levels of quantity given a sample of producers from their survey results. With the weakness of the data for this analysis, the costs outside of pollination fees were left fixed at historic average per acre levels. This adds a cost bias based on the historical reference into the system. Assuming that historical quantities and costs may be represented by the intersection of $q_{0}$ and $A V C_{o}$ in Figure 4.3, an increase in q should 
increase the average costs per unit as q shifts right along the red line. For example consider harvest costs that include activities such as shake, sweep and rake, pick-up and hauling as well as hulling and shelling nuts, all of which would be influenced by the quantity of nuts harvested. As yields increases per acre the costs to perform all of the harvesting activities to handle more nuts would be expected to rise on a per acre basis. In this study only one cost is endogenized (pollination fees) and allowed to change per unit in this system on a per acre basis. This would mean in some scenarios like in this example of more yield per acre, any producer surplus improvement would be overstated.

\subsection{Data}

The data and procedures underlying the bulk of this examination are defined more thoroughly in Maltsbarger (2017a). The references to data and procedures here provide a brief overview of sources with the more detailed explanations included for applicable data and procedures specific to the producer welfare analysis.

The data for total US acreage, plantings by vintage and grower prices were used as reported by the USDA's National Agricultural Statistic Service with the US utilization and trade data from the USDA's Production, Supply and Distribution online database (USDA-NASS 2015; USDA-FAS 2016). US cost of production data were derived from almond cost and return studies collected from the Agricultural and Resource Economics Department at UC Davis with numerous studies from 1980 to 2012 (UCDAVIS 2015). The proxy for water availability variable was derived from the Palmer Drought Severity Index (PDSI) provided by the National Oceanic and Atmospheric Administration (NOAA) Satellite and Information Service (NDMC 2017). The source for supply and utilization and price data for most countries outside the US was the Food and Agriculture 
Organization of the United Nations (FAO) from their online database FAOSTAT. Other price sources included the European Commission's online database (Eurostat), the USDA's Foreign Agricultural Service Global Agricultural Trade System Online (GATS) and Global Trade Information Services online database (GTIS). Also, all underlying macroeconomic data was from USDA and incorporated the International Macroeconomic Data Set (USDA-ERS 2015).

Producer surplus is proxied by multiplying net revenue per acre by the total bearing acres in each year. A challenge with using cash costs as the proxy for total average costs is that what is included as average variable costs may differ across sources. Understanding this may mean that net revenues may be either over or understated. Attempts were made to include only cash type costs as defined in the cost and returns studies from Agricultural and Resource Economics Department at UC Davis with the assumption made that those cash costs included are a reasonable proxy for average variable costs for Californian almond producers.

The Californian pollination fees were primarily from the Californian State Beekeepers Association (CSBA). The data used from CSBA was for the average almond pollination fees per hive based on their internal annual survey results with the reporting timeframe from 1995-2015. For years prior to 1995 almond cost and return studies from the Agricultural and Resource Economics Department at UC Davis were used to calculate the average pollination fees per hive (UCDAVIS 2015). The cost and return studies provided a pollination expense per acre with an assumed average pollination density. For the majority of contemporary studies, 2.5 hives per acres was the provided assumption. The pollination fee per hive was multiplied by the average 2.5 stocking density to estimate average pollination fees per acre. 


\subsection{Counterfactual assumptions}

The historical counterfactual scenario was designed to represent a world where CCD and the recent extreme drought event did not occur. To estimate the impacts if there had been no drought, the PDSI and extreme drought variables are set to zero for the 2011/12 to 2015/16 period instead of their actual historical values. The PDSI has the value of zero when conditions are neither wet nor dry. Both CCD indicator variables are also set to zero to reflect a scenario with no CCD.

The estimated model equations imply that the yields of almonds were influenced by water availability, but pre-testing indicated that the CCD variables did not have a statistically significant impact. On one hand as noted in Alston et al. (1995) and Maltsbarger (2017a), slightly drier than average flowering years had improved impacts on yields attributed to better pollination efficacy where bees were not hindered by precipitation. On the other hand, more extreme drought conditions were shown to have an increasingly negative impact on yields (Maltsbarger 2017a). This means in any given year where PDSI is shifted to zero yields may be positively or negatively influenced depending on the initial historic PDSI value.

With the exception of pollination rental fees, other variable cash costs of production per acre were held at the historical levels for this scenario. Also, all macroeconomic factors were held exogenous and at historic levels. Endogenous variables for each modeled country include production, trade, consumption and stock holding where applicable. These supply and demand factors determine equilibrium prices as described in the partial equilibrium modeling framework above. The counterfactual scenario was solved for the time period of 2005/06 through $2015 / 16$. The baseline reflects 
actual US supply and utilization data for the entire period. For other countries the baseline reflects actual historical data for 2005/06 to 2013/14, with a modeled solution for $2014 / 15$ and $2015 / 16$.

\subsection{Simulation results}

Total producer surplus is estimated for each year using equation (2b). Results are summarized in Table A.4.4, A.4.5 and A.4.6 in the appendix with producer surplus comparisons to the baseline illustrated in Figure 4.4. For Californian almond producers the total actual, or historical, producer surplus between 2005/06 through 2015/16 exceeded $\$ 20$ billion. The estimated sum during the same timeframe under the historical simulation without CCD (2005/06 through 2015/16) and without the influence of the extreme drought (2011/12 through 2015/16) was $\$ 19.4$ billion. The top line results indicate that the combination of CCD and extreme drought had a net positive producer surplus impact of approximately $\$ 656$ million.

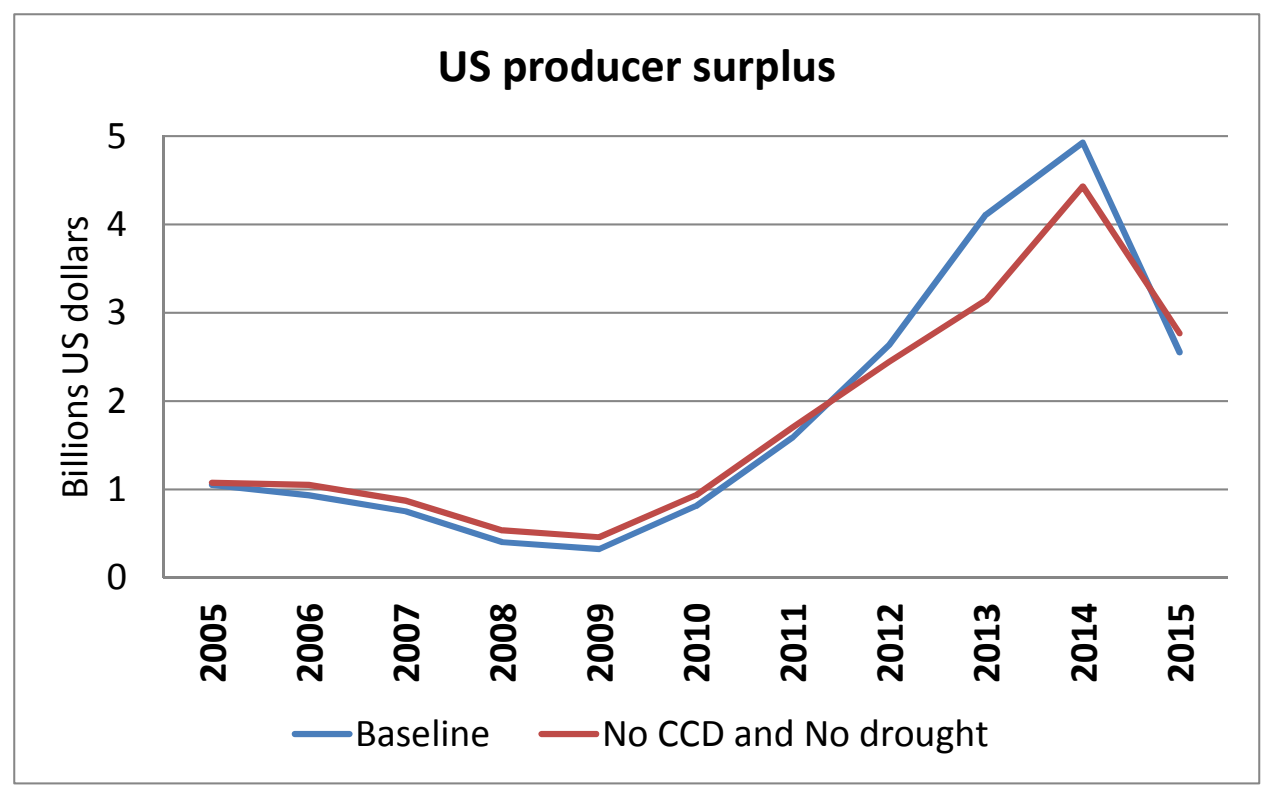

Figure 4.4: US producer surplus comparison to baseline with CCD and drought 
Results of this counterfactual simulation suggest that CCD and drought were a net benefit to Californian almond producers. Upon closer examination and as observed in Figure 4.5 select years of the simulation led to higher producer surplus while in other years producer surplus was lower than the baseline. To clarify these annual variations additional analysis was necessary. To parse out the differing effects of CCD and drought two additional historical simulations were developed. First, an alternate no-CCD only simulation was run retaining historical PDSI numbers. Following, another alternative simulation was run as a no-drought only scenario where PDSI was set to zero in each of the years from 2011/12 through 2015/16 and CCD remained.

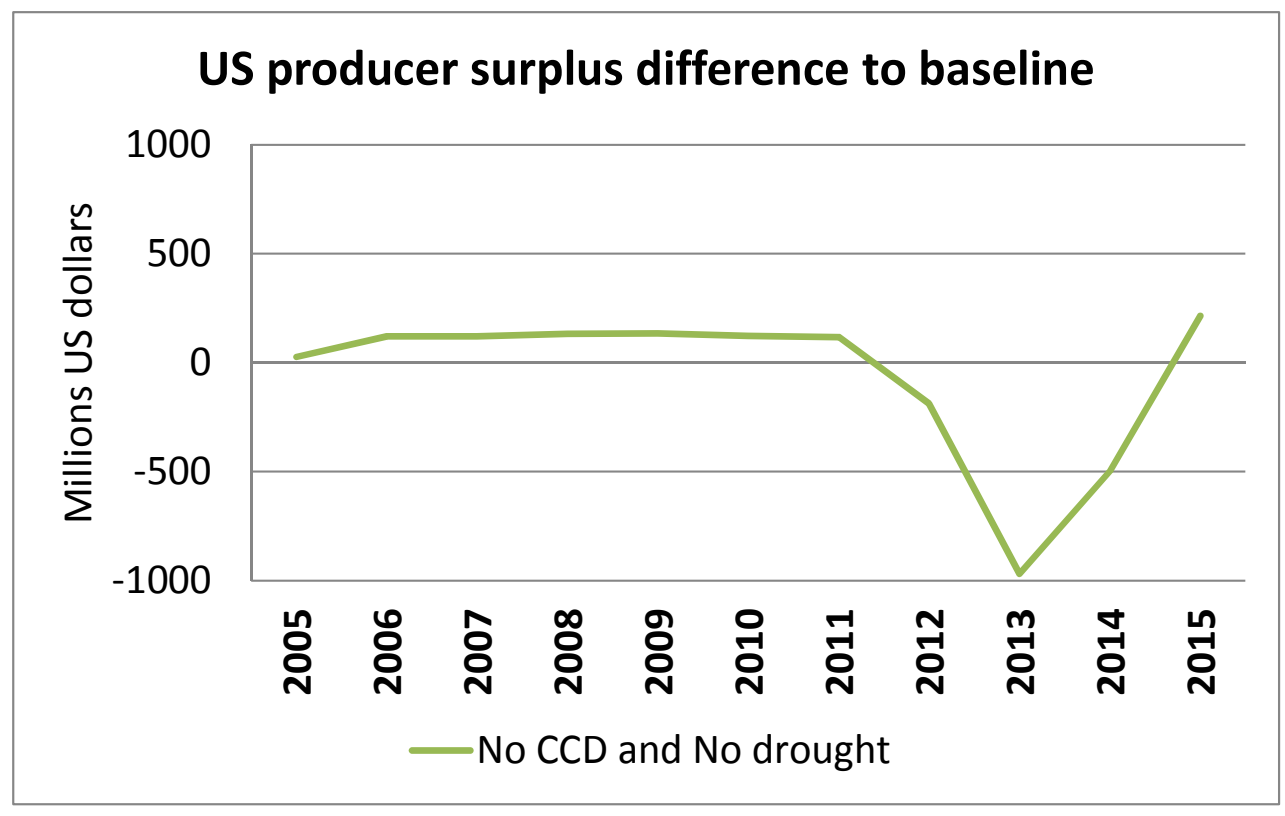

Figure 4.5: US producer surplus difference from the baseline with CCD and drought

In the first alternative, the no-CCD only simulation, it was observed that by itself the removal of CCD increased US almond producer surplus by $\$ 730$ million from 
2005/06 through 2015/16. As illustrated in Figure 4.6 producer surplus was higher through the beginning of the time period converging toward the baseline about 2011/12. The simulation results imply that the economic cost of CCD to US almond producers averaged $\$ 66$ million per year since the beginning of CCD in 2005. Even without a direct influence of CCD on aggregate US almond yields, this estimate suggests that the CCD phenomenon has been an economic cost to US almond farmers.

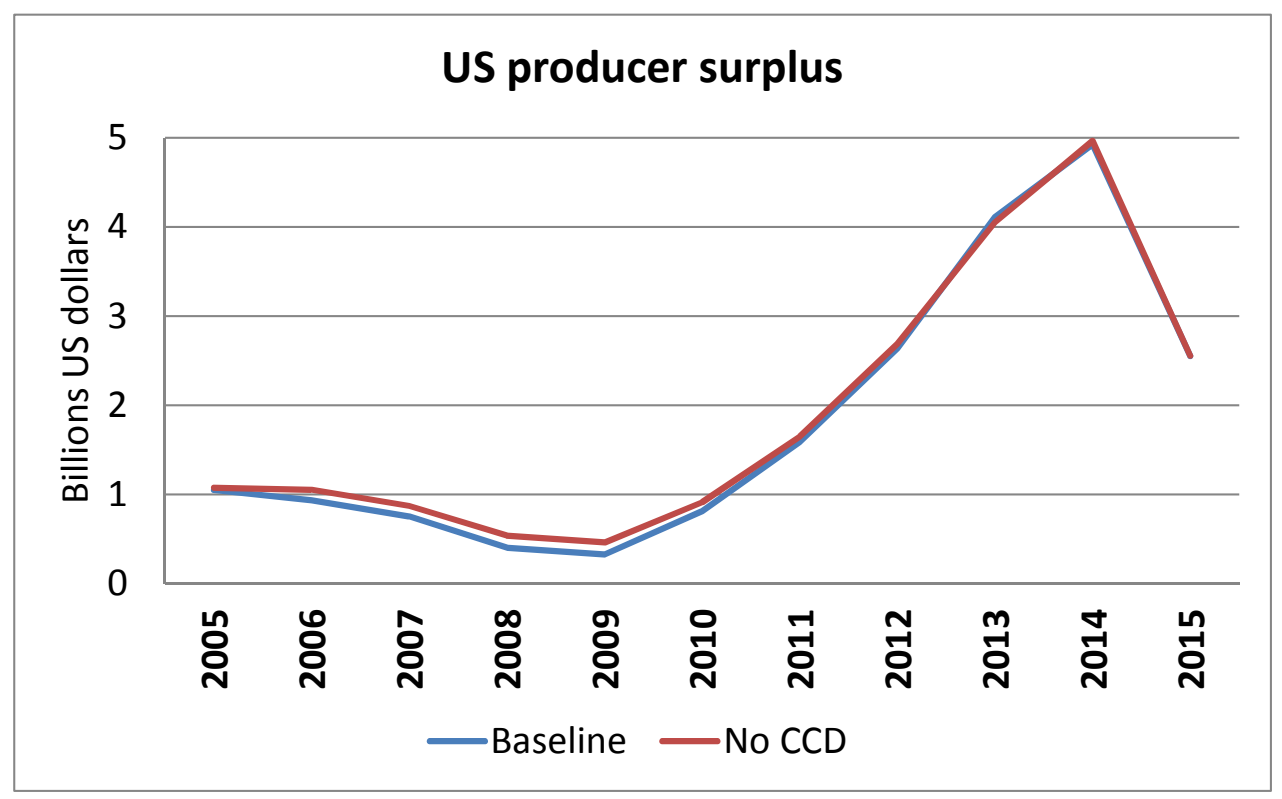

Figure 4.6: US producer surplus comparison to baseline with CCD

Model results indicate that $\mathrm{CCD}$ increased almond pollination fees by an average of $110 \%$ between 2005 and 2015. Despite the large hike in this cost, pollination fees remained a small share of almond cash costs. Prior to $\mathrm{CCD}$, almond pollination fees represented an average of $6 \%$ of total cash costs from 1980 to 2004 . By 2006 the almond pollination fee per hive was $160 \%$ that of the 2004 level. With this substantial price hike, the share of pollination fees of total cash costs increased to average 14\% for 2006-2015. 
Even without CCD the estimated share of pollination fees to cash costs by 2015 was estimated at $9 \%$, as increasing almond area continued to drive the simulated fees higher.

The reduced pollination fees in the simulation had a direct influence on almond costs of production as the removal of CCD improved net returns. This improvement in returns was partially offset as the simulated reduction of costs leant itself to improved returns and increased area through lowered removals and expanded plantings, consequently increasing production. As US almonds faces an inelastic excess demand (Maltsbarger 2017b), the increase in production led to a proportionally larger reduction in price reducing the revenue side of producer surplus. When combined, the reduction in the no $\mathrm{CCD}$ simulation was greater than the reduction in revenues, increasing producer surplus.

In the second alternative, no-drought only simulation, the removal of drought decreased US almond producer surplus by $\$ 1.3$ billion, illustrated below in Figure 4.7. The simulation results imply that the economic benefit of drought to US almond producers was $\$ 273$ million per year when averaged across the five years of drought. Despite being a shorter timeframe of influence the no-drought simulation results were more variable with larger changes from baseline than in the no-CCD scenario simulation results. 


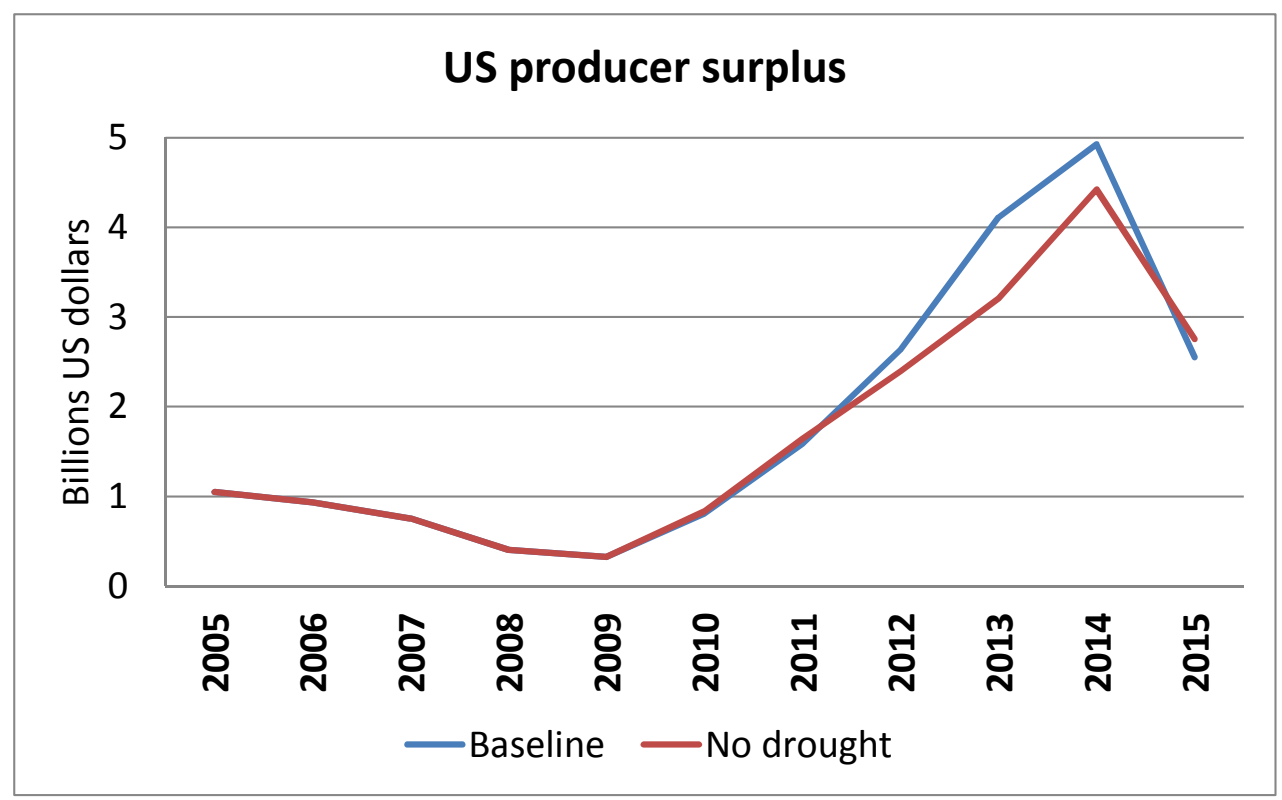

Figure 4.7: US producer surplus comparison to baseline with drought

The direct effect of shifting PDSI to zero from 2011/12 and ending 2015/16 led to improved yields in two years (2013/14 and 2014/15) and decreased yields in the other three years. As discussed previously, drier years improve pollination efficacy, increasing yields, but overly dry years have an increasingly negative impact on yields. Setting, PDSI to zero shifted dry years to neutral years. Simulated yields decreased in the counterfactual scenario when the baseline PDSI had implied a more modest drought. However, in cases of extreme drought in the baseline (a PDSI of -4 or more negative), yields in the no drought scenario increased. Also, despite the effect of a decline to yields from the baseline in 2015/16, production still increased in that year as a positive bearing area change more than offset the yield reduction.

For the 2011-2015 period as a whole, production in the no-drought scenario exceeded baseline values by $3.3 \%$. Considering that the US almond market faces an inelastic excess demand elasticity (Maltsbarger 2017b), the increase in US yields and 
thereby production was met with a larger proportional reduction in almond prices. As a result producer revenues shifted lower as the reduction in price more than offset the increase in production causing a fall in producer surplus when comparing the no-drought scenario to the baseline as can be seen in tables A.4.4, A.4.5 and A.4.6 in the appendix. The results from the no-drought only simulation indicate that at the aggregated state level, farmers were better off as a result of the extreme drought, despite individual cases where farmers may have been economically burdened.

The concert of the more modest improvement to producer surplus by removing CCD combined with the larger decline in producer surplus especially between 2012/13 and 2014/15 by removing the drought drove the sum of producer surplus to decline across the timeframe under the combined counterfactual scenario. The summed net effect of the counterfactual scenario was that the difference of the proportional decrease in revenue was more than the proportional reduction in production costs as illustrated in Figure 4.8.

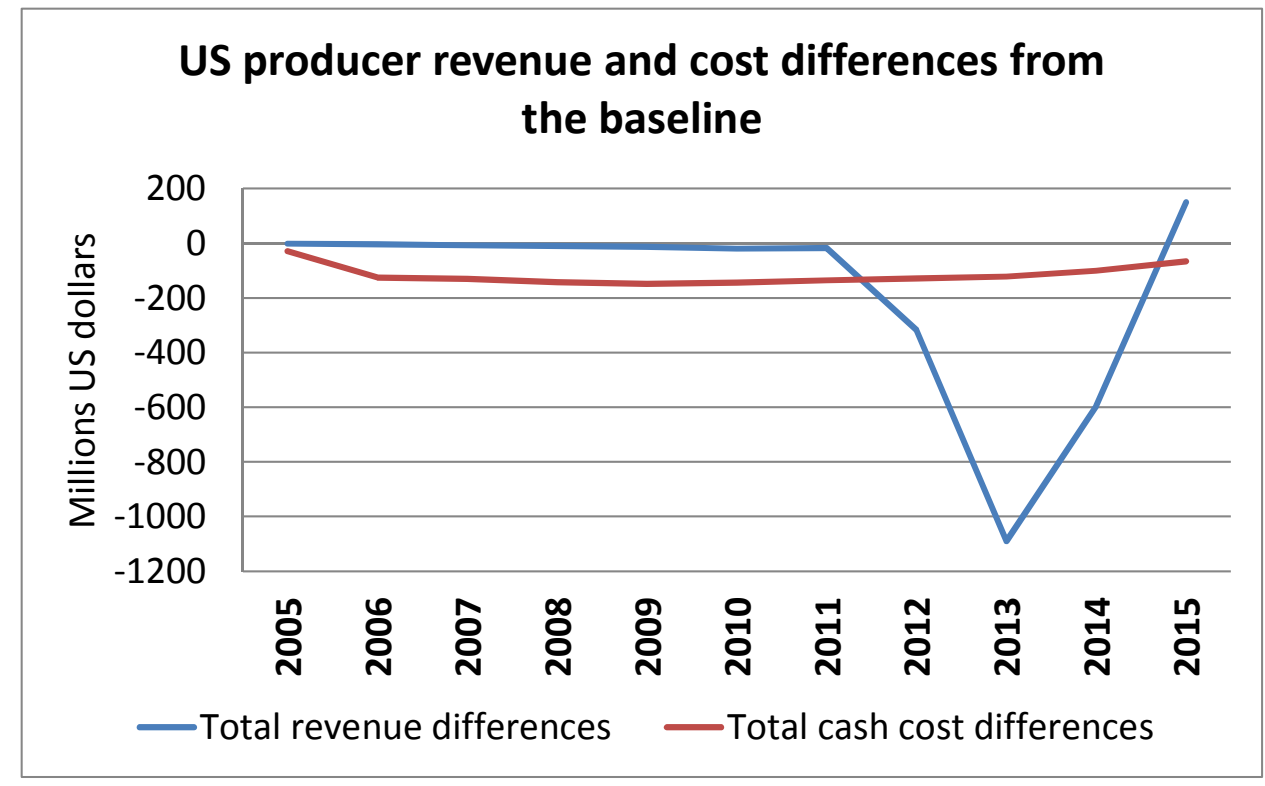

Figure 4.8: US producer revenue and cost differences from the baseline with CCD and drought 
It is important to note that all the estimated changes to producer surplus here primarily reflect the private gains or losses revealed by market transactions. These calculations do not explicitly estimate non-market effects associated with changes to the environment including any additional positive or negative externalities resulting from changes in commercial honeybee populations or changes in irrigation water sourcing ${ }^{14}$. Any externalities are not explicitly involved in farmers' private costs as included in the modeling system. Social costs and benefits could potentially be added to the private measures calculated in this study and become an extension for future research.

\subsection{Conclusion}

It is common for ESS studies to examine yield impacts whether from drought, climate change, pollination services, etc. as a benchmark to evaluate economic impacts when these ESS may be threatened or constrained. A challenge is that aggregate yield impacts may be muted leaving the eco-economic influences of individual ESS opaque. In this study yield estimates were influenced directly by a measure of water availability as detailed in Maltsbarger (2017a), and although CCD was not found to have a statistically significant influence on almond yields, pollination fees were found to be affected by CCD. Incorporating influences of both drought and CCD into a structural, partial equilibrium model of the global almond market, allowed for counterfactual, historic

\footnotetext{
${ }^{14}$ On one side producers may be seen as generating positive externalities by adding commercial pollinators during the spring and helping local flora and other early blooming commercial crops within the honeybees foraging range. Producers may also be seen as helping percolation in their local water basin by adding irrigation water from outside basin sources. On the other side negative externalities may exist as the addition of commercial pollinators may crowd out wild pollinators competing in limited foraging areas. Also, irrigation water may over tax groundwater resources limiting future water quality and water availability as well as increase subsistence and temporally limit surface water supplies that may be used by other sectors including environmental needs such as endangered river fauna.
} 
simulations to be estimated to calculate the producer surplus influences of these two threatened ESS.

This study therefore examined economic welfare impacts of colony collapse disorder (CCD) and extreme drought on US almond producers across the last decade. The analysis identified economic benefits of limited water availability from the extreme drought, and an economic burden from CCD. The largest effects were across the three years from 2012/13 through 2014/15 with the net difference to US almond producers across the whole time period amounting to a positive change of $\$ 656$ million in added producer surplus. This surplus difference was largely attributed to a combination of the effects from decreased US almond production attributed to water availability constraints and an inelastic excess demand facing the US almond market. In this case the implication is that the drought had increased producer surplus, because almond prices increased proportionally more than production was reduced.

The measured benefits to US almond producers may be overstated. First, walnut prices as a competing crop for land was held at historical levels. If walnuts are assumed to also be influenced by market changes historically then walnut price as an opportunity cost for land may become more or less competitive and affected land use changes in the simulations. Also, actual water costs are not measured directly, as only pumping and labor costs of irrigation are included in the data source. PDSI was included as a proxy for water availability, which may be implicitly assumed to represent an expected cost of water, whereas any actual water costs may have had a larger impact on farmer returns not captured by the simulation. Also, the environmental value or opportunity cost of water resources diverged from other uses, and other non-pecuniary impacts are not estimated. For these reasons the estimated costs and benefits to producers may not constitute a full 
accounting of the economic impacts of $\mathrm{CCD}$ and drought on California almond farmers for the period of analysis. Future research could improve these estimates by firming up accounting measures for water costs and considering other positive or negative externalities from both water availability and pollination.

\subsection{References}

Alston, J. M., Carman, H. F., Christian, J. E., Dorfman, J., Murua, J.-R., \& Sexton, R. J. (1995, February). Optimal Reserve and Export Policies for the California Almond Industry: Theory, Econometrics and Simulations. Giannini Foundation Monograph, 42, 1-130.

Alston, J. M., Kalaitzandonakes, N., \& Kruse, J. (2014). The Size and Distribution of the Benefits from the Adoption of Biotech Soybean Varieties. In Handbook on agriculture, biotechnology and development (pp. 728-751).

Brown, S., Madison, D., Westhoff, P., Binfield, J., Kruse, J., Meyers, S., et al. (2009). Undertanding Agricultural Models in the Classroom-Current US Agricultural Models: Corn, Soybeans, Wheat, Beef, Pork, Poultry. Food and Agricultural Policy Research Institute. Columbia, Missouri: University of Missouri.

Burgett, M., Rucker, R., \& Thurman, W. (2009, June). Honey Bee Colony Mortality in the Pacific Northwest (USA). American Bee Journal, 149(6), 573-575.

California State Beekeepers Association. (2016). Retrieved February 2016, from Resources \& Swarms Info: http://www.californiastatebeekeepers.com/news.html

Carman, H. (2011). The Estimated Impact of Bee Colony Collapse Disorder on Almond Pollination Fees. ARE Update University of California Giannini Foundation of Agricultural Economics, 14(5), 9-11.

Cheung, S. N. (1973). The Fable of the Bees: An Economic Investigation. Journal of Law and Economics, 16(1), 11-33.

Devadoss, S., Westhoff, P., Helmar, M., Grudmeier, E., Skold, K., Meyers, W. H., et al. (1989). The FAPRI Modeling System at CARD: A Documentation Summary. Ames, Iowa: Iowa State University.

FAPRI. (2004). Documentation of the FAPRI Modeling System. University of Missouri. Columbia, Missouri: FAPRI-UMC. 
Grafton, R. Q., Libecap, G., McGlennon, S., Landry, C., \& O'Brien, B. (2011). An Integrated Assessment of Water Markets: A Cross-Country Comparison. Review of Environmental Economics and Policy, 5(2), 219-239.

Harter, T., \& Dahlke, H. E. (2014). Out of Sight but not Out of Mind: California Refocuses on Groundwater. California Agriculture, 68(3), 54-55.

Heim, R. (2014, September 30). Weekly Weather and Crop Bulletin. Retrieved September 30, 2014, from U.S. Drought Monitor: http://droughtmonitor.unl.edu/

Just, R. E., Heuth, D. L., \& Schmitz, A. (2004). The Welfare Economics of Public Policy: A Practical Approach to Project and Policy Evaluation. Northampton, Massachusetts, USA: Edward Elgar.

Kremen, C., Daily, G. C., Klein, A.-M., \& Schofield, D. (2008). Inadequate Assessment of the Ecosystem Service Rationale for Conservation: Reply to Ghazoul. Conservation Biology, 22(3), 795-798.

Kruse, J. R. (2003). A Structural Model of the International Oilseed Sector: An Econometric Investigation. Columbia, Missouri: University of Missouri.

Lee, H., Champetier, A., Sumner, D. A., \& Bond, J. (2017). Bee-conomics Revisited: A Decade of New Data is Consistent with the Market Hypothesis. Giannini Foundation of Agricultural Economics, UC. Agricultural and Resource Economics Update, 20(5), 1-4.

Levin, M. D. (1984). Value of Bee Pollination to United States Agriculture. American Bee Journal, 124(3), 184-186.

Maltsbarger, R. D. (2017a). Does a Threatened Ecosystem Service Influence Perennial Farmer Investment Decisions? In Unpublished doctoral dissertation. University of Missouri-Columbia, MO.

Maltsbarger, R. D. (2017b). Excess Demand Elasticity of US Almonds. In Unpublished doctoral dissertation. University of Missouri-Columbia, Missouri.

Morse, R. A., \& Calderone, N. W. (2000). The Value of Honey Bees as Pollinators of US Crops in 2000. Bee Culture, 128(3), 1-15.

Muth, M. K., \& Thurman, W. N. (1995). Why Support the Price of Honey? The Magazine of Food, Farm \& Resources, 10(2), 13-17.

National Oceanic and Atmospheric Administration Satellite and Information Service (NOAA). (1981-2015). Retrieved 2016, from Divisional output indices: www7.ncdc.noaa.gov/CDO/CDODivisionalSelect.jsp 
Rodriguez, R. (2014, January 18). San Joaquin Valley Farmers Take Drastic Measures to Deal with Drought. FresnoBee.com.

Rucker, R. R., \& Thurman, W. N. (2012). Colony Collapse Disorder: The Market Response to Bee Disease. Property and Environment Research Center. Boseman, Montana: PERC.

Rucker, R. R., Thurman, W. N., \& Burgett, M. (2012, July). Honey Bee Pollination Markets and the Internalization of Reciprocal Benefits. American Journal of Agricultural Economics, 956-977.

SGM Sustainable Groundwater Management. (2015). Retrieved from CA.gov: http://www.water.ca.gov/groundwater/sgm/index.cfm

Sumner, D. A., Matthews, W. A., Medellin-Azuara, J., \& Bradley, A. (2014). The Economic Impacts of the California Almond Industry. University of California Agricultural Issues Center.

U.S. Department of Agriculture. (2015). Economic Research Service (ERS). Retrieved 2016, from International Macroeconomic Data Set: http://www.ers.usda.gov/dataproducts/international-macroeconomic-data-set/

U.S. Department of Agriculture. (2015). National Agricultural Statistics Service (NASS). Retrieved 2016, from Quick_Stats: https://www.nass.usda.gov/Quick_Stats/

U.S. Department of Agriculture. (2016). Foreign Agricultural Service (FAS). Retrieved 2016, from PS\&D: https://apps.fas.usda.gov/psdonline/

U.S. Department of Agriculture. (2017). United States Drought Monitor (NDMC). Retrieved 2017, from http://droughtmonitor.unl.edu/ 


\subsection{Appendix}

Table A.4.1: World almond demand and supply parameter estimates

\begin{tabular}{|c|c|c|c|c|c|c|c|c|c|}
\hline & Australia & Canada & China & $\begin{array}{c}\text { European } \\
\text { Union }\end{array}$ & Hong Kong & Iran & Japan & Turkey & $\begin{array}{l}\text { Rest of } \\
\text { World }\end{array}$ \\
\hline \multicolumn{10}{|l|}{ Demand Equation } \\
\hline In almond price & $\begin{array}{c}-0.192^{* * *} \\
(0.037)\end{array}$ & $\begin{array}{c}-0.267^{* * *} \\
(0.045)\end{array}$ & $\begin{array}{c}-0.009 * * * \\
(0.005)\end{array}$ & $\begin{array}{c}-0.142^{* *} \\
(0.059)\end{array}$ & $\begin{array}{c}-0.150^{* * *} \\
(0.047)\end{array}$ & $\begin{array}{l}-0.148 \\
(0.589)\end{array}$ & $\begin{array}{l}-0.119 \\
(0.164)\end{array}$ & $\begin{array}{c}-0.099 * * * \\
(0.035)\end{array}$ & $\begin{array}{l}-0.088 \\
(0.138)\end{array}$ \\
\hline In GDP/capita & $\begin{array}{c}3.481^{\star * *} \\
(0.247)\end{array}$ & $\begin{array}{l}0.975^{*} \\
(0.68)\end{array}$ & $\begin{array}{c}0.417^{* *} \\
(0.038)\end{array}$ & $\begin{array}{l}0.51^{* * *} \\
(0.103)\end{array}$ & $\begin{array}{c}6.874^{* * *} \\
(1.23)\end{array}$ & $\begin{array}{c}2.55 \\
(2.916)\end{array}$ & $\begin{array}{c}0.989 \\
(0.757)\end{array}$ & $\begin{array}{l}1.009^{* * *} \\
(0.233)\end{array}$ & $\begin{array}{c}2.854^{* * *} \\
(0.252)\end{array}$ \\
\hline In trend & - & $\begin{array}{c}0.816^{\star * *} \\
(0.237)\end{array}$ & - & - & - & $\begin{array}{l}-1.085 \\
(3.172)\end{array}$ & - & - & - \\
\hline Intercept & $\begin{array}{c}-26.479 \text { *** } \\
(2.787)\end{array}$ & $\begin{array}{l}-2.240 \\
(6.644)\end{array}$ & $\begin{array}{c}6.603^{* * *} \\
(0.388)\end{array}$ & $\begin{array}{l}7.87^{* * *} \\
(1.034)\end{array}$ & $\begin{array}{c}-57.539^{* * *} \\
(11.623)\end{array}$ & $\begin{array}{c}-6.522 \\
(13.69)\end{array}$ & $\begin{array}{l}-0.049 \\
(7.657)\end{array}$ & $\begin{array}{c}1.657 \\
(2.202)\end{array}$ & $\begin{array}{c}-10.421^{* * *} \\
(1.905)\end{array}$ \\
\hline \multicolumn{10}{|l|}{ Supply Equation } \\
\hline In almond price t- 1 & $\begin{array}{c}0.213^{\star *} \\
(0.1)\end{array}$ & - & $\begin{array}{l}0.070 * \\
(0.049)\end{array}$ & $\begin{array}{c}0.144 \\
(0.149)\end{array}$ & - & $\begin{array}{c}0.307 \\
(0.743)\end{array}$ & - & $\begin{array}{c}0.052 \\
(0.105)\end{array}$ & $\begin{array}{l}0.259^{*} \\
(0.181)\end{array}$ \\
\hline In almond price $\mathrm{t}-\mathrm{k}^{++}$ & $\begin{array}{c}0.038 \\
(0.114)\end{array}$ & - & $\begin{array}{l}0.115^{\star *} \\
(0.047)\end{array}$ & $\begin{array}{r}0.155++ \\
(0.122)\end{array}$ & - & $\begin{array}{c}0.132 \\
(0.612)\end{array}$ & - & $\begin{array}{r}0.029++ \\
(0.109)\end{array}$ & $\begin{array}{c}0.151 \\
(0.180)\end{array}$ \\
\hline In lagged production & $\begin{array}{l}0.46^{\star *} \\
(0.26)\end{array}$ & - & $\begin{array}{c}0.476^{\star * *} \\
(0.163)\end{array}$ & $\begin{array}{c}0.076 \\
(0.254)\end{array}$ & - & $\begin{array}{c}0.16 \\
(0.58)\end{array}$ & - & $\begin{array}{c}0.42^{* *} \\
(0.228)\end{array}$ & $\begin{array}{l}-0.044 \\
(0.235)\end{array}$ \\
\hline In trend ${ }^{+}$ & $\begin{array}{c}0.0845^{* *}+ \\
(0.037)\end{array}$ & - & $\begin{array}{c}0.029^{* * *}+ \\
(0.008)\end{array}$ & $\begin{array}{c}-0.012^{* * *}+ \\
(0.004)\end{array}$ & - & $\begin{array}{c}1.555 \\
(3.276)\end{array}$ & - & $\begin{array}{c}0.041^{* * *}+ \\
(0.016)\end{array}$ & $\begin{array}{l}1.635^{* * *} \\
(0.384)\end{array}$ \\
\hline Intercept & $\begin{array}{l}2.301^{* *} \\
(1.263) \\
\end{array}$ & - & $\begin{array}{l}3.57^{* * *} \\
(1.344) \\
\end{array}$ & $\begin{array}{c}10.91^{* * *} \\
(3.445) \\
\end{array}$ & - & $\begin{array}{c}2.112 \\
(11.749) \\
\end{array}$ & - & $\begin{array}{l}4.524^{* *} \\
(1.883) \\
\end{array}$ & $\begin{array}{c}6.014^{* * *} \\
(2.143)\end{array}$ \\
\hline
\end{tabular}

statistical significance at the $1 \%, 5 \%$ and $10 \%$ levels respectively. + denotes trend instead of In trend;++ denotes $t-k$ where $k=4$ except for European Union where $k=5$ and

Turkey where $\mathrm{k}=3$. 
Table A.4.2: World almond price linkage parameter estimates

\begin{tabular}{|c|c|c|c|}
\hline & $\ln$ U.S. Price & ln Lagged Own Price & Intercept \\
\hline Australia & $0.441 * * *(0.058)$ & - & $1.351 * * *(0.350)$ \\
\hline Canada & $0.962 * * * \quad(0.198)$ & - & $0.011 \quad(0.792)$ \\
\hline China & $1.007 * * * \quad(0.119)$ & - & -0.087 \\
\hline European Union & $0.959 * * *(0.080)$ & - & $-1.077 * *(0.294)$ \\
\hline Hong Kong & $1.422 * * *(0.113)$ & - & $-1.816 * * *(0.446)$ \\
\hline Iran & $1.184 \quad(0.756)$ & - & $0.032 \quad(2.915)$ \\
\hline Japan & $1.401 * * *(0.143)$ & - & $-1.772 * * *(0.557)$ \\
\hline Turkey & $0.445 * \quad(0.282)$ & $0.530 * *(0.159)$ & $-0.089 \quad(1.461)$ \\
\hline Rest of World & $0.949 * * *(0.087)$ & - & $(0.345)$ \\
\hline
\end{tabular}

Notes: Standard error is in parentheses. R-square is not available for equations estimated with restricted maximum likelihood estimator.

$\overrightarrow{\mathrm{N}}$ The asterisks $* * *, * * *$ denote statistical significance at the $1 \%, 5 \%$ and $10 \%$ levels, repsecitvely. All prices are in real term in US dollars. 
Table A.4.3: US parameter estimates

\begin{tabular}{|c|c|c|c|}
\hline Equation & Variable name & Coefficient estimate & Elasticity at mean \\
\hline \multirow[t]{5}{*}{ Planting } & Intercept & $14581^{* *}$ & \\
\hline & Lagged plantings in t-1 & $0.643^{* * *}$ & 0.649 \\
\hline & Deflated expected net returns & $768^{* * *}$ & 0.239 \\
\hline & Deflated lagged walnut grower price & $-5042^{*}$ & -0.396 \\
\hline & Palmer's drought severity index & $1959^{* \star *}$ & -0.034 \\
\hline \multirow[t]{4}{*}{ Removals } & Intercept & $15384^{* * *}$ & \\
\hline & Deflated expected net returns & $-294^{\star * *}$ & -0.202 \\
\hline & Lagged bearing area in $\mathrm{t}-20$ & $-0.095^{* *}$ & 0.276 \\
\hline & Palmer's drought severity index & $-736^{*}$ & 0.047 \\
\hline \multirow[t]{6}{*}{ Yield } & Intercept & $381^{* *}$ & \\
\hline & Trend & $85^{\star * *}$ & 1.210 \\
\hline & Yield t-1 & -0.44 & -0.438 \\
\hline & Yield $\mathrm{t}-1$ minus Yield $\mathrm{t}-2$ & 0.26 & 0.007 \\
\hline & Palmer's drought severity index & $-198^{*}$ & 0.875 \\
\hline & Palmer's drought severity index squared & $-11^{*}$ & -0.446 \\
\hline \multirow[t]{5}{*}{ Consumption per capita } & Intercept & 0.16 & \\
\hline & Deflated US almonds grower price & $-6.7^{\star *}$ & -0.291 \\
\hline & Deflated US walnuts grower price & 2.4 & 0.048 \\
\hline & real GDP per capita & $0.0000077^{\star *}$ & 0.682 \\
\hline & Shift trend beginning 2004 & $0.051^{* *}$ & 0.215 \\
\hline \multirow[t]{5}{*}{ Ending stocks } & Intercept & $29799^{*}$ & \\
\hline & Deflated US almonds grower price & -672908 & -0.155 \\
\hline & US almond production & $0.27^{\star *}$ & 1.277 \\
\hline & US almond production $\mathrm{t}+1$ & $-0.18^{* *}$ & -0.881 \\
\hline & US almond ending stocks t-1 & $0.43^{\star *}$ & 0.417 \\
\hline \multirow{2}{*}{ 1st stage expected net returns } & Intercept & 27 & \\
\hline & Deflated US almond net returns $\mathrm{t}-1$ & $1.21^{* * *}$ & 0.964 \\
\hline \multirow{3}{*}{ 2nd stage expected net returns } & Intercept & 125 & \\
\hline & Deflated US almond net returns $\mathrm{t}-1$ & $1.098^{* * *}$ & 0.872 \\
\hline & Difference of 1 st stage and actual net returns t-1 & $-0.495^{\star *}$ & -0.036 \\
\hline
\end{tabular}

*: Statistically significant at 0.10 level; ${ }^{* *}$ : Statistically significant at 0.05 level

***: Statistically significant at 0.01 level 
Table A.4.4: US almonds producers surplus estimates

\begin{tabular}{|c|c|c|c|c|c|c|c|c|c|c|c|c|}
\hline & $2005 / 06$ & $006 / 07$ & $2007 / 08$ & $08 / 09$ & 2009/10 & $2010 / 11$ & $2011 / 12$ & $2012 / 13$ & $2013 / 14$ & $2014 / 15$ & $2015 / 16$ & Total \\
\hline Baseline & 1048 & 933 & 752 & 403 & 325 & 810 & 1585 & 2634 & 4111 & 4926 & 2550 & 20077 \\
\hline $\begin{array}{l}\text { No CCD } \\
\text { difference to baseline }\end{array}$ & $\begin{array}{r}1075 \\
27\end{array}$ & $\begin{array}{r}1054 \\
122\end{array}$ & $\begin{array}{r}874 \\
122\end{array}$ & $\begin{array}{r}536 \\
133\end{array}$ & $\begin{array}{r}460 \\
135\end{array}$ & $\begin{array}{r}910 \\
100\end{array}$ & $\begin{array}{r}1648 \\
62\end{array}$ & $\begin{array}{r}2685 \\
51\end{array}$ & $\begin{array}{r}4049 \\
-62\end{array}$ & $\begin{array}{r}4963 \\
37\end{array}$ & $\begin{array}{r}2554 \\
3\end{array}$ & $\begin{array}{r}20807 \\
730\end{array}$ \\
\hline $\begin{array}{l}\text { No drought } \\
\quad \text { difference to baseline }\end{array}$ & $\begin{array}{r}1048 \\
0\end{array}$ & $\begin{array}{r}933 \\
0\end{array}$ & $\begin{array}{r}752 \\
0\end{array}$ & $\begin{array}{r}403 \\
0\end{array}$ & $\begin{array}{r}325 \\
0\end{array}$ & $\begin{array}{r}833 \\
24\end{array}$ & $\begin{array}{r}1641 \\
55\end{array}$ & $\begin{array}{r}2394 \\
-241\end{array}$ & $\begin{array}{r}3207 \\
-904\end{array}$ & $\begin{array}{r}4421 \\
-505\end{array}$ & $\begin{array}{r}2753 \\
203\end{array}$ & $\begin{array}{r}18709 \\
-1368\end{array}$ \\
\hline $\begin{array}{l}\text { No CCD and No drought } \\
\text { difference to baseline }\end{array}$ & $\begin{array}{r}1075 \\
27\end{array}$ & $\begin{array}{r}1054 \\
122\end{array}$ & $\begin{array}{r}874 \\
122\end{array}$ & $\begin{array}{r}536 \\
133\end{array}$ & $\begin{array}{r}460 \\
135\end{array}$ & $\begin{array}{r}933 \\
124\end{array}$ & $\begin{array}{r}1703 \\
118\end{array}$ & $\begin{array}{r}2446 \\
-189\end{array}$ & $\begin{array}{r}3144 \\
-968\end{array}$ & $\begin{array}{r}4430 \\
-495\end{array}$ & $\begin{array}{r}2766 \\
215 \\
\end{array}$ & $\begin{array}{r}19420 \\
-656 \\
\end{array}$ \\
\hline
\end{tabular}

Table A.4.5: US almonds production estimates

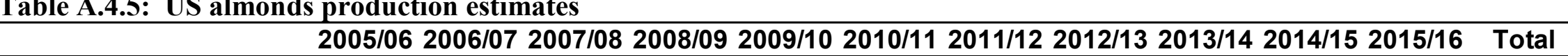

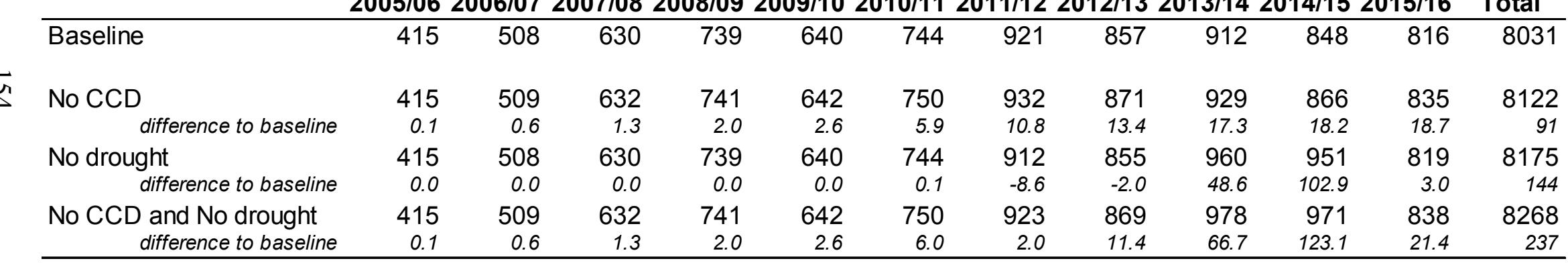

Table A.4.6: US almonds grower price estimates

2005/06 2006/07 2007/08 2008/09 2009/10 2010/11 2011/12 2012/13 2013/14 2014/15 2015/16 Average

\begin{tabular}{crrrrrrrrrrrr}
\hline Baseline & 2.81 & 2.06 & 1.75 & 1.45 & 1.65 & 1.79 & 1.99 & 2.58 & 3.21 & 4.00 & 2.84 & 2.38 \\
& & & & & & & & & & & \\
No CCD & 2.81 & 2.05 & 1.74 & 1.44 & 1.63 & 1.75 & 1.93 & 2.50 & 3.06 & 3.87 & 2.71 & 2.32 \\
difference to baseline & 0.00 & -0.01 & -0.01 & -0.01 & -0.02 & -0.04 & -0.06 & -0.08 & -0.15 & -0.13 & -0.13 & \\
No drought & 2.81 & 2.06 & 1.75 & 1.45 & 1.65 & 1.80 & 2.04 & 2.46 & 2.63 & 3.34 & 2.98 & 2.27 \\
$\quad$ difference to baseline & 0.00 & 0.00 & 0.00 & 0.00 & 0.00 & 0.01 & 0.05 & -0.12 & -0.58 & -0.66 & 0.14 & \\
No CCD and No drought & 2.81 & 2.05 & 1.74 & 1.44 & 1.63 & 1.76 & 1.98 & 2.38 & 2.49 & 3.21 & 2.85 & 2.21 \\
difference to baseline & 0.00 & -0.01 & -0.01 & -0.01 & -0.02 & -0.03 & -0.01 & -0.20 & -0.72 & -0.79 & 0.01 \\
\hline
\end{tabular}




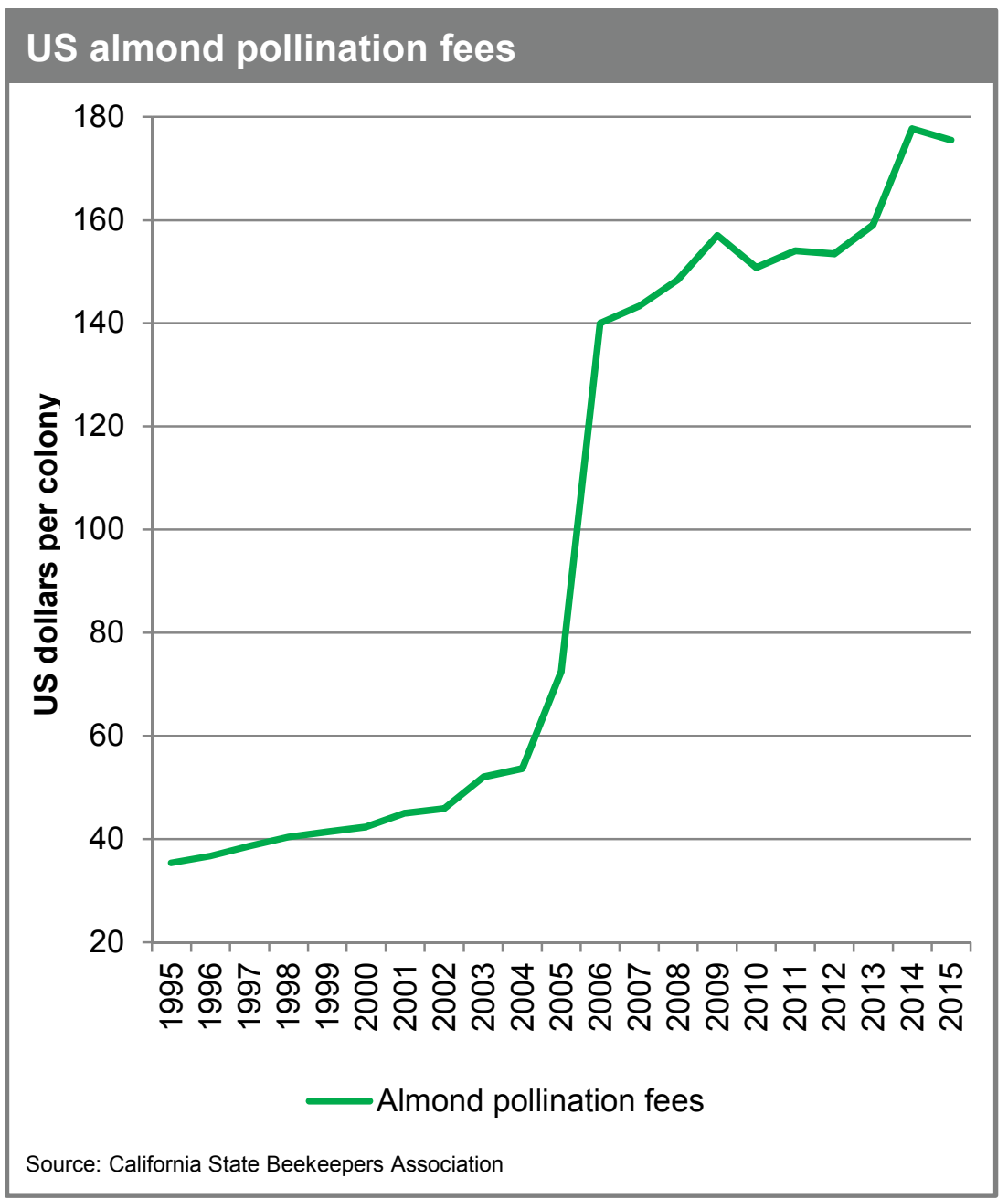

Figure A.4.1: US almond pollination fees 


\section{CONCLUSION}

Perennial crops literature has developed largely from the seminal work by French and Matthews (1971), and is based on the biological nature of the crops themselves as listed in the first essay (Chapter 2). This literature has segregated perennial crops from annual crops especially as it relates to perennial crop production. In this research each of the essays (Chapters 2, 3 and 4) worked to extend this rich literature by applying the idiosyncrasies of perennial crops in a different, new approach to examine the unique case of the US almond market.

In the first essay one objective was to extend the conceptual model that had been used to calculate excess demand elasticity of annual crops to incorporate the idiosyncrasies of perennial crops. This was accomplished by incorporating explicit temporal specificities that apply to the separate investment decisions that impact perennial crop supplies. In doing so a new conceptual model framework allowed for the second objective of the first essay, to estimate the excess demand elasticity of a facing the US almond market. Specific to this second objective it was found that the US almond market faces a relatively inelastic excess demand elasticity. For the 2003-2013 timeframe, the short-run excess demand elasticity for US almonds averaged -0.244 and 0.681 in the long run. Also, it was found that excess demand elasticity for almonds was more inelastic in 2003-2013 compared to a previous longer timeframe of 1980-2013. This was largely attributed to the increasing share of the US world supply of almonds in comparison to the rest of the world.

One extension of the excess demand elasticity conceptual model research is that it may be used first to calculate other perennial crops for cross commodity comparisons, 
and secondly, it may be generalized to calculate excess demand elasticity of other commodities that face multiple supply price influences such as those used in examinations of herd dynamics for livestock.

In the second essay (Chapter 3) the contribution to extend the perennial supply response literature was to incorporate an eco-economic approach into the separate structural investment decisions. This was accomplished by the addition of an explicit ecological explanatory variable as a proxy to represent an ESS directly into supply response decisions. As opposed to previous, traditional approaches where a shorter-run weather variable may or may not have been included in yield equations or a weather event such as a frost or freeze in a removals functions, this approach tested whether a longer-run measure of water availability to proxy an ESS provided a better fit historically for the observed behavior of US almond producers.

In each structural supply response investment decision including planting, removals and yield, the addition of this ESS proxy for water availability enhanced model fit as illustrated by smaller log likelihood and AIC numbers beyond that of the traditional model specifications tested. It is important to note that the US almond industry experienced an extreme drought persisting across five years ending in the spring of 2017. This extreme drought constrained surface water allocation for irrigation uses and placed the US almond producers in a historically unique situation. As it has been predicted that with the changing climate there is an increasing risk of future droughts and drought severity in the Western United States and California (e.g. Cook, Ault and Smerdon 2015; Diffenbaugh, Swain and Touma 2015), a forward looking analysis was used to test how the new specification would respond under another extreme drought in comparison to 
when no explicitly modeled water influence is included. From both the improved historical fit and the additional forward looking results, the use of the new specification implied that when an ESS is constrained the inclusion of a proxy for the constrained ESS better captures land use, production and price changes. With this knowledge a relevant extension of this research would be to simulate the impacts of long-term climate scenarios on a perennial crop where the availability of an ESS critical for agricultural production is threatened.

The caveat to the influence of the selected proxy for the ESS of water availability is that the relationships are unique to the history of US almond producers and may not be emulated for other perennial crops that have not faced an extreme drought and are not as dependent on similar sources of irrigation water. Despite this caveat the addition of a proxy for an ESS such as water availability into perennial supply response decisions may be adapted to other perennial markets where water availability or another ESS is constrained.

The third essay (Chapter 4) borrowed heavily from what was learned in the first two essays and leveraged previous literature on pollination fees to estimate the producer welfare impacts of a perennial crop market that faced two ESS threats.

It is common for ESS studies to examine yield impacts whether from drought, climate change, pollination services, etc. as a benchmark to evaluate economic impacts when these ESS may be threatened or constrained. A challenge is that aggregate yield impacts may be muted leaving the eco-economic influences of individual ESS opaque. In this essay CCD was not found to have a statistically significant influence on almond yields, although similar to other pollination fees literature, CCD was found to influence 
almond pollination fees (Ward, Whyte, \& James 2010; Carman 2011; Rucker, Thurman \& Burgett 2012).

Incorporating influences of drought via the proxy for water availability from the second essay and CCD through almond pollination fees as a cost of production into net returns, allowed the impacts of both threatened ESS to be modeled. A structural, partial equilibrium model of the global almond market was created and counterfactual, historical simulations were estimated. Using the historical simulations the producer surplus influences of these two threatened ESS were calculated incorporating a measure for producer surplus (Just, Hueth and Schmitz 2004).

The analysis identified economic benefits for California almond producers as a group from limited water availability from the extreme drought, and an economic burden from CCD. The simulation results imply that the economic cost of CCD to US almond producers averaged $\$ 66$ million per year since the beginning of CCD in 2005 , and the economic benefit of drought to US almond producers was \$273 million per year when averaged across the five years of drought.

The net difference to US almond producers across the whole time period was a positive change of $\$ 656$ million in added producer surplus. This surplus difference was largely attributed to a combination of the effects from decreased US almond production attributed to water availability constraints and an inelastic excess demand facing the US almond market. In this case the implication is that the drought had increased producer surplus, as almond prices increased proportionally more than production was reduced more than offsetting the smaller counter influences from CCD.

There are important limitations to note from the historical simulations. First, walnut prices as a competing crop for land were held at historical levels. If walnuts are 
assumed to also be influenced by both the threatened ESS and market changes, then walnut price as an opportunity cost for land may become more or less competitive and should affect land use changes in the simulations. Second, actual water costs are not measured directly, as only pumping and labor costs of irrigation are included as costs of production in the data source. PDSI was used as the proxy for water availability, and may be implicitly assumed to represent an expected cost of water, whereas any actual water costs may have had either a larger or smaller impact on farmer returns and were not captured by the simulation. Third, any externalities and social costs/benefits were also not captured by this analysis. Future research could improve these estimates by endogenizing walnut prices, firming up accounting measures for water costs and both quantifying and endogenizing any other positive or negative externalities from both water availability and pollination.

Each of the three essays provided unique extensions to the frameworks that examine perennial crops. The first essay extended the conceptual model that calculates excess demand elasticity to explicitly incorporate idiosyncrasies of perennial supply responses in order to provide an estimate of US almond excess demand elasticity. The second essay incorporated an explicit ecological explanatory variable into perennial supply response decisions extending the literature in an eco-economic way to better capture the influence that a threatened ESS has on observed perennial producer behavior. The third and final essay incorporated the eco-economic specifications from the second essay and endogenized almond pollination fees in order to estimate an economic valuation of the impacts of two threatened ESS on the US almond market. The results of the third essay were as expected and in accordance with the estimated excess demand 
implications from the first essay. The combination of these three essays not only provided unique extensions that may be applied to perennial crop literature, but also provided a in depth analysis of a specific perennial crop industry that had uniquely faced two threatened ESS both critical for agricultural production.

\subsection{References}

Carman, H. (2011). The Estimated Impact of Bee Colony Collapse Disorder on Almond Pollination Fees. ARE Update University of California Giannini Foundation of Agricultural Economics, 14(5), 9-11.

Cook, B. I., Ault, T. R., \& Smerdon, J. E. (2015). Unprecedented 21st Century Drought Risk in the American Southwest and Central Plains. Science Advances, 1(1).

Diffenbaugh, N. S., Swain, D. L., \& Touma, D. (2015). Anthropogenic Warming has Increased Drought Risk in California. PNAS, 112(13), 3931-3936.

French, B. C., \& Matthews, J. L. (1971). A Supply Response Model for Perennial Crops. American Journal of Agricultural Economics, 53, 478-490.

Just, R. E., Heuth, D. L., \& Schmitz, A. (2004). The Welfare Economics of Public Policy: A Practical Approach to Project and Policy Evaluation. Northampton, Massachusetts, USA: Edward Elgar.

Rucker, R. R., Thurman, W. N., \& Burgett, M. (2012, July). Honey Bee Pollination Markets and the Internalization of Reciprocal Benefits. American Journal of Agricultural Economics, 956-977.

Ward, R., Whyte, A., \& James, R. (2010). A Tale of Two Bees: Looking at Pollination Fees for Almonds and Sweet Cherries. American Entomologist, 53 (3), 170-1766. 


\section{VITA}

In 1999, Robert D. Maltsbarger graduated cum laude from the University of MissouriColumbia where he earned a Bachelor's degree in Agricultural Economics. In 2011, he earned a Master's degree in Agricultural Economics from the University of Missouri before transitioning into the Ph.D. program. He has worked as Senior Economist with IHS Markit in their Agricultural Service since 2010. 